\begin{abstract}
Title of thesis:

COLLEGE STUDENT PERCEPTIONS OF ALCOHOL USE ON UNIVERSITY CAMPUSES

Ana Vladimirova Popovska, Master of Arts, 2012

Thesis directed by: $\quad$ Professor Mary Ann Hoffman

Department of Counseling and Personnel Services

The proposed study examined the effects of gender, sensation seeking, alcohol expectancies, and perceived peer norms on alcohol consumption among college students through a biopsychosocial framework, proposing biological, psychological and social sources of influence on student alcohol use. The individual effects of the predictor variables were examined in a multiple regression model and correlational relationships between the independent variables and alcohol consumption were computed. Alcohol expectancies and peer norms were found to have moderate effects on alcohol use, gender had a small effect and sensation seeking had no effect. In addition, alcohol expectancies were found to partially mediate the relationship between perceived peer norms and alcohol use, supporting previous models of both direct and indirect effects of alcohol expectancies on alcohol consumption. Alcohol consumption rates along with the frequencies of 12 alcohol-related consequences were described for the current sample.
\end{abstract}




\title{
COLLEGE STUDENT PERCEPTIONS OF ALCOHOL USE ON UNIVERSITY CAMPUSES
}

\author{
by \\ Ana Vladimirova Popovska \\ Thesis submitted to the Faculty of the Graduate School of the \\ University of Maryland, College Park in partial fulfillment \\ of the requirements for the degree of \\ Master of Arts \\ 2012
}

Advisory Committee:

Professor Mary Ann Hoffman, Chair

Professor Jonathan Mohr

Professor William Strein 
(C) Copyright by

Ana Vladimirova Popovska

2012 


\section{TABLE OF CONTENTS}

Table of Contents..............................................................

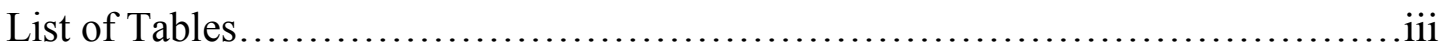

Chapter 1: Introduction....................................................... 1

Chapter 2: Literature Review............................................... 7

Overview of College Drinking......................................... 7

Correlates and Predictors of Alcohol Use in a Biopsychosocial Model........12

Sensation Seeking................................................17

Alcohol Expectancies..............................................28

Perceived Peer Norms................................................ 37

Importance of Examining Multivariate Relationships.....................51

Criterion Variable: Alcohol Consumption.................................53

Chapter 3: Statement of the Problem and Hypotheses..............................54

Chapter 4: Method.......................................................62

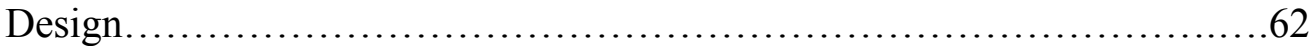

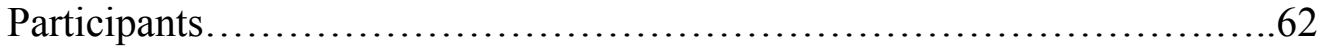

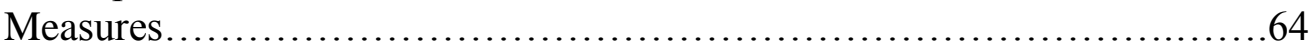

Procedures............................................................... 71

Preliminary Analyses...............................................73

Sample Descriptions of Alcohol Behaviors..............................79

Exploratory Factor Analysis of the Alcohol Expectancy Questionnaire......79

Chapter 5: Results..................................................... 84

Regression Model..................................................88

Exploratory Mediation Analysis..................................... 89

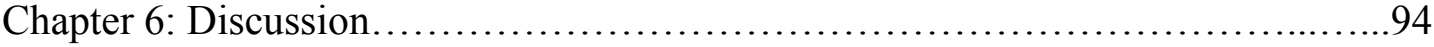

Overview of Sample.............................................94

Findings about College Drinking Behaviors............................ 95

Predictors of College Student Drinking from a Biopsychosocial

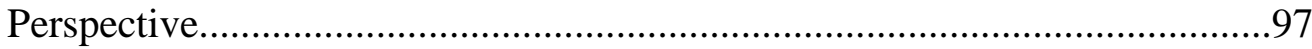

Limitations of the Study........................................... 108

Implications of Results and Future Research Directions...................112

Summary......................................................114

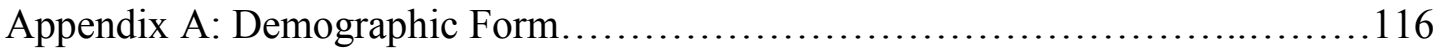

Appendix B: Individual Alcohol Consumption................................... 121

Appendix C: Perceived Peer Norms ....................................... 122

Appendix D: Impulsive Sensation Seeking Scale.............................. 124

Appendix E: Alcohol Expectancy Questionnaire............................... 125

Appendix F: Recruitment Script.......................................... 126

Appendix G: Informed Consent Form ..................................... 127

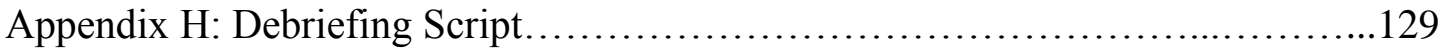

Appendix I: Principal Components Analysis................................... 130

Appendix J: Distribution of Scores for Key Continuous Variables...................134

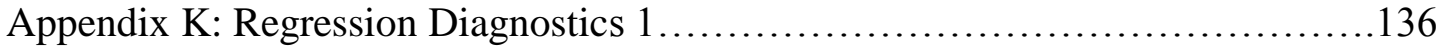

Appendix L: Regression Diagnostics 2 .................................... 137

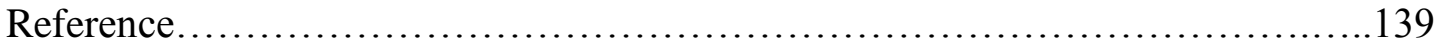




\section{List of Tables}

Table 1: Correlation matrix.

Table 2: Descriptive statistics.

Table 3: Multiple regression model.

Table 4: The mediator is regressed on the independent variable.

Table 5: The dependent variable is regressed on the independent variable.

Table 6: Combined regression equation.

Table 7: Frequency of occurrence of 12 alcohol-related consequences 


\section{Chapter 1}

Introduction

Many college students are faced with managing the freedom and responsibility of living on their own for the first time in their lives. For many, college is also a time for becoming part of a vibrant social environment with peers undergoing similar developmental challenges. Findings from large epidemiological studies show that compared to their peers who are not in college, college students drink significantly more often and more heavily (O’Malley \& Johnston, 2002). Research shows that nearly $80 \%$ of full-time undergraduates consume at least one alcoholic drink within a 12-month period, $70 \%$ drink monthly and more than $40 \%$ of full-time students engage in heavy drinking, broadly defined as consuming five or more drinks in a row on a single occasion (O’Malley \& Johnston, 2002).

American campuses are defined by a culture of excessive alcohol consumption, which often brings about serious consequences for student drinkers, other students who experience second-hand effects of alcohol due to their peers' drinking, and the entire institutions (Perkins, 2002). Despite increased alcohol prevention efforts between 1993 and 2001 - students reported being exposed to more prevention campaigns and more information on alcohol consumption, there have been no significant changes in student alcohol consumption patterns and rates, especially in heavy drinking (Wechsler, 2008). Overall, there is much converging evidence showing that college is a period of increased alcohol consumption for many students. Therefore, research is needed to elucidate the factors that contribute to the increased use of alcohol in the college environment. 
Most research on college student drinking has focused on prevalence rates and alcohol consumption patterns, with several large epidemiological surveys finding similar estimates of drinking rates across diverse campuses (O’Malley \& Johnston, 2002). Yet, there has been less focus on examining the specific factors that account for individual alcohol consumption, with research in this area spanning many variables with potential predictive effects but producing few integrative multivariate models (Baer, 2002). A major gap in the research literature has been investigating relationships between variables that come from different levels of analysis, such as the individual, social, and biological (Baer, 2002). In addition, Baer (2002) recommended that future research emphasize on both direct and indirect effects of variables related to college student drinking.

The purpose of the proposed research was to use a biopsychosocial framework to investigate the unique contributions of sensation seeking, gender, alcohol expectancies, and perceived social norms on alcohol consumption among college students. The proposed predictor variables were chosen based on their previously established relationships with alcohol consumption (Baer, 2002). In addition, the indirect effect of alcohol expectancies on the relationship between peer norms and alcohol use was tested in a meditational model, given prior support for the mediational effects of alcohol expectancies on alcohol use (Scheier \& Botvin, 1997). Finally, the prevalence rates of 12 alcohol-related consequences were examined in a frequency analysis.

Research shows that the personality trait of sensation seeking, which has strong neurobiological and genetic components (Zuckerman, 1994), is associated with 
multiple risk-taking behaviors, including college student drinking. Studies have consistently demonstrated a moderate relationship $(r=0.25)$ between sensation seeking and alcohol consumption in college students (Hittner \& Swickert, 2002; Zuckerman 2000). Findings show that on average, men of all age groups report higher levels of sensation seeking than women in their respective age groups (Zuckerman, 1994). In addition to biological determinants, psychosocial factors may also account for the behavioral expression of sensation seeking, including self-selection into environments that promote the expression of sensation seeking (Kahler, Read, Wood, \& Palfai, 2003).

Gender differences also exist in reported alcohol consumption among college students: men consistently report both more alcohol consumption and higher engagement rates in heavy drinking than do women (O’Malley \& Johnston, 2002). Research shows that both biological and psychosocial factors may underlie the observed gender differences in alcohol consumption (Hoeksema \& Hilt, 2006). Gender has been related to blood alcohol concentration levels, with women experiencing higher levels of intoxication than men after the same amount of alcohol consumption (Graham, Wilsnack, Dawson, \& Vogeltanz, 1998). In addition, differences exist in the severity of experienced alcohol-related consequences between men and women (Klatzky, Armstrong, \& Friedman, 1992). Differences in average body size and body-mass index between men and women may play a role in the above-mentioned findings but research has found that even after controlling for body weight, length of time spent on drinking, and amount of alcohol consumed, there still remain differences in blood alcohol concentration levels between men and women 
(Graham et al, 1998). It appears that gender differences exist in metabolizing alcohol, leaving women more vulnerable to the effects of alcohol than men, after controlling for body mass and alcohol amount (Graham et al, 1998). In addition to biological differences, differences in gender socialization processes related to alcohol use and gender norms for alcohol consumption may also contribute to the observed disparity in alcohol use among men and women (Nolen-Hoeksema \& Hilt, 2006).

College drinking is also largely perceived as a normative behavior (Borsari \& Carey, 2001). Two recent reviews on the influence of perceived peer norms on individual drinking behaviors conclude that commonly held misperceptions about actual alcohol consumption and alcohol-related attitudes of peers contribute to the perception that excessive drinking is both normative and embraced in the college environment (Borsari \& Carey, 2001; Perkins, 2002b). A large proportion of students (more than 70\%) overestimate the average amount and frequency of alcohol consumption of their peers and perceive their own consumption as lower than that of their peers (Perkins, 2006). Perceptions of close friends' alcohol consumption have been shown to have a stronger influence on individual students' alcohol consumption than perceptions of more distant reference groups, such as the average student or students of organizations to which the individual does not belong (Perkins, 2002). Overall, there is strong evidence to suggest that perceived peer norms are related to and predictive of individual alcohol consumption. Although peer norms are largely conceptualized as a social factor, the fact that research has largely focused on individual's perceptions of peer alcohol consumption suggests a cognitive component to the effect of peer norms. Differences in individual perception of social norms and 
the cognitive structures of perception may also contribute to the observed effect of peer norms on alcohol consumption (Baer, 2002).

Finally, cognitive factors such as beliefs about the effects of alcohol (also known as alcohol expectancies) exert an influence on individual alcohol consumption, as well (Hull \& Bond, 1986). Alcohol expectancies of different kinds, such as expectations about global positive changes, physical and social pleasure, and social assertion have been found to be significant predictors in previous models of college drinking (Martin \& Hoffman, 1991). Alcohol expectancies have also been related to severity of alcohol consumption, with heavier drinkers endorsing more positive expectations about the effects of alcohol than lighter drinkers (Brown, Goldman, \& Christiansen, 1985). Research suggests that expectancies may interact with gender to produce different effects on alcohol consumption for men and women (Abrams \& Wilson, 1979; Wilson \& Abrams, 1977) but there are few consistent upto-date findings to show how different domains of expectancies act differently across the sexes. Finally, the mediational effects of alcohol expectancies on the relationship of perceived peer norms and alcohol use were examined, based on previous theory and research showing reciprocal relationships between alcohol expectancies, prior drinking experience and the effect of observational learning on drinking behaviors (Jones, Corbin, \& Fromme, 2001; Scheier \& Botvin, 1997; Sher, Wood, Wood, \& Raskin, 1996). At least one study with college students found that alcohol expectancy partially mediated the effect of peer influence on alcohol use (Scheier \& Botvin, 1997). 
The current research examined the relationships between the predictor variables (gender, sensation seeking, perceived peer norms, and alcohol expectancies) and the outcome measure (alcohol consumption) in a series of correlational, multiple regression and mediational analyses. The direct effects of each predictor were assessed in a multiple regression model and the indirect effects of alcohol expectancies on the relationship between perceived peer norms and alcohol use were tested in a mediation analysis. Responses to a question about the rate of occurrence of 12 alcohol-related consequences produced a frequency analysis of these 12 consequences, providing more information about alcohol-related outcomes within the college population. This research has contributed to the study of college student drinking by examining predictors of college alcohol use in a multivariate model, testing both direct and indirect effects and conceptualizing sources of influence for each predictor through a biopsychosocial framework. 


\section{Chapter 2}

\section{Literature Review}

\section{Overview of College Drinking}

Alcohol drinking has been documented as a significant part of college

students' campus experience and many consider it a defining feature of contemporary college culture (Rabow \& Duncan-Schill, 1995). It is a widespread phenomenon with the potential for adverse consequences for both students and the campuses on which they reside (Perkins, 2002). Findings show that a large proportion of college students nationwide engage in heavy drinking, which can be defined as consuming five (for men) and four (for women) or more drinks in a row on one or more occasions in the past two weeks (Wechsler \& Nelson, 2008). Approximately $70 \%$ of full-time undergraduates report consuming at least one alcoholic drink per month and roughly $40 \%$ reported being heavy drinkers (O’Malley \& Johnston, 2002).

Large epidemiological studies provide important information on college drinking from a national perspective. Using data from five such large-scale surveys examining alcohol behaviors among American college students, O’Malley and Johnston (2002) estimated national prevalence rates of student alcohol use for the period 1991 - 1999 and trends in college drinking between 1980 and 1999. The following studies were included in their analysis: College Alcohol Survey (CAS) from the Harvard School of Public Health, The Core Institute (CORE) from Southern Illinois University, Monitoring the Future (MTF) from the University of Michigan, National College Health Risk Behavior Survey (NCHRBS) from Centers for Disease Control and Prevention, and National Household Survey on Drug Abuse (NHSDA) 
from Substance Abuse and Mental Health Services Administration. O'Malley and Johnston (2002) selected these five studies due to their national scope including large and diverse samples of college students, the use of probabilistic samples, and the utilization of repeated series designs. All five studies provided self-report data on alcohol behaviors from full-time undergraduate students attending 4-year institutions but they differed with respect to instrumentation, specific population and time period coverage, as well as methods and timing of data collection.

To gain a better understanding of the unique features of college student drinking, O'Malley and Johnston (2002) compared national drinking rates of college students with those of youth of comparable age who were not attending college, utilizing data from one or more of the national studies. Findings showed that college students had higher prevalence rates of alcohol consumption on all measures (annual, 30-day, heavy drinking) when compared to their non-college attending peers. The only exception was that non-college youth were more likely to drink on a daily basis than their college age peers. These findings suggest that college students may be at an increased risk for alcohol consumption during their college-attending years as compared to their non-college peers.

The prevalence rates of heavy drinking, broadly defined as consuming 5 or more drinks in a row during the two weeks or month prior to the survey across studies were found to be between $38 \%$ and $44 \%$ in the time period covered. It is important to note that definitions of heavy drinking varied slightly across the studies and when defining heavy drinking for men versus women. For example, some studies defined heavy drinking as consuming five or more drinks in a row for men and four or more 
for women in the past two weeks (CAS), whereas others defined it as five or more drinks in a row on a single occasion within the past 30 days (MTF). Despite study differences, the estimates of 30-day and heavy drinking prevalence rates of alcohol use among full-time college students for the period 1991 - 1999 were considerably consistent across the five studies, varying within a few percentage points only, as the above-mentioned statistics show.

More evidence that attending college is related to a higher rate of heavy drinking among young adults in university settings is further provided by a recent study on alcohol-related mortality and morbidity among U.S. college students (Hingson, Zha, \& Wietzman, 2009). This study examined several large data sets for trends in drinking behaviors and resulting consequences among college students and youth of comparable age who were not attending college. The study showed that heavy episodic drinking among college students, defined as having five or more drinks on an occasion, increased progressively during the time period examined (1999 and 2005). Overall, the rate of heavy episodic drinking within a 30-day time frame increased gradually from $41.7 \%$ to $44.7 \%$ of students between 1999 and 2005 . A similar trend of increase in heavy drinking was observed among non-college youth of similar age but a smaller proportion of non-college youth engaged in heavy drinking: (going from $36.2 \%$ in 1999 to $39.9 \%$ in 2005). The reported increase in heavy drinking rates among college students should be interpreted with some caution as not all studies found an increase in heavy drinking rates (Wechsler \& Nelson, 2008). Moreover, Hingson, Zha, and Wietzman (2009) based their findings on large probabilistic samples, which may have contributed to the statistical significance of the 
observed differences. Nevertheless, the reviewed evidence shows that heavy drinking rates have been persistently high among college students in the past two decades and that a higher proportion of college students engaged in heavy drinking than youth of similar age who did not attend college. The reasons for this observed trend are not entirely clear and a significant limitation of the reviewed large-scale epidemiological research is that studies mostly focused on prevalence rates rather than on specific factors that promote or are associated with increased alcohol consumption or its resulting consequences.

One of the major national studies of college drinking that sought to examine students' drinking patterns and resulting alcohol-related consequences beyond prevalence rates has been the College Alcohol Survey or CAS, mentioned before in the analysis by O'Malley and Johnston (2002). The study included four national surveys conducted in 1993, 1997, 1999, and 2001 among more than 14,000 full-time undergraduate students attending four-year institutions in 40 different states (Wechsler \& Nelson, 2008). In 2001, the CAS resurveyed 119 of the original 140 institutions that participated in the previous three survey years. Students were randomly selected from each college, giving an overall response rate of $52 \%$. The 2001 sample was representative of a national cross-section of students enrolled in 4year undergraduate institutions and as such, student sample demographics did not differ substantially from national student demographics, except for a larger percentage of women in the sample (64\%). The overrepresentation of women may have been due to the inclusion of five all-women's colleges. Seventy-four percent of the sample was White and 50.2\% were under legal drinking age. 
The primary outcome measure of the 2001 CAS survey was binge-drinking, defined as "the consumption of five or more drinks in a row for men and four or more drinks in a row for women on one or more occasions during the 2-week period immediately before the survey" (Wechsler \& Nelson, 2008). The main reason for including a gender-specific measure was to account for sex differences in levels of intoxication and to capture experienced alcohol-related consequences equivalently across the sexes. The rate of binge drinking among traditional college students in 2001 (18-23 years old, never married, living independently from their parents) was $48.6 \%$ for males and $40.9 \%$ for females and $44.4 \%$ overall. Trend analyses conducted for the 119 schools that participated in all survey years (1993, 1997, 1999, and 2001) showed no significant changes in binge drinking rates over the four time points.

Findings from the CAS surveys show that binge drinking is associated with many adverse consequences (Wechsler et al, 2002). The CAS measured alcoholrelated consequences experienced by student drinkers with a 12-item questionnaire, which included negative outcomes in areas such as academics, blackouts, unwanted, unplanned, or unprotected sexual activity, physical violence, interpersonal conflict, health issues, and driving after drinking. In addition, students were asked about experiencing eight different second-hand effects of others' drinking, which included violence (verbal, physical, or sexual) against the student, interrupted sleep or study, or having to take care of a drunken student (Wechsler et al, 2002). Results indicate that students were more likely to have reported experiencing more first-hand consequences in 2001 than in 1993. About $20 \%$ of students reported being more likely to have experienced five or more different consequences from the twelve 
measured in the survey due to their own drinking in 2001, which was a higher prevalence rate than in 1993 . Finally, $55 \%$ of surveyed students had experienced at least 2 second-hand effects of others' drinking, with the rate of experienced secondhand consequences being highest among residents of Greek life houses.

Despite the informative view of student drinking that CAS presents, it is not without limitations: students' self-reports of their drinking habits are often susceptible to retrospection bias and prevalence rates estimates were based on the responses of those students who agreed to fill out and return the surveys. In fact, CAS response rates declined over the years, reaching its lowest of 52\% in 2001 and although the researchers controlled for any potential non-response bias, it is not clear why more students did not respond to the survey and how this decline over the years may have affected the results.

\section{Correlates and Predictors of Alcohol Use in a Biopsychosocial Model}

A major limitation of much of the research on alcohol use in college students is that it focuses most often on rates of drinking rather than on variables associated with alcohol use. Those studies that examine correlates or predictors of alcohol use typically examine one or two variables that are not based on a theory or model that guides their selection. As can be imagined, there is a multitude of variables that have been associated with drinking rates and outcomes in the research literature on college populations (Baer, 2002; Larimer \& Cronce, 2002). For example, a recent review of the literature on individual variation in alcohol consumption among American college students shows that factors such as student demographics, family background, personality traits, cognitive factors, and the social context have all been 
related to drinking behaviors (Baer, 2002). Baer (2002) included only studies covering college populations in the United States within the last two decades of publication date. The review shows that personality traits, such as impulsivity, sensation seeking, extraversion, and neuroticism have been associated with greater quantities of alcohol consumed and more experienced alcohol-related consequences in the college student population. Cognitive factors such as drinking motives and alcohol expectancies have been established as predictors for college drinking. Lastly, the social context has been related to drinking rates through interpersonal influences such as perceived social norms and social affiliations have also been related to drinking rates.

Baer (2002) notes that most previous research has focused on investigating risk factors for student drinking through isolated theoretical models, largely ignoring the complex interactions between variables from different research frameworks. However, he notes that more multivariate models of drinking have emerged in the years preceding his review and he strongly recommends a continued examination of multivariate relationships of college drinking. Expanding existing models of college drinking to include variables at multiple levels of analysis could enhance the understanding of the complex relationships that exist between various predictors of alcohol consumption, alcohol-related negative consequences, and self-perceptions of drinking problems among college students.

One useful way to conceptualize college student drinking in an integrative multivariate model may be through examining various predictors of college student alcohol use in a biopsychosocial framework. The biopsychosocial model of health 
behaviors proposes that health outcomes are determined by variables at three different levels: the biological, the social, and the psychological (Engel, 1977). Engel (1977), a psychiatrist, was concerned that the dominant biomedical model in the science and practice of medicine at the time resulted in a reductionist perspective of health and illness that included only biochemical mechanisms. The reductionist approach ignored the contribution of psychological and sociocultural factors to human malaise and wellbeing and presented many challenges in conceptualizing mental illness. In his seminal essay, Engel (1977) suggested that three major dimensions of any medical or mental disorder be examined - the biological, the sociocultural, and the psychological. His thesis was based on the premise that multiple systems interacted to influence the well being of the individual in complex ways and that was being not captured by the reductionist approach dominating medicine and psychiatry at the time. He theorized that subsystems, such as cells and organs were intricately tied with suprasystems such as one's physical and socio-cultural environment and their effects on the whole organism (a system in itself) shaped experiences of health and illness. Engel (1977) was particularly concerned that by ignoring the contribution of socio-cultural and psychological factors to health outcomes, healthcare systems were fundamentally deficient in providing integrated, comprehensive care to patients. Moreover, their reductionist approach limited the accumulation of knowledge about the interactions between the three systems outlined above and as a result, the potential for better care. After Engel's call for change in medical practice and research, the biopsychosocial model was adopted to varying degrees by various mental health and medical disciplines, such as psychiatry, social work, and most notably health psychology (Suls 
\& Rothman, 2004). However, even in health psychology, research has not examined the three systems equally, with many studies overemphasizing the psychological dimension or not including variables from all three levels (Suls \& Rothman, 2004).

The biopsychosocial perspective provides an organizational framework that fits the study of college drinking particularly well, as individual alcohol consumption in students has been shown to be influenced by a variety of factors at many different levels of analysis (individual, social, biological), and there is currently a lack of theoretical integration of all the empirically supported influences on college drinking (for a review see Baer, 2002).

Following Baer's recommendation for an integrated analysis of college student drinking, we propose that variation in college student alcohol consumption may come from three main sources of influence, as suggested by the biopsychosocial framework of health outcomes: the biological, the psychological, and the social. We propose that the selected predictors will account for variance in the outcome through at least one of the levels of the biopsychosocial framework and in many cases, through more. We have selected variables that have been robustly associated with alcohol consumption and for which research and theory suggest that they contain biological, social, or psychological components. The caveat of our integration of the biopsychosocial framework in the currently proposed multivariate model is that variance cannot be parceled out by specific levels of the model (biological, social, psychological), as our variables are multi-faceted. However, we will review each variable through the biopsychosocial framework and propose that it accounts for 
variation in individual alcohol consumption through the different levels of the framework.

One of the goals of this research is to examine the direct effects of the selected variables and conceptualize them through the biopsychosocial perspective. Another goal is to test a model of indirect effects relating alcohol expectancies, perceived peer norms and alcohol use through the hypothesized mediational effect of alcohol expectancies on the relationship between perceived peer norms and alcohol use. The inclusion of this model is based on previous empirical research and addresses the gap in the literature mentioned by Baer (2002) about the scarcity of multivariate models with indirect pathways in the study of college drinking.

Following the recommendations outlined by Baer (2002), the effects of the predictor variables on individual variation in college student drinking will be examined through a biopsychosocial conceptualization. The following four predictors will be included: (1) the personality trait of sensation-seeking, which is hypothesized to have biological and psychosocial components (Zuckerman, 2000); (2) alcohol expectancies, which are thought to have cognitive and social components (Jones, Corbin, \& Fromme, 2001); (3) perceived peer norms, which, too are thought to have cognitive and social factors (Perkins, 2002); and (4) gender, which is conceptualized in biological and psychosocial dimensions (Nolen-Hoeksema \& Hilt, 2006). What follows is a brief review of each individual predictor as it relates to the literature on college student drinking. Gender differences will be discussed in a separate section. 


\section{Sensation seeking.}

Sensation seeking has been consistently identified as an individual risk factor for alcohol consumption among college students (Baer, 2002). It has been conceptualized as a multidimensional personality trait characterized by "the seeking of varied, novel, complex, and intense sensations and experiences, and the willingness to take physical, social, legal, and financial risks for the sake of such experience" (Zuckerman, 1994). Zuckerman (1994) proposed that sensation seeking has four key components: Thrill and adventure seeking is understood as the desire to participate in risky physical endeavors, such as sky-diving; Experience seeking is the pursuit of novel experiences, such as interacting with people of different cultures, traveling to new destinations, or learning about new things; Disinhibition is engaging in behaviors that involve reduced or little social restraint; And finally, boredom susceptibility refers to subjective reports of dislikes for the routine, mundane, and predicable.

Impulsive sensation seeking is another conceptualization of the construct that combines elements of impulsivity and sensation seeking in a supratrait (Zuckerman \& Kuhlman, 2000). Impulsivity refers to "the tendency to enter new situations, or rapidly respond to cues for potential reward, without much planning or deliberation and without consideration of potential punishment or loss of reward. Impulsivity can also be considered as a deficit in the capacity for inhibition of dangerous rewardseeking behavior." (Zuckerman \& Kuhlman, 2000). Impulsive sensation seeking is therefore "a need for change and novelty, a preference for uncertainty (risk) in social relationships and environments, and a tendency to forgo planning coupled with acting 
on impulse with little concern for consequences" (Joireman \& Kuhlman, 2004). It can be measured by the impulsive sensation-seeking scale of the Zuckerman-Kuhlman Personality Questionnaire (Zuckerman \& Kuhlman, 1993). Impulsive sensation seeking closely resembles the general construct of sensation seeking and in many cases, the two have been used interchangeably (Zuckerman, 2010).

Evidence suggests that a large proportion of the individual variance in sensation seeking may be due to heritability: Behavioral genetic studies show that sensation seeking is a highly heritable personality trait, with genetics accounting for $60 \%$ of the variance in this personality trait, compared to an average of $40 \%$ in other personality traits (Zuckerman, 2000). In addition, Zuckerman (1994) has proposed a biologically based theory of sensation seeking that links several brain neurochemical pathways with the expression of sensation seeking. The activation of a dopamine reward system is thought to guide approach behaviors, whereas a serotonergic inhibition system may be involved in the control of behavior, and finally, an arousal mechanism affects responses to stress and anxiety (Zuckerman, 2000; 2010). The theory proposes that over-activity in the approach system and under-activity in the inhibition system may account for some of the behavioral aspects of sensation seeking, such as exploration and disinhibition. Over-activity in the arousal system, on the other hand, inhibits exploration and novelty seeking behaviors, as stress and anxiety lead to less exploration (Zuckerman, 2010).

Many lines of research support the notion that biological factors are implicated in the expression of sensation seeking. Findings from both human and animal studies show that sensation seeking behaviors such as exploration of novel 
environments and responding to novel stimuli are related to the brain reward mechanisms and inversely related to the serotonergic inhibition loop and the noradrenergic arousal system (Zuckerman, 2000; 2010). In addition, psychophysiological studies have shown significant increases in the orienting response to novel stimuli in both humans and other animals high in sensation seeking compared to those low in sensation seeking (Zuckerman, 2000; 2010). Furthermore, high sensation seekers habituate faster to novel stimuli, suggesting that this response may relate to their tendencies to get bored easily and seek new stimuli repeatedly.

Neurotransmitters may not be the only control mechanism for the expression of sensation seeking. Both gonadal and stress hormones have been implicated in modulating the brain systems described above (Zuckerman, 2010). Testosterone, in particular, has been hypothesized to correlate with increased sensation seeking behaviors, thus possibly accounting for the observed differences in sensation seeking between men and women, but evidence for this link remains mixed and inconclusive (Rosenblitt, Soler, Johnson, \& Quadagno, 2001). Stress hormones, such as cortisol, on the other hand, are thought to correlate negatively with levels of sensation seeking due to their activation of the arousal noradrenergic loop, which relates to increased anxiety and decreased exploration and novelty seeking behaviors (Zuckerman 2000; 2010). Support for the interaction between cortisol and levels of sensation seeking has been found in experimental research with college men and women (Rosenblitt et al, 2001).

Besides the biological factors related to sensation seeking, it has also been recognized that interactions with the environment, including the social context, likely 
largely contribute to the expression of sensation seeking, as well (Zuckerman 2000; 2010). Most behavioral genetics twin studies on the heritability of sensation seeking have concluded that there is no influence of the shared environment on the expression of sensation seeking, leaving all non-inherited variation in this trait to influences from non-shared environment (Zuckerman, 2010). One study showed that the shared environment may contribute significantly, if properly assessed but even then, a large proportion of the variance remains to be explained by factors outside the family (Koopmans, Boomsma, Heath, \& van Doornen, 1995). Thus, the outside social environment may be largely responsible for additional influences on sensation seeking behaviors in individuals. Other psychological factors, such as personal gratification from engaging in sensation seeking behaviors may contribute, too. As with the rest of the predictors, our study does not allow us to partial out the variance due to biological and psychosocial contributions to the effect of sensation seeking on alcohol consumption. However, the reviewed lines of research suggest that sensation seeking may affect alcohol behaviors through both biological and psychosocial ways. In the following sections, we will first review the associations between sensation seeking and alcohol use, after which we will explore the influence of psychosocial factors that extend the understanding of sensation seeking behaviors beyond the biological hypothesis.

\section{The association of sensation seeking and drinking behaviors.}

In a study of the relationships between personality traits and six different areas of risk-taking (drinking, smoking, illicit drug use, risky sexual behaviors, reckless driving, and gambling) among college students, Zuckerman (2000) found that 
sensation seeking was significantly and positively correlated with alcohol consumption, smoking, use of illicit substances and risky sexual behaviors. In particular, the correlation between sensation seeking and drinking was 0.25 (p $<0.001)$ for college males and 0.43 for college females $(\mathrm{p}<0.001)$. The number of drinks consumed in a typical week in the past year and the most drinks consumed during any one day were used to assess drinking. Sensation seeking was measured with the impulsive sensation seeking scale from the Zuckerman-Kuhlman Personality Questionnaire (ZKPQ; Zuckerman \& Kuhlman, 1993). Impulsive sensation seeking was found to be a significant independent predictor of drinking, accounting for $2.05 \%$ of the variance in the multivariate regression model that contained all five personality traits and gender as predictors and the six areas of risk taking as outcome variables. Impulsive sensation-seeking also had a significant independent effect on smoking, illicit drug use, and risky sexual behaviors. Even though the variance accounted for may seem small, sensation seeking was found to be a significant predictor of risktaking behaviors among college students.

Not surprisingly, most research on sensation seeking and risk-taking has focused on alcohol consumption, giving us a strong empirical foundation to base our hypotheses on. Findings show that higher levels of sensation seeking are generally associated with increased quantity and frequency of alcohol use, including among college students (Zuckerman, 1994). Furthermore, Ball, Carroll, \& Rounsaville (1994) showed that among a sample of community substance abuse young adults, those high in sensation seeking may first start using alcohol and other substances earlier than those lower in sensation seeking. 
A meta-analysis examined the association between sensation seeking and alcohol use and tested for possible moderators of this association (Hittner \& Swickert, 2006). The authors included only empirical research articles with a focus on the relationship between alcohol use and sensation seeking and ones that directly assessed alcohol consumption. In addition to coding information needed for the computation of effect sizes, the authors coded a variety of potential moderator variables, such as the type of scale used to measure sensation seeking, the percentage of white participants in the sample, the percentage of male participants, type of alcoholic beverage, assessment of alcohol consumption, and others. The majority of included studies used Zuckerman’s Sensation Seeking Scale, Form V (SSS, Zuckerman, 1979).

The included 61 articles resulted in a total pool of 37, 058 participants. Most studies (93.4\%) were cross-sectional, used questionnaires (90.2\%), and focused on non-clinical populations (88.5\%). Twenty-eight of all 61 studies used college student samples with varying sample sizes $(20-4,927)$. As a result, $9,612(26 \%)$ of all participants were college students. The mean reported age across all 35 studies that provided such information was 23.7. Given the large proportion of college student participants in the included studies, findings from this meta-analysis could be of high relevance to college student populations.

The results showed that an overall measure of sensation seeking correlated with alcohol consumption at a mean rate of $r=0.263$ based on 54 studies. Generally (with few exceptions), higher levels of sensation seeking correlated positively with increased alcohol consumption. The observed mean relationships between alcohol use 
and individual subscales were as follows: $r=0.204$ for experience seeking (based on 15 studies); $r=0.189$ for boredom susceptibility (based on 14 studies); $r=0.144$ for thrill and adventure seeking (based on 13 studies); and the strongest relationship for individual subscales was observed between disinhibition and alcohol use (mean $\mathrm{r}=$ 0.368, based on 19 studies). Some researchers have proposed that the effect size between disinhibition and drinking could be inflated by the presence of drinkingspecific questions on the disinhibition subscale and as a result, they have used the disinhibition subscale without the items about alcohol use (Darkes, Greenbaum, \& Goldman, 1998).

Of relevance to the proposed study, both percent male and percent White participants were moderators of sensation seeking, showing that the relationship between sensation seeking and drinking is stronger for males and for Caucasians than for other racial/ethnic groups. Overall, the meta-analysis findings support previous research in showing the positive association between sensation seeking and alcohol use. It is noteworthy that despite the variety of study samples and methods included in the meta-analysis, the effect sizes of the observed relationships were small-tomoderate. It is unclear how these effect sizes may differ by sample size.

One of the limitations of the reviewed meta-analysis is the large variability in sample sizes across the included studies, which limits the reliability of observed effect sizes and creates an inequality in power to detect effect sizes between individual studies. Thus, arriving at an estimate of specific effect sizes, given the wide range of measurement and methodology tools used in the various studies is 
challenging. Another limitation of the studies included in the meta-analysis was their limited data on racial, gender, and cultural differences.

Johnston and Cropsey (2000) investigated the relationship between sensation seeking and participation in drinking games among heavy-drinking college students. One hundred seventy-two female and 84 male college students were recruited from introductory psychology courses. Students provided self-reports of their alcohol consumption, frequency of participation in drinking games, and thirteen negative alcohol consequences. Sensation seeking was measured using Zuckerman's Sensation Seeking Scale, Form V (SSS, Zuckerman, 1979).

The authors first compared students who did not play drinking games with those who played at least occasionally and they found that those who played drinking games had higher total sensation seeking scores and higher scores on all but one (boredom susceptibility) of the four sensation seeking components measured by the scale. Moreover, the mean number of weekly consumed drinks was positively associated with both drinking games participation and sensation seeking scores. Other comparisons revealed that heavy-drinking men who had higher sensation seeking scores endorsed more negative alcohol-related consequences than heavy-drinking men with lower sensation seeking scores. Overall, these findings show that higher levels of sensation seeking among heavy drinking college students were associated with both participation in drinking games and increased alcohol consumption and more experienced negative consequences related to it. 


\section{Psychosocial factors: Sensation seeking and the social context.}

The psychosocial factors that may influence the expression of sensation seeking behaviors may be one's selection of a social environment that facilitates the expression of such behaviors, as well as the subjective gratification effects of engaging in these behaviors. In light of the need for more knowledge on the multiple pathways of effect for risk factors associated with college alcohol use, the interrelationship between sensation seeking and the social context in which drinking occurs needs to be examined. In previous research, both sensation seeking and the social context have been found to be independent predictors of alcohol use (Baer, 2002). At least two studies with college students support the notion that students likely self-select into social environments that align with their sensation seeking behaviors, especially in the context of alcohol use.

One study examined to what extent impulsive sensation seeking and gender influenced college students' drinking behaviors through their selections of social environments that promote drinking (Read, Wood, \& Palfai, 2003). Impulsive sensation seeking was measured by impulsive sensation seeking subscale of the Zuckerman-Kuhlman Personality Questionnaire (Zuckerman \& Kuhlman, 1993). Environmental selection was measured through students' perceptions of their peers' attitudes about drinking (attitudinal norms) and through involvement in the Greek life system. Alcohol use was measured by several indicators of frequency, quantity, and heavy drinking.

This study consisted of two different samples of male and female college students recruited from undergraduate psychology classes in two settings - a rural 
public university (447 students, $86.6 \%$ White, $65 \%$ women) and an urban private university (421 students, 72\% White, 55\% women). In both samples, the authors found that white ethnicity and impulsive sensation seeking partially mediated the relationship between students' selections of environments that promote drinking and their own alcohol use. Moreover, both membership in a campus Greek organization and perceived peers approval of drinking were related to increased alcohol use among students. Results showed that even though men had greater alcohol consumption than women, they were not more likely than women to select social environments conducive to increased drinking.

Overall, these findings underscore the influence of the social environment on individual alcohol consumption and suggest that individual characteristics such as sensation-seeking may predispose to selecting heavy-drinking environments. Both impulsive sensation seeking and white ethnicity were found to be risk factors for increased alcohol consumption. Unfortunately, causal interpretations cannot be made due to the cross-sectional design of the reviewed studies.

To address the question of how self-selection into alcohol-promoting environments relates to sensation seeking, another study investigated whether association with alcohol-using peers mediated the relationship between sensation seeking and alcohol use and whether sensation seeking increased the likelihood of college student alcohol use (Yanovitzky, 2006). Peer influence was conceptualized and measured in two ways: overt peer pressure, which was defined as "a student's frequency of association with alcohol-using peers" and covert peer pressure, 
operationalized as "a student's degree of misperceptions about the college drinking norms".

The study sample consisted of 427 undergraduates from a large public northeastern university. Sample characteristics were: $55 \%$ female, $60 \%$ Caucasian, $53 \%$ lived on campus, and 3\% Greek life members. Information about alcohol-related behaviors, sensation seeking tendencies, frequency of association with alcohol-using peers, perceived norms for drinking, demographics, on- or off-campus residence, and membership in a fraternity/sorority was collected via anonymous surveys in the mail.

The results showed that both overt and covert peer pressure, as measured in the study, were significant predictors of individual alcohol consumption, after gender and race were controlled for. The analysis revealed that the frequency of association with alcohol drinking peers but not norms misperceptions mediated the relationship between sensation seeking and alcohol use. Such findings show the complex pathways via which sensation seeking and peer influence affect alcohol use besides the documented direct effects that these two variables have been found to have on alcohol consumption in college students.

Overall, the reviewed literature is consistent in demonstrating the association between sensation seeking and alcohol use in college students, showing support for both direct and indirect effects of sensation seeking on individual student alcohol consumption. The personality trait of sensation seeking is thought to impact alcohol use through both biological and psychosocial pathways, making it a good fit for the biopsychosocial framework of this study. 


\section{Alcohol expectancies.}

Effects from consuming alcohol are now believed to be due to both pharmacological and socio-cultural factors. Many randomized controlled laboratory experiments have shown that the belief that one has or has not consumed alcohol influences observable behavior and subjective perceptions of one's behavior independent of actual alcohol consumption (Hull \& Bond, 1986). Research suggests that specific beliefs about the consequences that alcohol is expected to produce in a given culture affects one's experiences of alcohol effects (Leigh, 1989). Such beliefs, also known as alcohol expectancies, have been defined as “individuals' beliefs about the effects of alcohol on their behavior, moods, and emotions" (Leigh, 1989, p.361).

Researchers have proposed different theories of how alcohol expectancies may impact drinking (Jones, Corbin, \& Fromme, 2001). Most theories fall in three major frameworks: Expectancy theory, which assumes a causal relationship between expectancies and drinking, such that expectancies predict drinking independent of prior alcohol use; Self-perception framework, on the other hand, suggests the opposite relationship - that drinking experience causes and predicts alcohol expectancies; Finally, the social learning perspective proposes that alcohol expectancies are reciprocally related to alcohol use social situations (Sher, Wood, Wood, \& Raskin, 1996). Many have emphasized the relevance of social learning theory in understanding the effects of alcohol expectancies (Jones, Corbin \& Fromme, 2001). From a social learning perspective, alcohol expectancies are assumed to be generated by previous experiences with alcohol combined with social factors that account for observational learning and modeling of drinking behaviors. Being in 
the form of cognitive structures, alcohol expectancies are then presumed to influence drinking behavior by guiding individual choices and regulating one's motivation to drink (Jones, Corbin, \& Fromme, 2001). For the purpose of the current study, we will view alcohol expectancies through the social learning framework, which proposes that alcohol expectancies have both social and cognitive components. This conceptualization fits well with the overarching biopsychosocial conceptualization in the current study.

\section{Alcohol expectancies and alcohol consumption patterns.}

In general, alcohol expectancies have been found to be strong correlates of alcohol consumption (Baer, 2002). Research has consistently demonstrated a positive association between alcohol expectancies and alcohol use, such that increased endorsement of positive alcohol expectancies corresponds to increased alcohol consumption and heavier drinking patterns (Jones, Corbin, Fromme, 2001). Stronger associations have been observed between alcohol expectancies and quantity of alcohol consumption than between expectancies and frequency of alcohol use (Jones, Corbin, \& Fromme, 2001). In addition, positive alcohol expectancies have been found to correlate more strongly and have higher predictive power for alcohol use than negative expectancies (Stacy, Widaman, \& Marlatt, 1990).

In a review of the literature, Leigh (1989) showed the predictive power of expectancies in estimating alcohol consumption - even when measured with two greatly different scales, alcohol expectancies still accounted for 10-19\% of the variance in alcohol consumption as measured by both quantity and frequency indices in a number of methodologically diverse studies. The review also found that 
expectancies were better predictors of drinking quantity than of frequency of drinking occasions. At the time (1989), less was known about the nature of the relationship between expectancies and actual drinking behavior, with research showing mixed evidence for the hypothesis that expectancies acted as mediators of drinking behavior. It was also unclear if expectancies were the cause or result of drinking, with some models showing a reciprocal relationship between the two (see Leigh (1989) for a review).

In a meta-analysis on the effects of alcohol consumption and expectancies, Hull and Bond (1986) examined eleven dependent variables related to drinking and drinking outcomes: aggression, alcohol consumption, physical sensations, mood, attention focus, locus of control, helping, motor performance, information processing, physiology, and sexual arousal. The authors selected only studies that used the balanced placebo design, where actual alcohol consumption was crossed with the belief of having consumed alcohol. This design is often used in studies attempting to separate the pharmacological effects of alcohol from the expectancy effects. Results showed that expectancies had a significant effect on social behaviors, and in particular illicit/prohibited behaviors and increased sexual arousal. Expectancies were not related to aggression but they were found to have a large positive effect on drinking motivation among alcoholics. Though significant, the effect of expectancies on sexual arousal was heterogeneous among studies. Such a mixed effect could be due to the variety of methods used to assess sexual arousal in different studies (such as self-report or physiological measures) but it could also be due to the context- and gender-specific effects of expectancies, as demonstrated by other researchers 
(Abrams \& Wilson, 1979; Wilson \& Abrams, 1977). Hull and Bond (1986) found that actual alcohol consumption had no effects on social behaviors and significant effects on the non-social remaining behaviors that were examined (information and memory processing, physical sensations, mood, task performance). The effects of alcohol consumption on task performance and physiological sensations were heterogeneous across studies but this may be due to differences in measures and alcohol dosage used in different studies. Interestingly, no significant interactions were found for the effects of expectancies and alcohol consumption. Given the robust findings about independent effects of alcohol expectancies and actual alcohol consumption, the authors recommend examining these variables independently in future research.

In addition to studies employing standardized measures of alcohol expectancies to demonstrate the link between expectancies and alcohol use, research that used subjective evaluations of the expected effects of alcohol and self-generated alcohol expectancies also shows strong associations between these measures of alcohol expectancies and drinking behaviors (Wood, Sher, \& Strathman, 1996). For example, Wood, Sher and Strathman (1996) found that subjective evaluations of the expected effects of alcohol were equally predictive of alcohol use as alcohol expectancies assessed on a standardized measure. In addition, the total number of self-generated alcohol expectancies correlated positively with and predicted unique variance in alcohol dependence symptoms above and beyond that predicted by subjective evaluations. Thus, findings are not limited by a biased assessment of alcohol expectancies with few well-established standardized measures only (Stacy, Widaman, \& Marlatt, 1990). However, most studies showing the relationship between 
alcohol expectancies and alcohol use have been cross-sectional in design and thus have failed to show that alcohol expectancies cause increased alcohol consumption.

\section{Bidirectional and multivariate relationships.}

Using prospective designs, several studies have demonstrated reciprocal relationships between alcohol expectancies and prior drinking experience, demonstrating support for the social learning theory of alcohol expectancies. Sher, Wood, Wood and Raskin (1996) examined the relationship between alcohol use and alcohol expectancies over a 3-year period in a sample of 465 college students (220 were female and 236 were classified as children of alcoholics to assess for increased risk of heavy drinking). Participants completed a 44-item alcohol expectancy questionnaire that assessed expectancies in four domains: tension reduction, social lubrication, activity enhancement and performance enhancement. Alcohol use was assessed with a variety of questions about frequency and quantity of alcohol consumption. Overall, 4 waves of data collection occurred within a 3-year period, showing that students held relatively stable alcohol expectancies during the first two years and showed a decrease in the subsequent two years. Men scored higher than women on all measures of alcohol use. Conservative analyses controlling for autoregressive effects and cross-sectional variances showed reciprocal prospective effects between alcohol expectancies and alcohol use in this sample, supporting previous findings of reciprocal effects in the literature. In addition, the authors found that the effects were dependent on the measurement interval between assessment periods in that alcohol expectancies varied as a function of alcohol use in a 1-year 
period but showed robust prospective effects on drinking within a 3-year period and the same relationships held across gender and family history of alcoholism.

Carey (1995) also demonstrated a prospective, reciprocal relationship between expectancies and drinking in a sample of college students, after controlling for current alcohol consumption levels. Alcohol consumption was measured with a quantityfrequency variability index and heavy drinking was assessed with questions about the maximum number of drinks consumed on a single day in the past 30 days and frequency of intoxication for the past 30 days. One hundred and forty students ( $61 \%$ women, 73\% White) completed the Alcohol Expectancy Questionnaire (AEQ; Brown, Christiansen, \& Goldman, 1987) and drinking pattern questions in a first session and returned after 4 weeks to complete the same drinking measures again and a measure of alcohol-related consequences. Two separate multiple regression analyses showed that alcohol expectancies had a small but significant independent effect on predicting both maximum daily alcohol consumption and frequency of intoxication, after controlling for gender and previous alcohol consumption (measured at time 1). In this particular study sample, global positive expectancies accounted for significant variance in maximum daily alcohol consumption and expectations of sexual enhancement predicted frequency of intoxication. These results suggest that alcohol expectancies predict future alcohol consumption above and beyond what previous drinking experience predicts. Such findings suggest that alcohol expectancies are not merely correlates of or a by-product of alcohol consumption but rather that they play a role in the initiation and maintenance of alcohol use. 
In addition to reciprocal relationships between alcohol expectancies and alcohol use, research has also tested the effects of expectancies in multivariate models. In a sample of college students, Wood, Nagoshi and Dennis (1992) found that alcohol expectancies for disinhibition and hostility, reasons for drinking and not drinking, perceived norms for alcohol use, and impulsivity all had significant independent effects on alcohol consumption, measured by a quantity-frequency index. Similarly, Katz, Fromme and D'Amico (2000) estimated the effects of outcome expectancies, sensation seeking, social conformity and prior experience with risk-taking behaviors (among which was heavy drinking) in a sample of 162 college students (58\% women, 95\% White) and a follow-up sample of 98 (61\% women) students. The personality trait sensation seeking was assessed with a version of the impulsive sensation seeking subscale from the Zuckerman-Kuhlman Personality Questionnaire (Zuckerman \& Kuhlman, 1993). The researchers found a positive association between sensation seeking and positive expectancies for heavy drinking and a negative association between sensation seeking and negative expectancies for heavy drinking. The reverse relationships were found for social conformity and expectancies. A hypothesized mediation effect of expectancies on the relationship between sensation seeking and heavy drinking was not supported, suggesting that sensation seeking and outcome expectancies act through independent pathways to influence heavy drinking.

Darkes, Greenbaum and Goldman (2004) examined alcohol expectancy mediation of several independent predictors of alcohol use. Measures on alcohol risk and protective factors, alcohol expectancies and alcohol use were completed by a 
random sample of 1366 first-year students (62\% female, 71\% Caucasian) in 5 annual waves of assessment. Each cohort was followed-up a year after the first assessment to re-assess alcohol use and only alcohol use assessed at the second time point was used in the analyses. Among the variables measured were sensation seeking, perceived peer norms, family history of alcoholism, affectivity, coping and religiosity. Alcohol expectancies were assessed with the 68-item version of the Alcohol Expectancy Questionnaire (Brown, Christiansen, \& Goldman, 1987). Alcohol use was measured by several indicators, including a quantity-frequency variability index. Alcohol expectancy mediation was assessed only for these variables that were shown to have significant independent effects on alcohol use in a multivariate model containing several predictors (anger, sensation seeking, religiosity, coping and antisocial behavior). Of those, only sensation seeking and religiosity had significant independent effects on alcohol use. Unfortunately, the researchers discarded measures of perceived peer norms because of their high correlation with self-reported drinking. Darkes, Greenbaum and Goldman (2004) showed that a common expectancy factor partially mediated the effect of sensation seeking on follow-up drinking measures. This is in contrast to findings by Katz, Fromme and D'Amico (2000) who did not find a significant alcohol expectancy mediation effect on the relationship between sensation seeking and drinking, although it should be noted that differences in measurement and procedures existed between the two studies. In a hierarchical mediation model where the effects of both the general expectancy factor and the unique factor effects of alcohol expectancies, sensation seeking was mediated by both the common expectancy factor and the unique factors of social and physical pleasure. 
The latter model accounted for more mediated variance than the common-factor mediational model, suggesting that results depend on how alcohol expectancy mediation is modeled.

Studies have also examined the mediational effects of alcohol expectancies on the relationship between peer influence and alcohol use. Scheier and Botvin (1997) tested whether alcohol expectancies mediate the influence of peer norms on alcohol consumption in adolescents through path analytic modeling. This relationship would be expected in a social learning framework where alcohol expectancies are believed to be formed by both direct experience and observational learning/modeling (Jones, Corbin, \& Fromme, 2001). Given the strong influence of perceived peer norms on alcohol use throughout adolescence, peers are expected to be a major source of observational learning and modeling for alcohol use (Perkins, 2002).

Scheier and Botvin (1997) used data gathered between 1985 and 1991 from students in 7th grade and beyond in 56 public schools in suburban areas. Students were followed up for a period of 5 years. A total of 789 students provided complete data for a 3-year panel study, whereas data from more than 900 students were available for cross-sectional analyses at different time points. Self-report measures of alcohol assessed quantity and frequency of alcohol consumption, as well as experiences of intoxication. Knowledge about the effects of alcohol was assessed independently of alcohol expectancies. In addition, perceived peer use and peer attitudes toward alcohol were measured. Expectations about positive social reinforcement from alcohol consumption were measured with a 7-item scale geared towards adolescents. 
Preliminary analyses showed some gender and time differences in both alcohol consumption and the measured psychosocial factors related to it. A crosssectional mediation analysis showed that both perceived friends' alcohol use and perceived friends' attitudes toward alcohol were significantly mediated by alcohol expectancies. The mediational effect was stronger for perceived friends' alcohol use (moderate effect size). An additional longitudinal analysis corroborated the findings from the cross-sectional study and also showed some reduction of the mediation effects over time. The longitudinal analysis showed that alcohol use was relatively stable over a 3-year period and that initial alcohol consumption indirectly influenced alcohol expectancies, providing further support for a bidirectional relationship between alcohol expectancies and alcohol use. In addition to mediating the effects of perceived peer alcohol use and perceived peer attitudes towards alcohol (peer norms), alcohol expectancies also independently predicted alcohol use over 1 year. Overall, these results provide support for both direct and indirect effects of alcohol expectancies on alcohol use in an adolescent sample, consistent with a social learning conceptualization of expectancies. The results also underscore the need for multivariate assessment of alcohol use.

\section{Perceived peer norms.}

Drinking is often perceived as normative in college and many students may conform to the pressure to drink in order to reinforce their sense of belonging to a group or avoid negative social evaluation. Two recent review papers on the influence of perceived peer norms on individual drinking behaviors concluded that commonly held misperceptions about the actual alcohol consumption and alcohol-related 
attitudes among peers contribute to the perception that excessive drinking are both normative and embraced in the college environment (Borsari \& Carey, 2001; Perkins, 2002).

Converging evidence shows the powerful influence of peer norms on individual drinking behavior: Perkins (2002) reviewed research on the role of social norms on individual student's alcohol consumption and found that during college, the influence of peer norms on drinking attitudes and behaviors far outweighs the influence of parent norms or other authority figures, such as faculty. This is presumably due to the increase of independence from their parents that most students have during college, as well as their increased time among peers, especially in residential colleges. Perkins (2002) concluded that peers had the strongest normative influence on individual behavior by late adolescence, where traditional-age college student population falls. Many studies in his review found that peer influence, measured in various ways (number of close friends in college, amount of time spent on socializing with other students, being member of a Greek-life organization or an athletic team) was a significant predictor of alcohol consumption of individual students (Perkins, 2002).

Like most other researchers, Perkins (2002) distinguished between two kinds of peer norms that are relevant to the study of drinking behaviors: attitudinal and behavioral. Attitudinal norms are commonly held beliefs about what people in a group accept as typical behavior. Thus, attitudinal norms reflect one's beliefs of the groups' expectations about a certain behavior. Or, as Borsari and Carey (2001) define it, attitudinal norms are "the perceptions of others" approval of drinking" (p.402), that 
"represent perceived moral rules of the peer group" (p.402). In this regard, studies have demonstrated that college students overestimate how permissive their peers are about drinking. Thus, students consistently rate the typical student and their own close friends as holding more permissive attitudes about drinking than themselves (Perkins, 2002; Borsari \& Carey, 2001).

Behavioral norms, on the other hand, refer to what the individual believes the typical alcohol consumption of his/her peers to be. Borsari and Carey (2001), for example, define behavioral or descriptive norms as 'the perception of others' quantity and frequency of drinking in discrete drinking situations" (p. 402). Similar to findings on attitudinal norms, studies have demonstrated that students largely overestimate the average alcohol consumption of their peers and rank their own consumption as lower than what they believe their peers consume. Exceptions to this kind of misperceptions are only found among fraternity men who are most likely heavy drinkers and who rank their own consumption higher than that of their peers but still overestimate the actual alcohol consumption of other fraternity men (Borsari \& Carey, 2001). The authors conclude that the elevations in both attitudinal and behavioral norms contribute to the perception of college as an environment where excessive drinking is endorsed. They found that personal alcohol consumption is positively associated with one's perception of others' drinking behavior and approval of drinking. This relationship was weaker for alcohol-related problems. Moreover, the perceived norms that influenced individual drinking the most were those about other individuals rather than entire institutions. 
The authors reviewed two types of evidence that exists to corroborate the relationship between perceived peer norms and drinking: surveys that provide correlational evidence linking norms misperceptions with alcohol use and intervention studies that provide experimental evidence showing decreases in alcohol consumption after changes in perceptions of peer norms. Various interventions have been used to target norms misperceptions among college students with many of them focusing on descriptive norms. Interventions have included personalized normative feedback, group sessions, mailed greeting cards, and campus-wide social marketing campaigns. In sum, the reviewed findings show that interventions targeted at changing descriptive norms resulted in reduced alcohol consumption (Borsari \& Carey, 2001).

The reviewed literature on student misperceptions of peer drinking norms has several limitations. Firstly, studies have defined the target population whose norms students are misperceiving in multiple ways, examples of which include best friends and the average student. It is possible that the degree of relatedness of the respondent (individual student) to the target population (close friends, typical students, teammates, etc.) may influence the extent and effect of misperception in drinking norms (Perkins, 2002). Thus, the generalizability of findings is limited not only to the population that was tested but also to the population that was used to define peer norms. Furthermore, intervention studies showing that changes in norms misperceptions result in reduced alcohol consumption have often included multiple components in their proposed interventions and evaluations of the effectiveness of 
these interventions have rarely assessed their individual components. Thus, it is not known which factors lead to the observed decrease in alcohol consumption.

Perkins (2006) analyzed data from the National College Health Assessment (NCHA) collected from the spring of 2000 to spring of 2003. The total pool of respondents was 76,145 students from 130 academic institutions throughout the United States. Only random samples, samples of at least 100 students, and the most recent survey data for each institution were used in the study. Perkins (2006) based his analysis on several questions drawn from the NCHA survey about: the quantity of personal alcohol use on the last occasion the respondent partied or socialized; the perceived amount of alcohol a typical student from the same institution consumed the last time they partied or socialized; whether respondents had received information on various health topics, including alcohol and other drug use; and whether they had experienced several negative alcohol-related consequences, ranging from personal injury, violence, blackouts, forced or unprotected sex, and academic struggles.

The author calculated the actual drinking norm for each institution as the median of students' responses about their own alcohol use at that institution. He then proceeded to estimate the misperception of the actual norm at each institution by examining the differences between students' perceived norms and the calculated actual norm. In the entire sample of 76,145 students, $15.2 \%$ underestimated the norm at their institution, $13.8 \%$ had accurate perceptions, and $71 \%$ overestimated the norm. This pattern of perceptions was found across institutions of different actual norms, including those where abstaining was the norm and those where students drank the most, suggesting that norms misperceptions (mostly overestimation of the norm) 
existed for the vast majority of students regardless of the actual norm of the school they attended.

Next, the author examined the effect of these misperceptions on students' own alcohol consumption, using multivariate regression analysis where actual norms, perceived norms, gender, age, race, year in school, full- vs. part-time student status, Greek life membership, hours per week a student works or volunteers, and geographical region of the school were entered as predictors. The results showed that the perceived norm was the strongest predictor of students' own alcohol use in this dataset $($ standardized beta $=0.33$ ), followed by gender $($ standardized beta $=0.24)$. In comparison, the standardized coefficient of the actual norm in predicting personal alcohol use was 0.12 . The raw coefficients showed that each one-drink increase in students' perceptions of the actual norm was associated with nearly a half-drink increase in their own consumption, controlling for the effect of the actual school norm. On the other hand, a one-drink increase in the actual norm was associated with roughly a one-third increase in personal consumption. Both results show that perceptions of other students' alcohol use had a stronger effect on students' own alcohol consumption than did the actual school norm calculated by researchers.

One of the limitations of Perkins' (2006) study was that report of one's own and perceptions of other students' alcohol use were measured in terms of the quantity of alcohol consumed on the last occasion the student or typical student partied or socialized. This one-time-one-index only measure of alcohol use can be problematic because it may not have captured respondents' typical alcohol use, as the last time they partied or socialized may have been exceptional in terms of how much alcohol 
they consumed. The actual drinking norm per institution was also estimated based on the median of reported personal use by students at that institution. On the other hand, there was a close parallel between the measure of a student's own use of alcohol and the measure of perceived use by a typical student from the same institution, reducing the error in estimating norms misperceptions and the independent effect of perceived norms once the actual norm has been controlled for. The large sample size together with the variety of institutions covered by the survey suggest that these findings are worth considering in evaluating the influence of perceived peer norms on students' drinking.

Another study examined misperceptions of campus norms for the frequency of alcohol use (Perkins, Meilman, Leichliter, Cashin, \& Presley, 1999). It was based on a large response set drawn from the CORE survey. The data for this analysis span the period between the fall of 1994 and spring of 1996 and included 48,168 students from 100 geographically diverse institutions. Students were asked how often they had used eleven different types of substances, including alcohol, within the past year. Then, they were asked how often they thought the average student on their campus used each listed substance in the past year. Frequencies of use were recorded as no use, yearly, monthly, weekly, and daily. The median of responses for each school was used as the actual norm for that school. The author justified the use of this measure of central tendency with the fact that data were ordinal and highly skewed and for most institutions, the median and the mode overlapped. The results showed that nearly $90 \%$ of students from campuses where the actual norm was no drinking at all or drinking on a yearly or monthly basis had inflated perceptions of the norm. The students who 
had the most accurate perceptions of the norm on their campuses where those attending schools where the actual norm was weekly drinking but even among them, $25 \%$ misperceived a higher norm. These results show that inflated misperceptions of the frequency of alcohol use are pervasive and occur on campuses of all levels of drinking actual drinking norms. Unfortunately, this analysis did not examine to what extent the misperceptions of campus norms for frequency of drinking affected individual student's alcohol consumption but based on previous theory and findings (see Perkins (2002) for a review), we can hypothesize that they are powerful determinants of the frequency of one's own drinking.

Finally, Perkins and Wechsler (1996) examined the effects of perceived peer norms on students' own alcohol use and experienced alcohol-related consequences. A subset of the CAS survey data from 1993 was analyzed. The survey had 17,592 student respondents (58\% female) from 140 diverse academic institutions in the United States. For this particular analysis, responses to questions about personal attitudes towards alcohol use and perceived campus norms of students' attitudes towards alcohol use were used. The results showed that controlling for background variables, such as age, year in school, number of close friends, religion, race, Greek life membership, and type of living environment, perceptions of the campus alcohol norm had the largest independent effect on individual alcohol use (beta $=0.24$ ). Moreover, heightened perceptions of the campus alcohol norm were also indicative of more alcohol-related problems experienced by the individual student throughout the academic year. It is important to note that the effect of perceived norms was independent of the actual campus norm, regardless of the level of typical alcohol use 
on a given campus. In particular, this study shows that perceived norms of campus alcohol use have an effect not only on personal alcohol use but also on experienced alcohol-related consequences. To our knowledge, the latter association has been examined much less often than the relationship between perceived norms and individual alcohol use.

The effect of perceived campus norms of drinking remained significant after personal attitudes about drinking were controlled for, as well. Moreover, it was shown that the effect of perceived norms was stronger for students who had more permissive personal attitudes about drinking, thus increasing their risk for engaging in drinking. This interactive effect suggests that aside from measuring students' own alcohol consumption and their perceptions of the campus alcohol norm, it is also important to assess their personal attitudes about drinking. It is likely that students who hold the most permissive attitudes about drinking and for whom it is shown that perceived norms have the strongest effect are the ones at greatest risk for high alcohol consumption.

Overall, findings show that perceived norms of peer alcohol use and perceived norms of peer attitudes towards alcohol use have strong effects on individual student alcohol consumption beyond the effect of actual campus norms. Studying the relationship between perceived peer norms and student alcohol use is essential in the social context of the campus that many students inhabit. In a biopsychosocial framework, perceived peer norms are conceptualized to influence student alcohol consumption through psychological and social components, as both the perception of 
the social influence to drink and actual peer drinking behaviors likely contribute to the effect of this predictor.

\section{Gender.}

The role of gender in alcohol consumption patterns can be described as multifaceted at best - both biological and psychosocial factors interplay to account for known differences in alcohol consumption between men and women but the exact contribution of each remains unclear and there still remains a lack of integrated explanations of the observed gap in alcohol consumption between men and women (Nolen-Hoeksema \& Hilt, 2006). College men consistently report consuming more alcohol than women (O’Malley \& Johnston, 2002). In addition, findings by O'Malley and Johnston (2002) showed that Black, White and Hispanic men had higher heavy drinking prevalence rates than women of each corresponding ethnic group and being White male college student was associated with the highest prevalence rate of heavy drinking in the college environment.

Although men drink more on average than women, women tend to suffer more severe alcohol-related consequences (Nolen-Hoeksema \& Hilt, 2006). Findings from studies in the general population show that women are more likely to develop alcohol-related disorders faster than men and women tend to experience more severe physical consequences, including a higher mortality rate, from alcohol abuse (Fillmore et al, 1997; Klatsky, Armstrong, \& Friedman, 1992). Studies with college students show that women suffer similar alcohol-related consequences as men after lower amounts of alcohol consumption (Wechsler \& Nelson, 2008). 
The literature suggests that both biological and psychosocial factors may account for the observed gender differences in individual alcohol consumption and alcohol-related consequences (for a review see Nolen-Hoeksema \& Hilt, 2006). Known biological differences exist in how men and women process alcohol and experience its physiological effects - for example, women have higher blood ethanol levels than men after an equivalent dose of alcohol, partly because of gender differences in body size, body-water content and the activity of the enzyme alcohol dehydrogenase (Graham et al, 1998). Clearly, the biological components of gender differences in alcohol consumption cannot be discounted but they could also hardly be separated from gender-related psychosocial processes (Nolen-Hoeksema \& Hilt, 2006).

As has been discussed in more detail in the alcohol expectancies section, the effects of alcohol on behavior are not solely physiological and pharmacological there are psychological and social factors that affect one's experiences with alcohol beyond the biological effects of the substance. Nolen-Hoeksema and Hilt (2006) identified some of the most researched psychosocial factors related to gender differences in alcohol consumption - among them are gender norms and gender socialization processes related to alcohol consumption, differences in drinking motivations and expectancies, gender differences in severe alcohol-related consequences, personality traits, affect and interpersonal relationships. Although most of the reviewed literature on gender norms and gender socialization processes in relation to alcohol consumption dates back to the 1980s and 1990s, these factors may still play a key role in shaping alcohol consumption patterns among college men and 
women today. Nolen-Hoeksema and Hilt (2006) reviewed findings that showed that differences in gender roles in relation to alcohol consumption still existed, indicating that female drinkers were perceived more negatively for their drinking than males. Thus, females may face harsher social sanctions and higher disapproval when they drink compared to males. Other differences in personality traits such as impulsivity, behavioral under-control and anti-sociality may also shape alcohol consumption patterns differently for men and women, as men tend to score higher on measures of these traits, which in turn have been related to alcohol consumption. In addition, gender differences in sensation seeking, perceived peer norms, and alcohol expectancies may also contribute to the gap between women's and men's drinking patterns. The next section will review in more detail gender differences related to each specific predictor in this study.

\section{Gender differences in sensation seeking.}

Research has consistently found that men score higher on measures of sensation seeking than women in all age groups (Zuckerman, 1994). The biological hypothesis of sensation seeking links the expression of this trait with testosterone levels but this link has received inconsistent support in the literature (Rosenblitt, Soler, Johnson, \& Quadagno, 2001). These authors showed that testosterone levels were not related to sensation seeking in a sample of college men and women. However, they found a significant interaction between sensation seeking and cortisol, such that higher levels of cortisol were associated with lower levels of sensation seeking in both genders, consistent with one of the stress-related premises of the biological hypothesis of sensation seeking. 
A meta-analysis on sensation seeking found that the relationship between sensation seeking and drinking is stronger for males and for Caucasians than for other racial/ethnic groups (Hittner \& Swickert, 2006). Zuckerman (2000) found that the relationship between gender and alcohol consumption, although initially significant, was not significant after the personality traits of sociability, aggression-hostility and impulsive sensation seeking were controlled for. Other research has previously documented a stronger relationship between sensation seeking and risk-taking (including alcohol use) for males than for females (Zuckerman, 1994). Johnston and Cropsey (2000) found that men and women who participated in drinking games differed from those of their respective gender who did not participate in drinking games along the dimension of disinhibition, one of the proposed key aspects of the construct of sensation seeking. In addition, higher sensation seeking scores were more likely to differentiate female participants in drinking games than male participants. For both genders, those who participated in drinking games drank more and more frequently than those who did not. The observed gender differences in sensation seeking and alcohol consumption could be due to unknown biological factors but it is also possible that gender socialization processes may lead women to express their sensation seeking tendencies differently from men.

Gender differences in alcohol expectancies and perceived peer norms.

Research suggests that men and women may hold different expectations about the effects of alcohol and some authors have examined gender differences in alcohol expectancy effects in the context of social interactions and social anxiety (Abrams \& Wilson, 1979; Wilson \& Abrams, 1977). They found that men who 
believed they had consumed alcohol showed reduced physiological and self-report indications of anxiety during an interaction with a female confederate, even when they had consumed a placebo drink (Wilson \& Abrams, 1977). Another study using the same design but involving a social interaction between a female participant and a male confederate showed that the effect of expectancies was reversed in women, suggesting gender and context differences in the effects of alcohol expectancies (Abrams \& Wilson, 1979). In both studies, participants interacted with a confederate of the opposite sex after having consumed an alcohol or placebo drink. Even though women's self-reports of anxiety did not differ from those of men, women showed signs of increased anxiety (measured by physiological indices and independent observers' ratings) after they were led to believe they had consumed alcohol.

Even though these past laboratory experiments demonstrated clear gender differences in alcohol expectancy effects, little is known about how change in gender roles over time may have affected present-day alcohol expectancies among men and women. Furthermore, there is little consistent evidence about gender differences in alcohol expectancies in naturalistic settings and across the alcohol expectancy domains measured by the Alcohol Expectancy Questionnaire (Brown, Christiansen, \& Goldman, 1987). Finally, research shows that both men and women overestimate the alcohol consumption of their same-sex peers but perceived same-sex drinking norms may have a higher predictive power for alcohol consumption than gender nonspecific norms in women (Lewis \& Neighbors, 2004). 


\section{Importance of Examining Multivariate Relationships}

Neighbors et al (2007) studied the effects of a diverse set of variables, including demographic variables, social norms, drinking motives, alcohol expectancies and evaluations of alcohol events on alcohol consumption and experienced alcohol-related consequences. The rationale for examining these variables together was to address the gap in the research literature in evaluating diverse factors which have been associated with college drinking but whose predictive power has not been examined outside the models that were used to develop them. However, they did not follow any specific theoretical rationale in selecting their variables. Rather, variables were selected based on their consistently documented associations with drinking behaviors and on their role in existing interventions for college drinking. A total of 818 (57.6\% female, $65.2 \%$ white) first-year undergraduates from a large public university on the West Coast participated after being screened to meet the inclusion criteria for heavy drinking.

Alcohol consumption was measured by asking participants to specify the average number of drinks consumed on each day of an imagined typical week in the past three months. The authors then summed the numbers of drinks for each day and used weekly drinking as the primary measure of alcohol consumption. Twenty-three alcohol-related problems were measured with the Rutgers Alcohol Problem Index (RAPI, 1989) and two additional items covered driving under the influence of alcohol.

Simultaneous regression analyses revealed that the set of selected predictors (demographics, alcohol expectancies, social norms, alcohol motives) accounted for 
$37 \%$ of the variance in alcohol consumption and $24 \%$ in the variance of alcoholrelated consequences. Relative to all predictors, descriptive norms had the largest independent effect on consumption $(\mathrm{d}=0.84)$, followed by fraternity/sorority membership $(d=0.47)$, gender $(d=0.41)$ and injunctive norms for friends $(d=0.39)$. Both positive and negative alcohol expectancies had relatively small unique effects on alcohol consumption ( $\mathrm{d}=0.05$ and 0.03 , respectively).

The largest independent effects on alcohol-related consequences were attributable to coping motives $(d=0.39)$, negative expectancies $(d=0.36)$, evaluation of negative effects ( $d=0.25$, explain this variable) and descriptive norms $(0.22)$. Injunctive norms had an effect of $d=0.18$ for friends and $d=0.19$ for parents. Positive expectancies had a very small negative effect $(\mathrm{d}=-0.04)$.

Finally, the authors showed that the relationship between social norms (both descriptive and injunctive for friends) and alcohol-related consequences was mediated by alcohol consumption. Even though the relationship between injunctive norms for parents and consequences was reduced in a mediation model where consumption was the mediator, it still remained significant. Furthermore, coping motives, negative expectancies, and evaluation of negative effects appear to be uniquely related with alcohol consequences only, suggesting that alcohol consumption and alcohol-related problems have unique, non-overlapping variance accounted for by different predictors. This finding can have implications for prevention programs, depending on their targeted effect and once again underscores the necessity to examine both consumption patterns and alcohol-related problems as distinct outcome variables. 


\section{Criterion Variable: Alcohol Consumption}

The predictor variables discussed above have been conceptualized in a biopsychosocial model, which is typically applied to health-related outcome variables (Suls \& Rothman, 2004). In the case of alcohol use, amount of alcohol consumption, measured variously, has been a common behavioral outcome in the literature. In the current study, the primary outcome variable will be alcohol consumption, measured by a quantity-frequency drinking index obtained from a quantity frequency measure used in past research (Martin \& Hoffman, 1993). 


\section{Chapter 3}

Statement of the Problem and Hypotheses

The primary purpose of the proposed research was to examine the unique contributions of sensation seeking, alcohol expectancies, perceived social norms, and gender to alcohol consumption among college students in a multiple regression model containing these variables as predictors. In addition, we were interested in examining the mediational effects of alcohol expectancies on the relationship between perceived peer norms and alcohol use. This research is important because more than $40 \%$ of college students are heavy drinkers, with many experiencing undesirable alcoholrelated consequences (Wechsler \& Nelson, 2008). Most research to date has used an epidemiological perspective on the study of college drinking, establishing a good knowledge base of alcohol prevalence rates and alcohol consumption patterns on college campuses across the USA (O’Malley \& Johnston, 2002). Yet, few studies have explored the factors underlying this phenomenon and even fewer have examined college drinking utilizing multivariate models that also tested for indirect effects (Baer, 2002). Therefore, the proposed study addresses this gap in the research literature by examining predictors of alcohol consumption in a multivariate model and testing for mediation effects of alcohol expectancies on the relationship between perceived peer norms and alcohol use. All predictors in the study were conceptualized in a biopsychosocial framework (Engel, 1977). For descriptive purposes, the prevalence rates of 12 alcohol-related consequences were measured.

The proposed predictors (sensation seeking, alcohol expectancies, perceived social norms, and gender) have each been established to have associations with 
alcohol consumption among college students (Baer, 2002). Research has found a moderate association between sensation seeking and alcohol consumption in college students (Zuckerman 1994, 2000). Similarly, alcohol expectancies have been found to predict alcohol intake in a variety of populations, including college men and women (Carey, 1995; Leeman et al, 2009). Finally, perceived norms about other students' drinking have been associated with increased individual alcohol intake among college students (Borsari \& Carey, 2002).

Within a biopsychosocial framework, sensation seeking is hypothesized to act through biological and psychosocial components (Zuckerman, 1994); Similarly, biological differences in the metabolism of alcohol and body size among men and women along with differences in gender role socialization processes and gender norms related to alcohol use suggest that gender also acts through biological and psychosocial components (Graham et al, 1998; Lieber, 1997; Nolen-Hoeksema \& Hilt, 2006). Alcohol expectancies and perceived peer norms may be conceptualized at both the psychological and social levels of the model, as they contain a cognitive component that is in the form of beliefs in the case of alcohol expectancies and perception in the case of perceived peer norms. In addition, both variables have a social component, as the formation of both is contingent on the social environment. Due to the complex interrelationships between the biological, psychological, and social levels of these variables, the current methods do not allow us to partial unique variance at each level. However, the biopsychosocial framework allows for a conceptual integration of the diverse sources of influence exerted by each predictor on the outcome variable of alcohol use. 
Based on the reviewed findings, the following hypotheses and research questions will be examined:

\section{Research Hypotheses}

The first goal is to examine previously found relationships between amount of alcohol consumption and the variables of interest: Thus, sensation seeking, alcohol expectancies, and perceived peer norms are hypothesized to correlate positively with amount of alcohol consumption, as follows:

Hypothesis 1a. Sensation seeking will correlate positively with amount of alcohol consumption.

Research has consistently demonstrated a positive relationship of moderate strength between sensation seeking and alcohol consumption. A study of college students' engagement in risky behaviors found the correlation between sensation seeking and alcohol use to be 0.25 ( $\mathrm{p}<0.001)$, (Zuckerman, 2000). A meta-analysis whose total participant pool was comprised of $26 \%$ of college students demonstrated a mean correlation between sensation seeking and alcohol use of $r=0.26$ (Hittner $\&$ Swickert, 2006). Other research has shown that college students with higher levels of sensation seeking were more likely to play drinking games than those with lower levels of sensation seeking and that higher levels of sensation seeking were associated with an increased number of weekly consumed alcohol drinks (Johnston \& Cropsey, 2000). These relationships were found in both men and women but in general, men score higher on measures of sensation seeking than women (Zuckerman, 1994), including college drinking males (Zuckerman, 2000). 
Hypothesis 1b. Alcohol expectancy subscales (Global Positive Change, Social and Physical Pleasure, and Social Assertion) will be positively correlated with amount of alcohol consumption.

Studies show that expectations about alcohol's effects of social facilitation, sexual enhancement, tension reduction, increased pleasure, global positive changes, and increased arousal are all positively associated with and predict alcohol consumption (Carey, 1995; Martin \& Hoffman, 1993), although not all subscales may be found significant predictor in a given regression model. Martin and Hoffman (1993) found that expectancies measured by three of the subscales of the Alcohol Expectancy Questionnaire (Global Positive Change, Social and Physical Pleasure, and Social Assertion) were significant predictors of alcohol consumption among college students, along with other variables such as living arrangement and peer influence. Other studies showed that problem drinkers held more positive alcohol expectancies than non-problem drinkers (Lewis \& O’Neill, 2000) and similarly, heavier drinkers obtained higher scores on the Alcohol Expectancy Questionnaire than did lighter drinkers (Brown, Goldman, \& Christiansen, 1985; Brown, Goldman, Inn, \& Anderson, 1980).

Researchers typically administer the entire Alcohol Expectancy Questionnaire (Brown, Christiansen \& Goldman, 1987) with all six expectancy subscales but then analyze anywhere from 1-3 subscales - for example, Martin \& Hoffman (1993) included only three of the six subscales they administered in their final model. In the current study, the researchers plan on using the three subscales (Global Positive Change, Social and Physical Pleasure, and Social Assertion) used by 
Martin and Hoffman (1991) in their study of college drinking. However, after data collection, the psychometric properties of all six subscales will be examined for their relationships to the outcome measure of drinking and relation to the other five subscales before a final determination is made about which subscale to include in the regression. An examination of these psychometric properties before including individual subscales in the regression model is essential because of the potential for shared variance between the subscales (multicollinearity).

Hypothesis 1c. Perceived peer norms of alcohol consumption will correlate positively with reported personal alcohol consumption.

Perkins (2006) estimated that around $70 \%$ of students erroneously perceive their peers' alcohol use as higher than it actually is reported to be, with only $14 \%$ holding accurate perceptions of their peers' drinking. The widely held misperception that other students consume more alcohol than they actually do along with the erroneous belief that one's peers consume more alcohol than one does have been positively associated with individual alcohol use (Borsari \& Carey, 2002). Perkins (2006) found that for each one-drink increase in perceptions of peer average alcohol consumption, there was a nearly one-half-drink increase in individual student consumption. Other research has consistently shown that perceived peer norms have a significant effect on individual student drinking above and beyond the actual amount of alcohol typically consumed by other students, even in college cultures with high levels of heavy drinking (Perkins, 1999). Overall, perceptions of peer alcohol consumption are usually exaggerations of actual peer alcohol consumption for the 
majority of students and these misbeliefs have been consistently associated with increased personal alcohol use.

Hypothesis $2 a$. Men will report higher levels of alcohol consumption than will women.

Results from large epidemiological studies show that on average, college men report consuming greater quantities of alcohol than college women (O’Malley \& Johnston, 2002). There are also differences in the proportion of men and women who engage in heavy drinking - nearly $49 \%$ of men can be classified as heavy drinkers, compared to $41 \%$ of women (Wechsler \& Nelson, 2008).

Hypothesis $2 b$. Men will report higher levels of sensation seeking than will women.

Research has consistently shown that men in all age groups, including college men, score higher on measures of sensation seeking than women (Zuckerman, 1994, 2000).

Hypothesis 3: Sensation-seeking, alcohol expectancies, perceived social norms, and gender will each predict unique variance for individual alcohol consumption.

All of these variables have been previously related to alcohol consumption among college students (Baer, 2002) but to our knowledge, they have not been previously examined in a single model. Investigating their unique effects on individual student alcohol consumption within a biopsychosocial framework is likely to generate new knowledge about how such diverse variables contribute to college drinking. Moreover, it will contribute to understanding college drinking from a multi- 
level perspective and to conceptualizing this phenomenon within a biopsychosocial model.

Research Question 1. Are there gender differences in responses to each of the alcohol expectancy domains as measured by the subscales of the Alcohol Expectancy Questionnaire (Brown, Christiansen \& Goldman, 1987)?

Early studies on alcohol expectancies and gender found that expectations of consuming alcohol had different effects on men and women in a social situation involving interacting with a confederate of the opposite gender (Abrams \& Wilson, 1979; Wilson \& Abrams, 1977). In two separate studies, men and women were randomly assigned to conditions of either consuming an alcoholic or non-alcoholic beverage, paired with a manipulation of their beliefs about whether they had consumed alcohol or not, regardless of actual consumption. Then, they were introduced to a confederate of the opposite gender and participated in a brief interaction with him/her. Men showed signs of relaxation in this laboratory set-up after being led to believe they had consumed alcohol (regardless of whether that was actually true or not), whereas women displayed signs of anxiety, as shown by both physiological measures and ratings of outside observers.

Despite these early findings on clear gender differences on the effects of expectations about having consumed alcohol, it is presently unclear how gender affects the different domains of alcohol expectancies. Most studies on gender effects of alcohol expectancies have manipulated specific conditions, such as being with a confederate in a lab (Abrams \& Wilson, 1979; Wilson \& Abrams, 1977) and much of this type of research on gender effects dates back to 1970s and 1980s. Thus, it is 
unknown how changes in gender roles and college drinking patterns over time have affected the effects of gender on alcohol expectancies. We are therefore interested in investigating any potential gender differences across the six different expectancy domains of social facilitation, sexual enhancement, tension reduction, increased pleasure, global positive changes, and increased arousal.

Research Question 2. What are the frequencies of 12 alcohol-related consequences among college students?

Wechsler and Nelson (2008) estimated the frequencies of the same 12 alcohol-related consequences reported by a representative, nation-wide sample of undergraduates surveyed in 1999. We are interested in calculating the frequencies of these 12 consequences for a non-representative sample, compare them to the ones reported by Wechsler and Nelson (2008), and see if there are gender differences in experienced consequences. 


\section{Chapter 4}

\section{Method}

\section{Design}

This study was based on a correlational field design as it investigated the correlates and predictive power of several independent variables on alcohol consumption in a naturalistic setting. The strengths and limitations of the methods and design are discussed in a separate section.

\section{Participants}

An a-priori power analysis, specifying moderate effect sizes, a family-wise error rate of 0.05 , and power of 0.80 was conducted for three sets of statistical analyses - point-biserial correlations, multiple regression, and t-tests. The highest sample size estimate given for any of the three types of tests, specifying 5 statistical tests per fmily and reducing alpha to 0.01 for each individual test was 163 . Our sample size is 186 , meeting the a-priori requirements of the power analysis for this number of tests. Although our final analyses were based on a larger number of statistical tests than a-priori specified, statistical significance was detected even with reduced power.

The sample consisted of 186 undergraduate students at the University of Maryland, College Park recruited from several undergraduate classes. All students were between the ages of 18 and 24 (mean age was 20.46, SD 1.27, both median and mode age was 21) as this was an eligibility requirement for the current study. The majority of the sample was comprised of upperclassmen $(32.4 \%$ were junior and $43.8 \%$ were senior students), while only $7.6 \%$ were freshmen and $10.8 \%$ were 
sophomore. One student did not report their class standing. There were 138 women (74.2\%), 46 men $(24.9 \%)$, and $1(0.5 \%)$ who indicated "other" gender in this sample. One student ( $0.5 \%$ of all respondents) did not report his/her gender. More than half of those who reported their race were Caucasian (113 students or 60.8\%), 24 were Asian/Asian-American or Pacific Islander (12.9\%), 19 were Black (10.2\%), 7 were Hispanic or Latino/a (3.7\%), 20 (10.8\%) reported mixed race, 1 identified himself/herself as Iranian (0.5\%) and $1(0.5 \%)$ as Middle Eastern. Regarding the mixed race category, participants had the option to either select "Mixed Race" from several options or indicate more than one race. Both those who selected "Mixed Race" and those who selected more than one race are reported here as mixed-race. One participant did not report their race. Of the entire sample, $36(19.5 \%)$ reported they belonged to a Greek organization.. The majority of students $(73.1 \%)$ lived with roommates or housemates who were also students, $19.9 \%$ lived with parents or other relatives, $3.8 \%$ lived alone, $1.6 \%$ lived with a spouse or partner, and $1.1 \%$ had roommates or housemates who were not college students.. The largest proportion (45.2\%) lived in an off-campus house or apartment, $30.1 \%$ lived in a co-ed residence hall or dormitory or other university housing, $15.1 \%$ indicated they lived with parents or other relatives and commuted to campus, $7 \%$ lived in a fraternity or sorority house, $2.2 \%$ lived in a single-sex residence hall or dormitory, and $0.5 \%$ ( 1 respondent) did not answer. Students reported having on average 4.2 drinks in social situations with responses varying from 0 to 15 drinks. They also perceived that both their close friends and a typical student on their campus drink significantly more than they do. 


\section{Measures}

\section{Demographics.}

A demographic questionnaire was created by modifying two subscales (Student Life and Background) from the College Alcohol Study (Wechsler \& Nelson, 2008), to which the researchers added several additional items designed specifically for this study. Questions in the demographic form inquired about participants' age, status as an enrolled student, grade point average, current living situation, drinking habits, background and demographic information, alcohol use, alcohol-related consequences. The demographics measure was presented after all other measures in order to minimize the effect of priming background variables on students' responses. For a copy, please see Appendix A.

\section{Alcohol consumption.}

Alcohol consumption was measured by a quantity-frequency index derived from the Quantity-Frequency Measure described by Gonzales (1990) and used by Martin \& Hoffman (1993). The measure is included in Appendix B. In general, quantity-frequency measures assess average alcohol consumption by inquiring about the frequency and quantity of alcohol intake over a specific period of time (Sobell \& Sobell, 2003). The test-retest reliability of the Quantity-Frequency Measure was 0.79 (Gonzales, 1990). Comparisons with other measurement instruments, such as daily diary reports have shown that quantity-frequency measures tend to produce lower estimates of alcohol consumption (Sobell \& Sobell, 2003) but their brevity is a considerable advantage over the length and time commitment required by other measures, such as daily reports. 
For the current measure, scores were obtained by multiplying the total number of drinks consumed per occasion by the frequency of drinking episode. The total score produced in this way is referred to as the drinking index. There were 11 frequency categories in the measure, varying from "I have never had alcohol" (11) to drinking "3 or more times a day" (1). Each frequency category was assigned a weight equal to its item number, which then was reverse-scored, such that drinking 3 or more times a day received a weight of 10 and I have never had alcohol, a weight of 0 , with intermediate values in-between. The internal reliability consistency of the measure for the current study was 0.76 (based on two items).

\section{Perceived peer norms.}

Perceived peer drinking norms was measured as the average of the drinking indices of three close friends whose alcohol consumption was reported by the student. The measure has the same format as the Quantity-Frequency Measure and has been used in previous research on peer drinking norms in college students (Martin \& Hoffman, 1993). Students were first asked to list a close friend's initials and then to rate the frequency of that friend's alcohol consumption over a month period and the quantity of alcohol per drinking episode, similar to how participants rated their own frequency of alcohol consumption and quantity of alcohol per drinking occasion. They repeated this procedure for a total of three close friends. The drinking index for each close friend was then computed exactly the same way it was computed for participants - by multiplying the coded weight of frequency of drinking by number of drinks per occasion. Close friends' drinking indices were averaged and the mean was used as a measure of perceived peer norms. Scores can range from 0 to 106 . The 
internal reliability consistency of the 6-item measure used to derive an average peerdrinking index for this sample was 0.82 .

Research has found differential effects for the referent group used in questions about others' perceived alcohol use - in general, the closer the referent to the individual (such as a close friend or member of the same Greek life organization), the stronger the predictive power of perceived norms about that referent group on individual drinking (Perkins, 2002).

Previous research has used many different measures of peer influence and perceived peer alcohol use, in particular. However, many studies have used parallel phrasing of questions about personal alcohol use and perceived alcohol use by peers (Perkins \& Wechsler, 1999); Perkins et al, 2005). The actual drinking norm is generally calculated as the mean of reported personal alcohol use, which can then be compared to the perceived norm. Using parallel phrasing in questions about actual and perceived alcohol use helps minimize error in measuring the effect of perceived peer norms, at least with regard to how questions about one's own and others' perceived consumption are phrased. The current study also uses measures that have parallel phrasing of questions about one's own alcohol consumption and how one perceives the alcohol consumption of one's close friends.

\section{Sensation seeking.}

Sensation seeking was measured using the Impulsive Sensation Seeking subscale of the Zuckerman-Kuhlman Personality Questionnaire Cross-Cultural 50items version (Zuckerman \& Kuhlman, 1993). This version is based on the original Zuckerman-Kuhlman Personality Questionnaire developed to assess five personality 
traits, including impulsive sensation seeking. The original version, which has undergone several revisions, has been tested with a normative sample of several thousand college students, yielding high internal consistency and test-retest reliabilities (Zuckerman, 2000). It is scored on a true/false scale (true $=1$, false $=0$, scores on all items are summed up to produce an overall score) with a higher number of "true" responses reflecting higher levels of impulsive sensation seeking. Example items are "I'll try anything once."; I prefer friends who are excitingly unpredictable.; "I often do things on impulse." This measure has previously been used in research on the relationship between sensation seeking and college drinking (Johnston \& Cropsey, 2000; Zuckerman, 2000). It was selected because it captures an aspect of sensation seeking that may be particularly salient for drinking -impulsivity. Unlike other sensation seeking measures, it does not include explicit questions about drinking (except for an indirect one about "wild partying"). Scores on this measure can range from 0 to 10 . The internal reliability consistency of the 10 -item impulsive sensation seeking scale in the current sample was 0.75 .

\section{Alcohol expectancies.}

The Alcohol Expectancy Questionnaire (AEQ) was developed by Brown, Christiansen and Goldman (1987) to assess cognitive expectancies about the effects

of alcohol. The questionnaire was developed in two versions - for adults (ages 19 and older) and adolescents (ages 12-19). Both have been used with college student populations, yet there is little conclusive evidence about which version is better for use with college students. This may be due to the fact that college students are often at the transition between adolescence and adulthood and neither version truly captures 
their age range and developmental status. Moreover, the scale in its many versions is available in different lengths, ranging from 68 questions to 120 questions (Rubio, Bucholz, Neuman, \& Rauch, 2003). The present study used the AEQ adult form composed of 68 questions. This version was preferred for its brevity and the fact that the adult form has been shown to have better reliability and validity estimates than the adolescent version (Brown, Christiansen, \& Goldman, 1987). Furthermore, we expected our participant pool to include students older than 19, making the adult version more suitable for the present sample than the adolescent one.

The AEQ questionnaire was constructed from a selection of statements by respondents varying in degree of drinking from non-drinkers to excessive alcohol users and representing an age range of 15-60 years (Brown et al, 1987). An initial pool of 216 verbatim statements was content and factor analyzed and items with factor loadings greater than 0.30 on a given scale and limited loadings on any other scales were retained. An item was included only when its removal resulted in a lowered coefficient alpha for the entire scale and each item had to be located under one subscale only.

The different subscales measure different categories of alcohol expectancies, all of which are considered positive or desirable alcohol effects: Global Positive Changes contains items such as "Drinking makes the future seem brighter", "Alcohol seems like magic"; Sexual Enhancement has items such as "After a few drinks, I am more sexually responsive", "I am more romantic when I drink"; Physical and Social Pleasure is represent by items such as "Having a few drinks is a nice way to celebrate special occasions"; Increased Social Assertiveness contains items such as "A few 
drinks make it easier to talk to people", "Drinking gives me more confidence in myself"; Relaxation and Tension Reduction has items such as "Alcohol makes me worry less"; and Arousal and Aggression contains items such as "I feel powerful when I drink, as if I can really influence others to do as I want".

The original AEQ instrument has a two-point response scale, with Agree and Disagree as the only options but Martin \& Hoffman (1991) in their study on predictors of college alcohol use designed a 5-point Likert-type scale to increase variability in responding. In the current study, we utilized a 7-point Likert-type scale, with the following response options: strongly disagree, disagree, slightly disagree, neutral, slightly agree, agree, and strongly agree. Research shows that a 7-point response scale is preferred over a 5-point one if researchers' goal is to capture more variability in responding (Krosnick \& Presser, 2010). For analyses in the current study, the answer options in the 7-point response scale were assigned the following values: strongly disagree (-3), disagree (-2), slightly disagree (-1), neutral (0), slightly agree (1), agree (2), and strongly agree (3). Therefore, scores on the scale could be both positive and negative.

Internal consistency reliability for individual subscales in a sample of 176 non-problem drinker adults ranged from 0.72 to 0.92 with a mean of 0.84 (Brown, Christiansen \& Goldman, 1987). Test-retest reliability was computed on a sample of 465 college students. The mean test-retest reliability coefficient was 0.64 after 8 weeks. Discriminant validity was assessed with respect to social desirability. The rationale for using social desirability was that some alcohol effects might be viewed as more socially desirable (increased gregariousness) than others (increased 
aggression). Thus, the authors tested whether reports of expectancies of such behaviors varied with motivation to present oneself in socially desirable ways. The average correlation between scores on alcohol expectancy scales of the AEQ (adult version) and scores on a social desirability measure among a sample of 324 male and female college students was -.14, with estimates ranging between 0.01 and -.16 (Brown, Christiansen, \& Goldman 1987).

The internal reliability consistency for each of the six individual AEQ subscales for the present study was as follows: 0.95 for Global Positive Changes (based on 174 respondents and 13 list-wise excluded cases), 0.91 for Sexual Enhancement (based on 182 respondents and 5 list-wise excluded cases), 0.89 for Social and Physical Pleasure (based on 183 respondents and 4 list-wise excluded cases), 0.94 for Social Assertiveness (based on 180 respondents and 7 list-wise excluded cases), 0.90 for Relaxation (based on 182 respondents and 5 list-wise excluded cases), and 0.88 for Arousal/Aggression (based on 181 respondents and 6 list-wise excluded cases). The internal reliability consistency for the entire AEQ scale (68 items) was 0.98 based on 159 respondents and 28 list-wise deleted cases. The individual AEQ subscales for the current study were highly inter-correlated with Pearson's $r$ estimates ranging from 0.71 to 0.85 .

In order to verify whether items loaded on their expected factors given the high correlations between subscales, we performed principal components analysis similar to the one used to develop the scale. Details on this analysis will be presented in the section on results but it was evident that items did not load on the expected factors, as a result of which two new factors were identified. One contained a 
combination of items that can be broadly described as general positive expectancies and the other factor consisted mainly of items related to sexual and romantic expectancies. The internal reliability consistency of the general positive expectancies factor (24 items) was 0.97 based on 177 valid and 10 list-wise deleted cases. The internal reliability consistency of the sexual and romantic expectancies factor ( 9 items) was 0.92 based on 181 valid and 6 list-wise deleted cases.

\section{Procedure}

The investigators contacted instructors of undergraduate counseling, psychology, and education courses at the University of Maryland and asked them to distribute a recruitment script (attached in Appendix F) to their students, either via email or via their course websites. Only currently enrolled students between the ages of 18 and 24 were eligible to participate. They were invited to participate for either course credit (at the discretion of their instructors) or the opportunity to win one of three \$20 gift certificates to amazon.com. In addition, the announcement script contained information about the purpose of the study, anticipated time commitment (between 25 and 30 minutes), online link to the survey and contact information of the student researcher.

The survey was conducted on SurveyMonkey.com through a shared departmental account to which the researchers were given access. Participants were first presented with an introductory page outlining the eligibility criteria, which asked them to verify that they were currently enrolled as undergraduate students at the University of Maryland and were between 18 and 24 years old. A consent form was presented next (included in Appendix G) asking participants to check a box in 
agreement to the terms and eligibility criteria outlined in the consent form. In addition, the informed consent contained information about the purpose of the study, required activities, expected time for completion (between 25 and 30 minutes), any risks and benefits related to the study, confidentiality, and contact information for the researchers. Due to the shared nature of the account, the researchers could not guarantee complete confidentiality and responses to the survey items were collected independently of identifying information given by participants for the purposes of receiving course credit or participating in the raffle. Two-hundred and four all participants consented to the survey but 5 did not submit any responses beyond the consent statement, one responded to only one questions beyond the consent and another responded to two. Another 11 participants were excluded from the sample due to incomplete responses, leaving a total of 186 participants who were included in the data analysis.

The survey consisted of the following questionnaires: Quantity Frequency Measure (Gonzales, 1990), Perceived Peer Norms (adapted from Gonzales, 1990), Impulsive Sensation Seeking Subscale (Zuckerman \& Kuhlman, 1993), Alcohol Expectancy Questionnaire (Brown, Christiansen \& Goldman, 1987), and a demographic form. The instruments were presented in the following order: measures of personal alcohol consumption and perceived peer alcohol consumption along with other drinking-related questions such as experiences of negative consequences and perceived alcohol consumption of typical students on campus, Alcohol Expectancy Questionnaire, Impulsive Sensation Seeking, and demographic questions about race, age, gender, class standing, and living situation. At the end of the survey, a brief 
description of the study (see Appendix $\mathrm{H}$ ) was presented as well as links to support resources on campus and online (including sexual assault information) in case participants experienced distress while completing the survey. For the purposes of gift certificate drawing, eligible participants' names and email addresses will be collected independently of survey data through a separate link.

\section{Preliminary Analyses}

All statistical analyses were performed using the statistical software package SPSS, Version 20. Missing values were identified before any statistical analyses were performed. Missing data from eighteen participants were discarded: five only indicated their consent to participate in the survey but did not complete any parts of it, one completed only one question beyond the consent and another completed two, and the remaining eleven left large parts of their surveys blank.

Of the eleven participants who completed part of the survey, five respondents stopped shortly before or right after the first 27 questions about personal and peer drinking. They had no scores on the AEQ, sensation seeking scale, or demographics. Another five stopped partway through the Alcohol Expectancy Questionnaire, which was the longest measure in the survey (68 items). Of those five, two stopped after 28th question of AEQ ("I often feel sexier after I've had a couple of drinks) and the other three stopped after 42nd question ("Drinking helps me get out of a depressed mood"). It is worth mentioning that AEQ questions were presented on 5 different pages, 14 at a time (the last page containing only 12 items). Thus, these participants stopped at the end of the second or third pages of the AEQ measure. Finally, one participant gave four widely dispersed responses on the AEQ and skipped the 
remaining 64 items. This participant's responses were discarded as she/he may have browsed through the survey with the intention of skipping to the end for extra credit.

Other than the discarded surveys described above, the remainder of the surveys had relatively few missing values and no pattern to these missing values was discerned. Specifically, there were 35 missing values for the entire Alcohol Expectancy Questionnaire on a total of 28 items (one item, Alcohol can act as an anesthetic, that is, it can deaden pain had 4 missing values, and the rest had one or two missing values per item). The default setting in SPSS for handling missing values is list-wise deletion, which eliminates any missing values from the analysis and uses only cases with complete data (Schlomer, Bauman \& Card, 2010). This setting was used by SPSS in calculating the internal reliability consistency estimates for all scales. Although the authors argue that this procedure may result in a loss of statistical power and biases in the results due to ignoring missing data, there are good reasons for using it in our case. Substituting missing data in a measure such as the Alcohol Expectancy Questionnaire with means or other measures of central tendency would be unwise because this instrument measures a variety of internal beliefs and any measure of central tendency would be close to meaningless. One can argue that the mean of individual subscales could be used for replacing missing values on a given item but that would contradict our finding that the items loaded differently than expected and we would not be sure which mean to use. Thus, for the purposes of calculating internal reliability consistency using only available data through listwise deletion was the method of choice. For calculating correlations, however, we preferred a more flexible approach called pairwise deletion of missing values. This 
ensured that the most data was retained for each correlation as cases were excluded only in analyses with required variables (Schlomer, Bauman, \& Card, 2010). Overall, there was a relatively small proportion of missing cases in the entire dataset.

The impulsive sensation seeking scale had only one missing value. In addition, missing values were discovered in the following variables: 1 missing value was found for each of race, age, gender, college year, Greek membership, 9 missing values were found for GPA, 2 missing values were found for relationship status, 3 missing values were found for personal average number of drinks, 8 missing values were found for reporting the number of occasions in the past 30 days on which one got drunk, 7 missing values were found for the average number of drunks of a typical student on campus, 2 missing values were found for Friend A's usual number of drinks, and one missing value was found for each of the following variables: Friend B's frequency and usual number of drinks, and Friend C's frequency of drinking. It is important to note that the missing values for Friend A's usual number of drinks (1 value), Friend B's frequency and usual number of drinks, and Friend C's frequency of drinking were due to one participant's responses. This participant provided only the frequency of Friend A's drinking and usual number of drinks of Friend C, so this participant's missing values for close friends' drinking were replaced with what the participant provided for Friends A's and C's drinking. The average close friends' drinking index for this participant was thus formed at 16, which was also close to the typical student drinking index of 20 this participant provided. The other missing value for usual number of drinks of Friend A was found in another participant's responses and again, it was replaced with the mean (3) of the usual number of drinks this 
participant indicated for friends B and C (1 and 5, respectively). There were 7 missing values for the usual number of drinks a typical student has and they were replaced with the mean of scores that the rest of the sample indicated (5.17 which was rounded to the nearest whole number or 5). Among the twelve questions about alcohol-related consequences, there were 5 missing values total: 1 missing value for missing class, 2 for getting behind in school work, 1 for getting hurt or injured, and 1 for requiring medical treatment for alcohol overdose.

Data were next examined for normality and slight deviations were found in several continuous variables. Scores on the sensation seeking scale were highly symmetrically distributed as demonstrated by skewness of 0.13 but they displayed slight flattening shown by kurtosis of -0.73 . Scores on the general positive expectancy factor of the Alcohol Expectancy Questionnaire displayed some deviations from normality as shown by skewness of -1.15 and kurtosis of 1.54 . Scores on the second factor of the AEQ, sexual and romantic expectancies showed less deviation from normality with skewness of -0.28 and kurtosis of -0.70 . The distribution of personal drinking index scores had skewness of 1.37 and kurtosis of 4.29. The distribution of peer drinking index scores had skewness of 1.5 and kurtosis of 5.26. Although these estimates suggested some deviations from normality, examination of variable distributions did not show extreme deviations that warranted variable transformations. For a depiction of each distribution, please see Appendix I.

Descriptive analyses were performed on all measures and a correlation matrix along with means and standard deviations are reported in Tables 1 and 2. 
Table 1.

Correlation Matrix.

\begin{tabular}{|c|c|c|c|c|c|c|c|c|c|}
\hline & $\begin{array}{l}\text { Personal } \\
\text { Drinking } \\
\text { Index }\end{array}$ & $\begin{array}{l}\text { Peer } \\
\text { Norms }\end{array}$ & $\begin{array}{l}\text { Sensation } \\
\text { Seeking }\end{array}$ & $\begin{array}{l}\text { General } \\
\text { Positive } \\
\text { Expect. }\end{array}$ & $\begin{array}{l}\text { Sexual } \\
\text { \&Romanti } \\
\text { c Expect. }\end{array}$ & Gender & Age & $\begin{array}{l}\text { Heavy } \\
\text { Drinking }\end{array}$ & $\begin{array}{l}\text { Drunk in } \\
\text { Past } 30 \\
\text { days }\end{array}$ \\
\hline $\begin{array}{l}\text { Personal } \\
\text { Drinking } \\
\text { Index }\end{array}$ & 1 & & & & & & & & \\
\hline $\begin{array}{l}\text { Peer } \\
\text { Norms }\end{array}$ & $.62^{* *}$ & 1 & & & & & & & \\
\hline $\begin{array}{l}\text { Sensation } \\
\text { Seeking }\end{array}$ & .025 & .06 & 1 & & & & & & \\
\hline $\begin{array}{l}\text { General } \\
\text { Positive } \\
\text { Expect. }\end{array}$ & $.59^{* * *}$ & $.36 * *$ & .04 & 1 & & & & & \\
\hline $\begin{array}{l}\text { Sexual } \\
\text { and } \\
\text { Romantic } \\
\text { Expect. }\end{array}$ & $.42^{* *}$ & $.25 * *$ & $.15^{*}$ & $.68^{* *}$ & 1 & & & & \\
\hline Gender & -.15 & -.13 & -.07 & .02 & $-.15^{*}$ & 1 & & & \\
\hline Age & -.08 & 0.06 & .00 & .05 & .07 & -.04 & 1 & & \\
\hline $\begin{array}{l}\text { Heavy } \\
\text { Drinking }\end{array}$ & $.57^{* *}$ & $.42 * *$ & .05 & $.43^{* *}$ & $.26^{* *}$ & .07 & $\begin{array}{l}-.03 \\
\end{array}$ & 1 & \\
\hline $\begin{array}{l}\text { Drunk in } \\
\text { Past } 30 \\
\text { days }\end{array}$ & $.63^{*}$ & $.38 * *$ & .05 & $.42^{* *}$ & $.28^{* *}$ & -.05 & -.14 & $.53 * *$ & 1 \\
\hline
\end{tabular}

$* \mathrm{p}<0.01$

$* * \mathrm{p}<0.001$ 
Table 2.

Descriptive Statistics.

\begin{tabular}{|l|r|r|r|r|}
\hline & \multicolumn{1}{|c|}{ Mean } & \multicolumn{1}{c|}{ Std. Deviation } & \multicolumn{1}{c|}{ Range } & N \\
\hline Personal Drinking Index & 20.24 & 15.09 & $0-100$ & 183 \\
\hline $\begin{array}{l}\text { Average Drinking Index of 3 Close } \\
\text { Friends (Peer Norms) }\end{array}$ & 23.63 & 14.90 & $0-106$ & 185 \\
\hline Sensation Seeking & 4.34 & 2.66 & $0-10$ & 186 \\
\hline General Positive Expectancies & 13.20 & 28.71 & $(-72)-(72)$ & 186 \\
\hline Sexual and Romantic Expectancies & -5.65 & 11.35 & $(-27)-23$ & 186 \\
\hline Age & 20.46 & 1.27 & $18-24$ & 185 \\
\hline GPA & 3.27 & .56 & $1.0-4.0$ & 177 \\
\hline $\begin{array}{l}\text { Number of occasions getting drunk } \\
\text { drunk in past 30 days. }\end{array}$ & 2.57 & 3.08 & $0-20$ & 178 \\
\hline
\end{tabular}




\section{Sample Description of Alcohol Behaviors}

This sample reported that they typically consumed a mean of 4.12 (SD 2.56)

drinks in social situations. The range varied from 0 to 15 drinks. The majority of students (48.4\%) indicated that they had alcohol once or twice a week, 17.7\% reported having alcohol 2 or 3 times a month, whereas $11.8 \%$ reported having alcohol 3 or 4 times a week. Only 6.5\% indicated never having had alcohol, 3.8\% reported having alcohol less than once a year and $6.5 \%$ - less than once a month but at least once a year. In addition, the mean number of occasions in the 30 days prior to taking the survey that students got drunk (feeling unsteady, dizzy, or sick to one's stomach) was 2.57 (SD 3.1), with a range of 0 to 20 occasions. Furthermore, 56.3\% of the 183 students could be categorized as heavy drinkers, defined by Wechsler and Nelson (2008) as having five or more drinks in a row for men and four or more for women. Heavy drinking was estimated from a question on the demographic form borrowed from the College Alcohol Study (Wechsler \& Nelson, 2008) about the number of drinks beyond 4 that one had had in the two weeks prior to the survey and the indicated gender of the student.

\section{Exploratory Factor Analysis of the Alcohol Expectancy Questionnaire}

The analysis showed that the original subscales of the Alcohol Expectancy Questionnaire were strongly intercorrelated, showing robust evidence of multicollinearity. In order to make a more informed decision about which scale(s) to include in the final analysis, we performed a principal components analysis on the entire scale. In its beginning, the Alcohol Expectancy Questionnaire was developed from a large pool of participants' statements about their expectations about the effects 
of alcohol by factor-analyzing all items and retaining those that loaded on 6 factors (Brown, Christiansen, \& Goldman, 1987). The method of extraction used in the initial development of the scale was principal components with Varimax rotation and findings from this analysis were later replicated in a study on a 68-item version of the scale in a community sample (Rubio, Bucholz, Neuman, \& Rauch, 2003). The same methods of extraction and rotation were used (principal components with Varimax rotation), which resulted in the replication of factor loadings in the majority of items. In both the original and replication study, the authors did not justify their choice of extraction method and rotation. The literature on factor analysis shows that both the extraction method and rotation can impact the results of the analysis and in most cases, principal axis factoring is preferred when the goal is to study the underlying structure of the data, rather than to reduce the number of items in a scale, which is often the function of principal components analysis (Fabrigar, Wegener, MacCallum, \& Strahan, 1999). Similarly, oblique rotation is used to allow factors to correlate with one another, which is not allowed in an orthogonal rotation such as Varimax (Kahn, 2006). However, principal components analysis was preferred here because the initial development of the Alcohol Expectancy Questionnaire, as well as subsequent research does not specify whether the different expectancy domains should be viewed as separate constructs.

Results of the principal analysis on the current sample showed that items did not load as expected. Based on the scree plot, two factors were retained: the first explaining (see Appendix J). Although the scree test for retaining factors can be subjective, in this case there was a detectable drop in eigenvalues between the second 
and third factors, as well as indistinguishable decreases in eigenvalues from the third factor on. The inclusion criteria for retaining items were: 1) an item needs to load at least 0.50 on one factor and 2) there must be at least a 0.30 difference in the loadings of an item on the two factors. These inclusion criteria are relatively stringent, given that most recommend retaining items when they load 0.30 on a given factor (Fabrigar et al, 1999).

The items retained under the first factor were a mix of disinhibition, social facilitation, and general positive effects of alcohol. The second factor, however, was remarkably consistent in that items shared the theme of sexual or romantic expectations. We termed the first factor general positive expectations about the effects of alcohol and the second factor sexual and romantic enhancement expectations. All but one items (I often feel sexier after I've had a couple of drinks) of the original sexual enhancement subscale loaded under this second factor, in addition to three other similarly themed items (Alcohol makes me feel better physically; I am more romantic when I drink; A couple of drinks makes me more aroused or physiologically excited). The items retained under each factor are presented below and factor loadings along with the scree plot can be found in Appendix J. The internal consistency reliability for each newly identified subscale was 0.97 (general positive expectancies, 24 items) and 0.92 (sexual and romantic expectancies, 9 items).

In addition, the two subscales were correlated at $r=0.653$ (large effect) with one another. A test of multicollinearity using the variance inflation factor (VIF) statistic was performed in a regression model containing the two expectancy scales identified through factor analysis, sensation seeking, gender, and perceived peer 
norms. The two alcohol expectancy scales had similar VIF values: 2.1 for general positive expectancies and 2.0 for sexual and romantic expectancies. The VIF values of the remaining variables were close to 1 . Although the VIF values were deemed acceptable, we were guided by previous research showing that positive expectancies are the strongest predictor of alcohol use compared to other types of expectancies (Stacy, Widaman, \& Marlatt, 1990) in selecting only the general positive expectancy subscale as a predictor in the multiple regression model.

Factor 1: General Positive Expectancies: Drinking adds a certain warmth to social occasions./ When I'm drinking, it is easier to open up and express my feelings./Time passes quickly when I'm drinking./Drinking gives me more confidence in myself./Drinking makes me feel good./Having a few drinks is a nice way to celebrate special occasions./When I'm drinking I feel freer to be myself and do whatever I want./Drinking makes it easier to concentrate on the good feelings I have at the time./Alcohol allows me to be more assertive./When I feel "high" from drinking, everything seems to feel better./I find that conversing with members of the opposite sex is easier for me after I've had a few drinks./Drinking is pleasurable because it's enjoyable to join in with people who are enjoying themselves./If I'm feeling restricted in any way, a few drinks make me feel better./If I have a couple of drinks, it is easier to express my feelings./After a few drinks, I don't worry as much about what other people think of me./Alcohol enables me to have a better time at parties./Alcohol makes me worry less./A few drinks makes it easier to talk to people./After a few drinks I am usually in a better mood./A few drinks makes me feel less shy./I feel like more of a happy-go-lucky person when I drink./Drinking makes 
get togethers more fun./If I'm cold, having a few drinks will give me a sense of warmth./It is easier to act on my feelings after I've had a few drinks.

Factor 2: Sexual and Romantic Expectancies: I'm a better lover after a few drinks./Women can have orgasms more easily if they've been drinking./I enjoy having sex more if I've had some alcohol./I am more romantic when I drink./I feel more masculine/feminine after a few drinks./Alcohol makes me feel better physically./Sometimes when I drink alone or with one other person it is easy to feel cozy and romantic./After a few drinks, I am more sexually responsive./A couple of drinks makes me more aroused or physiologically excited. 


\section{Chapter 5}

\section{Results}

This chapter presents the results to the hypotheses outlined in Chapter 3. Hypotheses are re-iterated, followed by a description of the statistical analyses used to test them, corresponding results, and conclusions about whether a hypothesis was supported or not. All statistical analyses were conducted with the software package SPSS, version 20.

Hypothesis 1a. Sensation seeking will correlate positively with amount of alcohol consumption.

Scores on the Impulsive Sensation Seeking Scale from the ZKPQ-50 (Zuckerman \& Kuhlman, 1993) were correlated with drinking index scores from the Quantity-Frequency Index (Gonzales, 1990) and a Pearson's r coefficient was computed. This correlation was not significant so this hypothesis was not supported. Hypothesis $1 b$. Individual alcohol expectancy subscales will be positively correlated with amount of alcohol consumption.

After the original alcohol expectancy subscales were examined for the presence of multi-collinearity, which was confirmed, and items did not load on their expected factors in a principal components analysis, two new factors emerged (general positive and sexual and romantic expectancies). Scores on these new subscales were correlated with personal drinking index scores from the QuantityFrequency Index (Gonzales, 1990). Factor 1 (general positive expectancies) correlated significantly with personal Quantity-Frequency Index $(r=0.59$, large effect), as did Factor 2 (sexual and romantic expectancies) ( $\mathrm{r}=0.42$, medium effect). 
Hypothesis $1 c$. Perceived peer norms of alcohol use will correlate positively with personal drinking index.

The Pearson correlation between the average quantity-frequency index of three close friends and personal drinking index was found to be $r=0.62$ (large effect).

Hypothesis $2 a$. Men will report higher levels of alcohol consumption than will women.

A between-groups t-test was conducted on drinking index scores of men and women to determine if any significant difference exists between the two groups. Men had a significantly higher average drinking index than women $\left(\mathrm{t}_{179}=2.15, \mathrm{p}<0.05\right)$.

Hypothesis $2 b$. Men will report higher levels of sensation seeking than will women.

Although men had a slightly higher mean score on this variable, an independent-samples t-test showed that there was no significant difference in the mean scores of the two groups $\left(\mathrm{t}_{182}=1.24, \mathrm{p}>0.05\right)$. This represented a small effect $(\mathrm{r}=0.15)$.

Hypothesis 3: Sensation-seeking, alcohol expectancies, perceived social norms, and gender will each predict unique variance for individual alcohol consumption.

Simultaneous multiple regression analysis was used to test this hypothesis. Regression analysis is a general linear model of estimating linear relationships between several variables and finding an optimal model fit using standard ordinary least squares approximation (Cohen, Cohen, West, \& Aiken, 2002). As any linear model, statistical conclusions reached through regression depend on a set of 
assumptions that the data are expected to meet. The assumptions of linear regression are linearity (the relationship between the predictor variables and the dependent variable should be linear), normality (population errors of each variable should be normally distributed), homoscedasticity (error variance should be constant across values of a variable), independence (errors of one observations should not correlate with errors of another), no measurement error in the variables of interest, and proper model specification (Cohen et al, ). Violations of different degrees of the abovementioned assumptions may lead to erroneous estimates in the final analysis.

To check for deviations from the assumptions of linearity, normality, homoscedasticity, and independence, graphic plots of the relationships between the selected variables were examined. The assumptions of linearity, homoscedasticity, and independence were examined by graphic plots of standardized regression residuals vs. standardized regression predicted value for the relationships between each independent variable and the dependent variable (the plots are attached in Appendix K). All three assumptions would require that the distribution of residuals in each plot be random and located within two standard deviations of the mean. Any pattern different from that would suggest a degree of violation of the assumption. As can be seen from the plots in Appendix K, some deviation from linearity, homoscedasticity, and independence was observed in the relationships between general positive expectancies and personal drinking index and peer norms and personal drinking index. Deviations from linear relationships pose the risk of misestimating the true relationship between the variables but many relationships in behavioral research are not perfectly linear and examination of the graphs does not 
warrant variable transformations in this particular case, although we acknowledge the presence of some deviation from linearity (Cohen et al, 2002). The regression standardized residuals appeared normally distributed (with slight deviations) in a PP plot of regression residuals vs. predicted values, thus showing no evidence for substantial skewness.

Similarly, the distributions of residuals were not perfectly homoscedastistic but some authors have suggested that slight deviations from the homoscedasticity assumption have little influence on significant tests (Berry \& Feldman, 1985). In the current analysis, we acknowledge slight heteroscedasticity in the distribution of residuals of general positive expectancies and peer norms. Finally, the assumption of independence of observations is hardly ever met in behavioral research, due to the complex interrelationships that often exist among psychological variables (Cohen et al, 2002). Examination of PP plots and score distributions of the relationships between each predictor and the dependent variable (see Appendix L) showed slight but non-problematic deviations from normality in most relationships.

Due to the ordinary least squares approximation method, coefficient estimates in linear regression may be highly susceptible to outlying values in both predictor and dependent variables. Graphic residual plots and casewise diagnostics may suggest the presence of several potential outliers in the set of examined variables but none of the potential outliers were removed, as 17 data cases had already been discarded prior to performing regression diagnostics and removing more cases could result in biasing of the model fit parameter estimates, rather than securing a better fit to the data. 


\section{Regression Model}

Sensation-seeking, general positive expectancies, perceived social norms, and gender were included in a simultaneous multiple regression model to determine if each variable had a unique effect on the outcome variable of alcohol consumption.

The results from this analysis showed that all of the variables except for sensation seeking contributed unique variance to the prediction of alcohol consumption. In this model, peer norms and general positive expectancies had medium effects on personal drinking index (st. beta $=.451$ and .424 , respectively) and gender had a small effect $($ st. beta $=-.11)$.

Table 3.

Multiple Regression Model.

\begin{tabular}{|c|c|c|c|c|c|}
\hline \multicolumn{6}{|c|}{ Coefficients $^{\mathrm{a}}$} \\
\hline \multirow[t]{2}{*}{ Model } & \multicolumn{2}{|c|}{$\begin{array}{c}\text { Unstandardized } \\
\text { Coefficients }\end{array}$} & \multirow{2}{*}{$\begin{array}{c}\text { Standardized } \\
\text { Coefficients }\end{array}$} & \multirow[t]{2}{*}{$\mathrm{t}$} & \multirow[t]{2}{*}{ Sig. } \\
\hline & $\mathrm{B}$ & Std. Error & & & \\
\hline \multirow{5}{*}{$\begin{array}{l}\text { (Constant) } \\
\text { Peer Norms } \\
\text { Sensation Seeking } \\
\text { Gender } \\
\text { General Positive } \\
\text { Expectancies }\end{array}$} & 10.08 & 2.44 & & 4.13 & .000 \\
\hline & .46 & .06 & .45 & 8.11 & .000 \\
\hline & -.19 & .30 & -.03 & -.63 & .53 \\
\hline & -3.59 & 1.77 & -.11 & -2.03 & .044 \\
\hline & .22 & .03 & .42 & 7.69 & .000 \\
\hline
\end{tabular}

\begin{tabular}{|l|r|r|r|c|}
\hline \multicolumn{5}{|c|}{ Model Summary $^{\mathbf{b}}$} \\
\hline Model & R & R Square & $\begin{array}{c}\text { Adjusted R } \\
\text { Square }\end{array}$ & $\begin{array}{c}\text { Std. Error of the } \\
\text { Estimate }\end{array}$ \\
\hline 1 & $.736^{\mathrm{a}}$ & .542 & .532 & 10.360 \\
\hline
\end{tabular}

a. Predictors: (Constant), General Positive Expectancies, Gender, Sensation Seeking, Perceived Peer Norms

b. Dependent Variable: Personal Drinking Index 


\section{Exploratory Mediation Analysis}

An exploratory mediation analysis was performed to examine whether the relationship between individual alcohol consumption and perceived peer norms might be mediated by alcohol expectancies. A mediation analysis requires that the relationship between a predictor and outcome be fully or partially explained by a third variable, which is assumed to be caused by the predictor (Barron \& Kenny, 1986). In the current case, we hypothesized that general positive alcohol expectancies would mediate the relationship between perceived peer norms and individual alcohol consumption, as cognitive beliefs about the effects of alcohol may be formed as a result of peer influence and students' perceptions about close friends' drinking. Thus, observing others, especially one's close friends drink, may influence one's own judgment about the expected effects of alcohol, which in turn influences one's own alcohol consumption.

Baron and Kenny (1986) specify that a mediation analysis requires successful completion of several sequential steps: First, it must be shown that the independent variable predicts the mediator; Then, it must be confirmed that the independent variable affects the dependent variable; And finally, the initial relationship between the independent variable and the dependent variable must be reduced or completely eliminated when the dependent variable is regressed on both the independent variable and the mediator.

Following these steps, we found that the independent variable significantly predicted the mediator (standardized beta $=0.36, \mathrm{p}<0.001$ ). Then, the mediator accounted for significant variation in personal drinking index (standardized beta $=$ 
$0.62, \mathrm{p}<0.001)$. And finally, that relationship was attenuated when both peer norms and general positive expectancies were entered in a simultaneous regression model where personal drinking index was the dependent variable (tables $4-6$ present the three steps of the mediation analysis).

The hypothesis that general positive expectancies partially mediated the relationship between peer norms and personal drinking index was supported. 
Table 4.

The Mediator is Regressed on the Independent Variable

\begin{tabular}{|c|c|c|c|c|c|c|}
\hline \multicolumn{7}{|c|}{ Coefficients $^{\mathrm{a}}$} \\
\hline \multirow{3}{*}{\multicolumn{2}{|c|}{ Model }} & \multirow{2}{*}{\multicolumn{2}{|c|}{$\begin{array}{c}\text { Unstandardized } \\
\text { Coefficients }\end{array}$}} & \multirow{3}{*}{\begin{tabular}{|c|}
$\begin{array}{c}\text { Standardized } \\
\text { Coefficients }\end{array}$ \\
Beta \\
\end{tabular}} & \multirow[t]{3}{*}{$\mathrm{t}$} & \multirow[t]{3}{*}{ Sig. } \\
\hline & & & & & & \\
\hline & & $\mathrm{B}$ & Std. Error & & & \\
\hline \multirow{2}{*}{1} & (Constant) & -3.29 & 3.71 & & -.89 & .38 \\
\hline & \begin{tabular}{|l|} 
Peer Norms \\
\end{tabular} & .70 & .13 & .36 & 5.29 & .00 \\
\hline
\end{tabular}

Table 5.

The Dependent Variable is Regressed on the Independent Variable

\begin{tabular}{|c|c|c|c|c|c|c|}
\hline \multicolumn{7}{|c|}{ Coefficients $^{\mathrm{a}}$} \\
\hline \multirow{2}{*}{\multicolumn{2}{|c|}{ Model }} & \multicolumn{2}{|c|}{$\begin{array}{c}\text { Unstandardized } \\
\text { Coefficients }\end{array}$} & \multirow{2}{*}{$\begin{array}{c}\begin{array}{c}\text { Standardized } \\
\text { Coefficients }\end{array} \\
\text { Beta }\end{array}$} & \multirow[t]{2}{*}{$\mathrm{t}$} & \multirow[t]{2}{*}{ Sig. } \\
\hline & & $\mathrm{B}$ & Std. Error & & & \\
\hline \multirow{2}{*}{1} & (Constant) & 5.56 & 1.66 & & 3.36 & .001 \\
\hline & Peer Norms & .63 & .06 & .62 & 10.53 & .000 \\
\hline
\end{tabular}

Table 6.

\section{Combined Regression Equation}

\begin{tabular}{|c|c|c|c|c|c|c|}
\hline \multicolumn{7}{|c|}{ Coefficients $^{\mathrm{a}}$} \\
\hline \multirow{2}{*}{\multicolumn{2}{|c|}{ Model }} & \multicolumn{2}{|c|}{$\begin{array}{c}\text { Unstandardized } \\
\text { Coefficients }\end{array}$} & \multirow{2}{*}{$\begin{array}{c}\text { Standardized } \\
\text { Coefficients }\end{array}$} & \multirow[t]{2}{*}{$\mathrm{t}$} & \multirow[t]{2}{*}{ Sig. } \\
\hline & & $\mathrm{B}$ & Std. Error & & & \\
\hline \multirow{3}{*}{1} & (Constant) & 6.29 & 1.45 & & 4.34 & .000 \\
\hline & Peer Norms & .48 & .06 & .47 & 8.50 & .000 \\
\hline & $\begin{array}{l}\text { General Positive } \\
\text { Expectancies }\end{array}$ & .22 & .03 & .42 & 7.57 & .000 \\
\hline
\end{tabular}


Research Question 1: Are there gender differences in responses to each of the alcohol expectancy domains as measured by the subscales of the Alcohol Expectancy Questionnaire?

This research question was not explored because the subscales of the Alcohol Expectancy Questionnaire changed due to unexpected item loadings and analyses based on the new subscales would produce results that could not be compared to other findings in the literature.

Research Question 2: What are the frequencies of 12 alcohol-related consequences among college students?

The frequencies of 12 alcohol-related consequences among college students are presented in table 3 . 
Table 7.

Frequency of Occurrence of 12 Alcohol-related Consequences

\begin{tabular}{|l|l|l|l|l|l|}
\hline & $\begin{array}{l}\text { Not at } \\
\text { all }\end{array}$ & Once & Twice & $\begin{array}{l}3 \\
\text { Times }\end{array}$ & $\begin{array}{l}4 \text { or } \\
\text { more } \\
\text { times }\end{array}$ \\
\hline $\begin{array}{l}\text { Have a } \\
\text { Hangover }\end{array}$ & $31.2 \%$ & $\begin{array}{l}12.9 \\
\%\end{array}$ & $15.1 \%$ & $10.2 \%$ & $30.6 \%$ \\
\hline Miss a class & $70.8 \%$ & $\begin{array}{l}11.9 \\
\%\end{array}$ & $6.5 \%$ & $5.9 \%$ & $4.9 \%$ \\
\hline $\begin{array}{l}\text { Get behind in } \\
\text { school work }\end{array}$ & $71.7 \%$ & $\begin{array}{l}12.5 \\
\%\end{array}$ & $5.4 \%$ & $2.7 \%$ & $7.6 \%$ \\
\hline $\begin{array}{l}\text { Do something } \\
\text { you later regret }\end{array}$ & $61.8 \%$ & $\begin{array}{l}18.8 \\
\%\end{array}$ & $9.1 \%$ & $5.4 \%$ & $4.8 \%$ \\
\hline $\begin{array}{l}\text { Forget where } \\
\text { you were or } \\
\text { what you did }\end{array}$ & $63.4 \%$ & $\begin{array}{l}18.8 \\
\%\end{array}$ & $8.1 \%$ & $2.7 \%$ & $7.0 \%$ \\
\hline $\begin{array}{l}\text { Argue with } \\
\text { friends }\end{array}$ & $89.8 \%$ & $4.8 \%$ & $3.2 \%$ & $0.5 \%$ & $1.6 \%$ \\
\hline $\begin{array}{l}\text { Engage in } \\
\text { unplanned } \\
\text { sexual activity }\end{array}$ & $73.1 \%$ & $\begin{array}{l}17.7 \\
\%\end{array}$ & $5.4 \%$ & $2.7 \%$ & $1.1 \%$ \\
\hline $\begin{array}{l}\text { Not use } \\
\text { protection when } \\
\text { you had sex }\end{array}$ & $79.0 \%$ & $\begin{array}{l}11.3 \\
\%\end{array}$ & $7.0 \%$ & $0.5 \%$ & $2.2 \%$ \\
\hline $\begin{array}{l}\text { Damage } \\
\text { property }\end{array}$ & $93.0 \%$ & $3.2 \%$ & $2.2 \%$ & $0.5 \%$ & $1.1 \%$ \\
\hline $\begin{array}{l}\text { Get into trouble } \\
\text { with the local or } \\
\text { campus police }\end{array}$ & $97.8 \%$ & $2.2 \%$ & $0 \%$ & $0 \%$ & $0 \%$ \\
\hline $\begin{array}{l}\text { Get hurt or } \\
\text { injured }\end{array}$ & $85.5 \%$ & $9.6 \%$ & $2.7 \%$ & $0.5 \%$ & $1.6 \%$ \\
\hline $\begin{array}{l}\text { Require medical } \\
\text { treatment for an } \\
\text { alcohol } \\
\text { overdose }\end{array}$ & $100 \%$ & $0 \%$ & $0 \%$ & $0 \%$ & $0 \%$ \\
\hline
\end{tabular}




\section{Chapter 6}

\section{Discussion}

The purpose of this study was to examine the effects of a set of selected variables on individual alcohol drinking in college students, conceptualized through the biopsychosocial model of health behaviors (Engel, 1977). This chapter presents a discussion of the findings, implications for future research and practice, and limitations to the current study.

\section{Overview of Sample}

The majority of this sample was composed of women (76\%) and upperclassmen (78.2\%). Half the students were of legal drinking age and most students lived in campus-affiliated or near-campus residences (84.9\%) and resided with other students $(74.3 \%)$. About $20 \%$ of the students in the sample $(23 \%$ of the women and $11 \%$ of the men) indicated membership in a Greek organization. Greek membership was significantly and positively correlated with heavy drinking $(\mathrm{r}=0.21$, small effect) and the number of times one got drunk in the previous 30 days $(r=0.33$, medium effect). These findings corroborate previous research, which has shown that Greek membership is associated with increased alcohol consumption among college students (Baer, 2002; Larimer \& Cronce, 2002; O’Malley \& Johnston, 2002). In addition, results of this study showed that drinking is common among college students: about $60 \%$ of the sample reported consuming alcohol on a weekly basis (ranging from once to four times a week). In contrast, only $7 \%$ reported never drinking alcohol. In general, students consumed about four drinks in social situations with some participants reporting that they drank up to 15 drinks. 
An independent-samples t-test showed that there were no statistical

differences in the prevalence rates of heavy drinking between students who were younger than 21 years and thus under the legal age limit for drinking and students who were 21 and older. Similarly, there were no group mean differences in alcohol consumption as measured by personal drinking index between underage students and those who were of legal drinking age. These results suggest that alcohol consumption is similar between underage students and students who are 21 and older.

\section{Findings about College Drinking Behaviors}

\section{Alcohol consumption.}

Amount of alcohol consumed was measured by a quantity-frequency index composed of multiplying an assigned weight to students' reported frequency of drinking with their usual number of alcohol drinks consumed in social situations. Men reported significantly higher average drinking index than women $(r=0.15$, small effect), confirming previous findings that college men tend to drink more one average than college women (O’Malley \& Johnston, 2002; Wechsler \& Nelson, 2008). Some have argued that this difference between men and women may be due in part to differences in body size and inherent metabolical differences in the processing of alcohol between men and women which might lead to women feeling the effects of alcohol with fewer drinks than men (Nolen-Hoeksema \& Hilt, 2006). It is important to note that the quantity-frequency index is not a direct measure of the actual amount of alcohol consumed by students in a given time period because it is composed of a weighted item (frequency of drinking in different time periods) and a self-reported average number of drinks for an unspecified period of time. This measure requires 
participants to approximate both their frequency and quantity of alcohol consumption, introducing error in the final estimate (Sobell \& Sobell, 2002).

\section{Heavy drinking.}

Heavy drinking is another important way that alcohol use is commonly assessed. Heavy drinking rates were estimated using a question from the CAS measure and the gender of the participant. The current study found that $56.3 \%$ of the sample could be categorized as heavy drinkers based on Wechsler's definition of heavy drinking, which requires men to drink five or more drinks on a single occasion and women to drink four or more drinks for them to be classified as heavy drinking (Wechsler \& Nelson, 2008). The percentage of heavy drinkers in the current sample appeared larger than what has been previously reported in the literature but we could not test to see if this difference was statistically significant. Past large-scale epidemiological studies have estimated heavy drinking rates to be between $38 \%$ and $44 \%$ in the years 1980 - 1999 (O’Malley \& Johnston, 2002). In addition, the most recent College Alcohol Survey from 2001 found the prevalence rate of heavy drinking among college students to be $44.4 \%$ (Wechsler \& Nelson, 2008).

These studies also found some gender differences in the percentage of heavy drinkers: The College Alcohol Study from 2001 estimated the prevalence rate of heavy drinking for men to be $48.6 \%$ and $40.9 \%$ for women (Wechsler \& Nelson, 2008). In the current sample, $51.1 \%$ of male participants could be classified as heavy drinkers and $57.7 \%$ of female participants. An independent-samples t-test showed that these differences were not statistically significant in the current sample $\left(t_{180}=-0.77, p\right.$ $=0.45)$. However, these estimates are higher for both men and women than 
previously reported findings from other large-scale surveys (O'Malley \& Johnston, 2002). It could be argued that trends in heavy drinking have changed in the past 10-12 years since the most recent findings of these nation-wide surveys came out and that there is an indeed an increase in the prevalence of heavy drinking, as suggested by Hingson, Zha, and Wietzman (2009) However, the observed estimates could also be due to sample-specific characteristics of our study. An analysis of college binge drinking from another large-scale survey (The College Student Health Survey) from 2010 showed lower estimates of binge drinking for both men (45.2\%) and women (31.7\%) than what we found (Velazquez, Pasch, Laska, et al, 2011). One important difference between their study and our study was in the measure of binge or heavy drinking - we used different cut-off points for men and women (5 vs. 4 drinks) whereas they used a single cut-off point of 5 drinks consumed in a setting during the past two weeks, which may have resulted in the lower estimate of binge drinking among college women.

The differences in measuring heavy drinking have been underscored elsewhere in the literature (O’Malley \& Johnston, 2002), making it difficult to compare estimates from studies that used different measures. Other criticisms have suggested that Wechsler's definition of heavy drinking may be too lenient, resulting in an overestimate of this behavior (Wechsler \& Nelson, 2008). Another major disadvantage to date regarding research on college drinking is that is has been largely based on epidemiological studies that survey a variety of colleges and universities across the country including ones where drinking might be less common. While this approach is invaluable in assessing college student drinking from a nation-wide 
perspective, it is limited in understanding differences that may exist in college drinking behaviors due to university- or sample-specific characteristics because samples from different colleges are usually grouped in aggregate and only average estimates are reported (O’Malley \& Johnston, 2002).

It is important to point out that the current estimates of student drinking were based on a self-report measure, as were most previous findings in the literature. Even though a definition of a "standard drink" was provided in the beginning of the measure, participants may have misestimated what counts as a "drink" in terms of the size of the drink or they may not pay attention to the precise quantity of alcohol they consume. Finally, combined drinks are hard to measure by a standard size, so our measure of a standard drink was at best an approximation of how much students thought they drank.

\section{Alcohol-related consequences.}

It has been argued that most research on college drinking has focused on drinking rates but has overlooked other indicators of drinking, such as alcohol-related consequences (Larimer \& Cronce, 2002). Following their recommendation to assess drinking in terms of both quantity and experienced consequences, we assessed drinking-related consequences with a question from the College Alcohol Study about the frequency of occurrence of 12 alcohol-related consequences in order to better describe the alcohol-related behaviors of this sample. Based on participants' reports, it can be seen that some alcohol-related consequences are more prevalent than others. For example, most students have experienced a hangover (68.8\%) and of those 30.6\% have experienced a hangover 4 or more times. In terms of more serious consequences, 
a large minority had experienced a blackout at least once (34\%) or had engaged in unplanned sexual activity (27\%) or not used protection when having sex (21\%). Compared to the prevalence rates of the same alcohol-related consequences reported by a nationally representative sample in College Alcohol Survey from 2001 (Wechsler et al, 2003), our sample reported higher rates of engaging in unplanned sexual activity (27\% vs. $21.6 \%)$ and not using protection when having sex (21\% vs. $10.4 \%$ ), and higher rates of blackout (34\% vs. $26.8 \%$ ). However, it needs to be kept in mind that the report of prevalence rates of these consequences from 2001 does not indicate whether they were experienced once or multiple times by students, so currently reported comparisons are based on the premise that these consequences were experienced at least once. Finally, the differences in the reported prevalence rates could not be analyzed for statistical significance.

\section{Sensation seeking and drinking.}

It was hypothesized that sensation seeking would be positively correlated with scores on the measures of alcohol consumption in this study. However, results showed that the correlation between sensation seeking and personal drinking index was not significant. Previous studies have reported small-to-medium positive correlations between sensation seeking and alcohol consumption (Hittner \& Swickert, 2006; Zuckerman, 2000) although these studies varied in who was sampled and how alcohol consumption and sensation seeking were measured. In a study on the relationship between impulsive sensation seeking and risk behaviors that used the same measure of sensation seeking as the one used in the current research, Zuckerman (2000) found a correlation of 0.25 for alcohol consumption and sensation 
seeking among college men and 0.43 among college women. Similarly, Hittner and Swickert (2006) found a mean correlation between sensation seeking (measured overall) and alcohol consumption in a meta-analysis of 61 studies. The effect sizes varied if scores from the sensation seeking subscales of disinhibition, experience seeking, boredom susceptibility, and thrill and adventure seeking were used instead of an overall score and disinhibition was found to have the strongest correlation with alcohol use (Hittner \& Swickert, 2006).

Sensation seeking was hypothesized to influence drinking behaviors through both biological and psychosocial pathways, both of which have been related to alcohol use in previous research (Zuckerman, 2000). For example, research has shown that students may self-select into social environments that promote alcohol consumption through their sensation-seeking tendencies, thus linking sensation seeking, alcohol consumption and peer influence (Read et al, 2003). These authors found that sensation seeking partially mediated the relationship between students' perceptions of peer attitude about drinking and their own alcohol use (Read, Wood \& Palfai, 2003). In addition, Zuckerman (2000) found that impulsive sensation seeking accounted for $2.05 \%$ of the variance in alcohol use in a multivariate model with five personality traits and gender as predictors of several risk-taking behaviors, providing evidence for the effects of sensation seeking in both bivariate and multivariate relationships.

In the present study, sensation seeking was not only unrelated to personal drinking index but further analyses showed that it was not related to heavy drinking or to the number of occasions of getting drunk in the past 30 days. These non- 
significant findings were unexpected given prior evidence that sensation seeking is related to heavy drinking and heavy drinkers with higher scores on sensation seeking tend to experience more alcohol-related negative-consequences than heavy drinkers with low sensation seeking scores (Johnston \& Cropsey, 2000). Finally, it has been shown that women score lower on measures of sensation seeking than men (Zuckerman, 1994) but findings from the current study did not support this difference. Although mean drinking scores of men were slightly higher than those of women, this difference was not significant.

Several reasons may be implicated in the non-significant findings between sensation seeking and alcohol use (including heavy drinking) and they will be discussed next. Firstly, cited studies that examined the relationship between sensation seeking and alcohol consumption among college students used various measures of sensation seeking and different college samples. The large majority of studies included in the meta-analysis by Hittner and Swickert (2006) used the Sensation Seeking Scale V (Zuckerman, 1994), which is a 40-item measure with four subscales assessing different aspects of the construct (thrill and adventure seeking, experience seeking, disinhibition, and boredom susceptibility). The overall score of sensation seeking correlated with alcohol consumption at a small effect size $(r=0.26)$ but there was variability in the strength of the correlations between scores from the different subscales of the measure and alcohol consumption. The correlation between disinhibition and drinking had the highest effect size $(r=0.37)$ of all subscales, whereas the measure used to assess sensation seeking in the current study did not include disinhibition separately from other aspects of the construct. 
In addition, the scale used in the current research was specifically designed for the supratrait impulsive sensation seeking, composed of both sensation seeking and impulsivity, whereas the Sensation Seeking Scale V (Zuckerman, 1994) measured different aspects of a single trait. The difference in the targeted construct may have further contributed to the difference between results in the current study and previous findings. The impulsive sensation seeking scale from the ZKPQ-50 (Zuckerman \& Kuhlman, 1993) was chosen because of its brevity and lack of direct references to alcohol consumption to avoid item contamination. One reason why the expected significant relationship between sensation seeking and drinking may not have been found in the current study is that findings of some previous studies may have been due in part to some sensation seeking measures that included alcohol specific items.

In a study on sensation seeking and risk behaviors, Zuckerman (2000) used the same subscale to measure impulsive sensation seeking as in the current study and he found a positive correlation representing a small-to-medium effect $(r=0.25)$ between sensation seeking and alcohol consumption for college men and a moderateeffect correlation $(r=0.43)$ for the same relationship among college women. However, the overall model showed that impulsive sensation seeking contributed only $2.05 \%$ of the variance in a multivariate regression model that contained six areas of risk taking as predictors and five personality traits. Thus, it may be that impulsive sensation seeking does not contribute much variance to individual alcohol consumption, requiring higher power to detect its small effect.

In our initial power analysis, we specified a moderate effect for each independent variable. However, the effects sizes reported in the literature for the 
relationship between sensation seeking and alcohol use vary from small to moderate (Hittner \& Swickert, 2006; Zuckerman, 2000), depending on the measure and aspect of sensation seeking used. Thus, we may have overestimated the true effect we expected to find and we may have needed more participants to detect a small rather than a moderate effect, given one existed in the population. Thus, with respect to the relationship between sensation seeking and alcohol consumption, we may have simply lacked power.

\section{Perceived peer norms.}

The current research found moderate positive relationships between perceived peer norms and each of the following variables: personal drinking index, heavy drinking, and number of occasions of getting drunk in the past 30 days. In the current sample, perceived peer norms were also positively related $(r=0.18$, small effect) to Greek membership. The findings were congruent with our hypothesis that perceived peer influence would be related to alcohol consumption, as previously shown in the literature (Perkins, 2002). In a study on college student drinking, students' perceptions of their peers' drinking were found to have an independent effect of a moderate size $($ beta $=0.33$ ) on personal alcohol consumption (Martin \& Hoffman, 1993). Similarly, Neighbors et al (2007) found that perceived peer drinking had the largest independent effect on alcohol consumption among a set of variables that included alcohol expectancies, drinking motives, Greek membership, evaluations of alcohol effects and consequences and perceived drinking norms of several referent groups. The moderate relationship between perceived peer norms and alcohol consumption in this sample suggests that peer norms may be a continued influence on 
individual behaviors beyond adolescence, especially in a college environment where most students reside with other students on or near the campus, making peer interactions a significant factor in everyday students' lives.

Through the biopsychosocial framework, the effect of perceived peer norms on alcohol use may be conceptualized as having both a social and a cognitive component. Although peer drinking behaviors affect the individual student alcohol use through social influence, it is ultimately the individual's perceptions of peer alcohol use that is used as a measure of this social influence, leading others to conceptualize this variable as a cognitive rather than a social factor (Baer, 2002). In the current study, we contend that it is likely that both a social and a cognitive pathway of influence may operate to affect student alcohol use. The methods of this study did not allow us to separate the effects of the hypothesized social and cognitive components of perceived peer norms but the guiding framework allowed us to conceptually integrate the multifaceted influence of perceived peer norms on alcohol use.

\section{Alcohol expectancies.}

As hypothesized, general positive alcohol expectancies were positively correlated with personal drinking index $(r=0.59$, large effect $)$, heavy drinking $(r=$ 0.43 , medium effect) and the number of occasions on which students reported getting drunk $(r=0.42$, moderate effect). Sexual and romantic alcohol expectancies were also moderately and positively correlated with personal drinking index $(r=0.42$, medium effect) and positively correlated with heavy drinking $(r=0.26$, small effect) and number of occasions on which students got drunk $(r=0.28$, small effect). In addition, 
sexual and romantic expectancies were negatively correlated with gender, such that women were less likely to agree with statements about sexual and romantic expectancies than men.

These findings relate to previous research that shows that higher scores on alcohol expectancy measures are associated with increased alcohol consumption and predict alcohol use (Carey, 1995; Jones, Corbin \& Fromme, 2001). Multivariate models also show that alcohol expectancies predict individual alcohol use when tested with drinking motives, perceived social norms, demographics and evaluations of drinking events and consequences (Neighbors, 2007). Wood, Nagoshi and Dennis (1992) found that alcohol expectancies had an independent effect on alcohol consumption besides the effects of perceived norms, impulsivity and reasons for drinking and not drinking. In addition, many have contended that alcohol expectancies may influence individual drinking through indirect mediational pathways, by linking alcohol use with other variables, such as peer influence (Scheier \& Botvin, 1997). Scheier and Botvin (1997) found partial mediation effects of alcohol expectancies for the relationship between perceived peer norms and alcohol use in a sample of adolescents. This effect is consistent with a social learning perspective on alcohol expectancies, which posits that alcohol expectancies are developed and maintained through both direct and observational experience with drinking (Jones, Corbin \& Fromme, 2001).

In the current study, an exploratory mediation analysis was conducted to understand the indirect effects of alcohol expectancies on the relationship between perceived peer norms and alcohol consumption. In line with previous findings, the 
mediation analysis showed that general positive alcohol expectancies partially mediated the relationship between peer norms and individual alcohol consumption. This analysis was based on the assumption that perceived peer norms caused alcohol expectancy beliefs, which in turn had an effect on personal drinking (Baron \& Kenny, 1986). Previous research has supported the hypothesis that alcohol expectancies mediate the effect of perceived alcohol use by friends in both cross-sectional and longitudinal designs (Scheier \& Botvin, 1997). As previously described, beliefs about the effects of alcohol are not independent of the socio-cultural environment and social influences (Leigh, 1989). In addition, such beliefs are likely modeled through experience with alcohol (Hull \& Bond, 1986), which in turn is affected by peer influence, as seen in the current and previous studies.

Finally, there are mixed findings about gender differences in domain-specific alcohol expectancies, such as sexual and romantic expectancies. Rauch and Bryant (2000) found no differences in scores between men and women on the Sexual Expectancy subscale of the AEQ (Brown, Christiansen, \& Goldman, 1987) after controlling for alcohol quantity and when subjects were not primed with any context regarding alcohol drinking. However, when they primed subjects with either a blinddate context or a long-term relationship context, women scored higher on the sexual expectancy scale in the context of the long-term relationship than in the context of a blind date but there were no significant differences for gender across context after controlling for drinking quantity. Other previous research has also produced mixed findings about gender differences in the effects of alcohol expectancies (Abrams \& 
Wilson, 1979; Hull \& Bond, 1986; Martin \& Hoffman, 1992; Wilson \& Abrams, 1977), so this area remains in need of more investigation.

\section{Predictors of College Student Drinking from a Biopsychosocial Perspective}

Each of the four independent variables was conceptualized to exert an effect on individual alcohol consumption, as specified by the biopsychosocial framework. The premise of the biopsychosocial model is that health outcomes are affected by biological, psychological, and social influences (Engel, 1977). In the current study, peer norms and alcohol expectancies were conceptualized to have both social and cognitive influences on the outcome variable, whereas gender and sensation seeking had biological and psychosocial contributions. This conceptualization could not be tested empirically with the methods used in the current study but aided in integrating the diverse body of literature for each predictor variable and helped in the understanding of the multiple pathways of influence on individual alcohol use in college students. Moreover, examining college drinking using this multi-perspective model allows for increased ecological validity of the study of college alcohol consumption, which occurs in a complex environment where many factors may influence the outcome.

The results from the multiple regression analysis showed that both peer norms and general positive alcohol expectancies had significant independent medium effects on personal alcohol use, controlling for gender and sensation seeking, and gender had a small independent effect, controlling for the remaining variables. However, the independent effect of sensation seeking in the model was not significant and as previously stated, sensation seeking was not significantly related to personal drinking 
index. The mediation analysis showed that alcohol expectancies had a partial indirect effect on the relationships between perceived peer norms and alcohol use, corroborating previous findings (Scheier \& Botvin, 1997).

\section{Limitations of the Study}

\section{Sampling, recruitment, and design.}

This study had several limitations that affected the generalizability and interpretation of the findings. First, a convenience was used rather than a random sample of the targeted population. The recruiting method had the potential for a selfselection bias among participants with regard to which students are asked to participate and which choose to participate of those offered the opportunity in this research about college drinking. A disadvantage of this type of sampling was that it did not allow us to calculate a response rate based on all of those who were offered the chance to participate and test for differences between responders and nonresponders. In addition, the study was primarily advertised in intermediate and advanced-level counseling and psychology courses, so a self-selection bias with regard to who had chosen to sign up for these courses was likely already present. Our recruitment strategy may have resulted in the large percentage (79\%) of upperclassmen and women (76\%) in the sample. Our recruiting methods may have lead to sampling of more advanced students as most of the instructors that were contacted taught upperclassmen courses. Thus, the limitations in our sampling method may have lead to the observed differences in alcohol rates between the current study and previous research. 
The correlational field design employed in the current study posed several limitations, as well, because correlational analyses are useful in elucidating the strength of the relationship between two variables but they do not establish cause and effect. Furthermore, being cross-sectional, this study was limited to gathering data at one point in time. This type of design does not allow for the investigation of relationships over time and is inherently limited by the time period during which data were collected - in this case at the end of the semester when many students needed last-minute course credit, which in itself may have affected responding in ways unknown to or outside the control of the researchers.

\section{Use of self-report measures.}

The self-report nature of the measures used is yet another limitation although it is difficult to assess drinking behavior without use of self-report and the vast majority of these types of studies do rely on self-report. In general, self-report measures have been found to be reliable in reporting private behaviors but they are susceptible to error (Bolger, Davis, \& Rafaeli, 2002). The most frequently incurred problems have to do with failure to report events accurately because of retrospection bias, forgetting, inability to recall specific instances of the studied behavior and other memory difficulties. Self-report measures are also susceptible to social desirability bias, whereby participants present themselves and their behaviors more favorably than they are in reality for the purposes of gaining social acceptance. Finally, selfreport measures are based on the assumption that participants are capable of accurate introspection, which may not always be the case (Bolger, Davis \& Rafaeli, 2002). 
Another issue related to the survey design of this study is that the order of presentation of the measures was not randomized. This introduces the possibility that the order in which measures are presented affects participant responding, either by priming or fatigue. The fact that the survey was under 30 minutes minimizes the effect of fatigue on responding but it is unknown whether responses to later questions may have been affected by the material presented in earlier sections of the survey by means of priming.

\section{Problems with the Alcohol Expectancy Questionnaire.}

Although the internal reliability consistency estimates were high for the original AEQ subscales and the questionnaire as a whole, the subscales were highly intercorrelated and a principal components analysis showed that items did not load as expected for the current sample. Two new factors were identified from the total pool of items but only the general positive expectancies factor was included in the final analysis.

One factor that may have affected initial item loading in the current sample may be our choice to change the form of the response scale from agree/disagree to a 7-point Likert type of scale that not only contains gradations of agree/disagree but also contains a "neutral" option. The reason for this change was two-fold: first, to increase variance in responses, which was also used in Martin and Hoffman (1990). Secondly, we believed that a forced-choice questionnaire would not adequately capture the responses of those who did not drink or had no experience with drinking or did not hold particular expectations about the effects of alcohol. Although we believed that this type of answer scale would serve our population better, it may have 
also contributed to the discrepancies in item loadings that we observed with the original subscales. However, when the answer scale was collapsed into the original; dichotomous true/false format with all "neutral" items transformed into "false" responses, items still did not load into the expected factor structure. Thus, it appears that item loadings need to be examined on a sample-by-sample basis and discrepancies from the original scale described and dealt with on a case-by-case basis. Still another problem with the Alcohol Expectancy Questionnaire may have been its length. Although we used a shorter version of the questionnaire, it appears that 68 items still lead to participant attrition as shown by several participants who dropped out before completing the entire measure. We recommend future revisions of the scale to provide even shorter versions that could be used in combination with other instruments without increasing subject attrition.

\section{Sensation seeking measure.}

The insignificant relationship between sensation seeking and drinking has already been discussed and is further discussed later in this chapter. This may be due to the measure of sensation seeking that was selected for this study or it may be that a different construct should be considered for future research.

Despite its limitations, this study also has several strengths. It is important to note that the set of selected variables have not often been examined together utilizing a model or framework such as the biopsychosocial model to examine college drinking. Thus current findings contributed to knowledge about the unique effects of the predictors in combination with one another as well as the mediation effect of alcohol expectancies on drinking. Simple correlations aided in estimating the 
magnitude of bivariate relationships and comparing findings with previous reports in the literature. In addition, this study furthered the application of the biopsychosocial model to research on college drinking outcomes and addressed gaps in the literature by testing variables at all levels of the mode. Because of its exploratory scope, the present study cannot address all possible questions regarding the selected variables in the proposed framework but it is our belief that it furthered understanding of college drinking by testing relationships between variables whose independent effects have rarely been tested together and providing an updated picture of alcohol consumption rates and related consequences in a sample from a large public mid-Atlantic university.

\section{Implications of Results and Future Research Directions}

One of the findings in the current study suggests that heavy drinking rates may be on the rise among college students. In the current sample, $57 \%$ of students could be classified as heavy drinkers. Students reported a mean number of 4.2 drinks per social occasion, which is close to the cut-off for men and definitely classifies women as heavy drinkers. Despite limitations in defining heavy drinking, possible trends of increased heavy drinking among college students despite increased efforts on the part of university administrations to curb drinking has been documented elsewhere (Wechsler \& Nelson, 2008). In an analysis of drinking rates among college students and their non-college enrolled peers, (Hingson, Zha \& Wietzman, 2009) found that the prevalence rate of heavy drinking increased from $41.7 \%$ to $44.7 \%$ between 1999 and 2005 for college students and remained significantly higher than heavy drinking rates among non-college youth of similar age. Our study found even 
higher prevalence rates of heavy drinking (57.6\%) among college students. The observed increase in heavy drinking calls for the need of more research into this phenomenon, as well as examination of the definitions and methods used to study it. Our study also found that the prevalence rate of heavy drinking was higher among women than men (57\% vs. $51 \%$ ) but this difference was not statistically significant. Yet, it is usually men who have been shown to drink more than women and larger proportions of men were classified as heavy drinkers in previous studies (O’Malley \& Johnston, 2002; Wechsler \& Nelson, 2008). The current finding may be due to an oversampling of women but it may also indicate a shifting trend in the prevalence rate of heavy drinking among men and women.

Our findings did not support the results of many previous studies that the personality trait sensation seeking is related to alcohol consumption. In the current sample, sensation seeking did not correlate significantly with any of the measures of drinking (personal drinking index, number of drinks, frequencies, heavy drinking, number of times getting drunk). Furthermore, there were no significant gender differences in sensation seeking scores, as previously found by Zuckerman (1994, 2000). It may be possible that measuring sensation seeking in different ways may have contributed to differences in reported effect sizes of this variable on alcohol consumption and gender differences in levels of this trait. It is also possible that our sample did not have the power to detect such differences. However, it is conceivable that tendencies in sensation seeking may be shifting over time and differences between men and women on this particular trait are diminishing, especially if measured by the Impulsive Sensation Seeking subscale of the Zuckerman-Kuhlman 
Personality Questionnaire (Zuckerman \& Kuhlman, 1993). A shift in the levels of sensation seeking between men and women can potentially challenge the biological aspects of the theory of sensation seeking (Zuckerman, 2000, 2010), which has linked sensation seeking to testosterone levels and heredity.

Despite the fact that heavy drinking was more prevalent in women, gender differences in alcohol consumption were still observed in the direction suggested by previous studies (O’Malley \& Johnston, 2002). Men had a significantly higher average drinking index than women, indicating that they consumed more alcohol on average. Some have argued that a larger body size and faster metabolical processing of alcohol in men may account for such differences (Lieber, 1997). It may also be that social norms may shape male drinking as more normative and socially acceptable than female. Finally, such differences may be mediated by other unknown factors but it is clear that more research is needed in elucidating gender differences in college drinking.

\section{Summary}

In summary, the current study examined correlates and predictors of college alcohol consumption utilizing the biopsychosocial framework to select variables. Hypothesized positive relationships about individual drinking and peer norms, as well as individual drinking and alcohol expectancies were confirmed but there was no evidence for a relationship between alcohol consumption and sensation seeking. In a simultaneous regression model examining drinking level, peer norms, general positive alcohol expectancies, and gender predicted unique variance but sensation seeking did not. 
The use of the biopsychosocial model provided a framework to investigate a set of variables related to college drinking. This allowed for a multi-perspective analysis of complex individual, social, and biological factors that may influence alcohol use in college students and addressed gaps in the literature on both college drinking (Baer, 2002) and the application of the biopsychosocial framework to health outcomes research (Suls \& Rothman, 2004). However, the methods of the current study did not allow for empirical testing of the proposed conceptualization of biological, psychological and social pathways of influence that each predictor may have. Although previous research supports the multifaceted nature of the predictor variables, future research may benefit by continuing to examine how their contribution to college student drinking is affected by the proposed sources of variance within the biopsychosocial model. 


\section{Appendix A}

Demographic Form.

1. How old are you? (Choose one answer)
○ 18
○ 19
○ 20
○ 21
○ 22
○ 23
○ 24
- 25 or older

2. Are you male or female?
○ Male
- Female
o Other

3. Which of these racial or ethnic groups describes you best? (Choose all that apply):

- Asian/Asian American/Pacific Islander

- Black/African American

- Caucasian

- Hispanic

- Native American

- Mixed race

○ Other (Please specify:

4. What is your current year in school? (Choose one answer)

- Freshman $\left(1^{\text {st }}\right.$ year $)$

- Sophomore $\left(2^{\text {nd }}\right.$ year $)$

- Junior $\left(3^{\text {rd }}\right.$ year $)$

- Senior $\left(4^{\text {th }}\right.$ year $)$

$\circ 5^{\text {th }}$ year or beyond (undergraduate)

5. Are you a member of a fraternity or sorority? (Choose one answer)
○ Yes
○ No

6. With whom do you currently live? (Choose one answer)

- Alone

- Roommate(s) or housemate(s) who are also college students

- Roommate(s) or housemate(s) who are not college students

○ Spouse or partner 
- Parent(s) or other relatives

7. Where do you live during the current school year while you are at college?

(Choose one answer)

- Single-sex residence hall or dormitory

○ Co-ed residence hall or dormitory

O Other university housing

○ Fraternity/sorority house

- Off-campus house or apartment

- I live with parent(s) and/or other relatives and commute to campus

8. Which of the following best describes your grade point average? (Chose one answer)
○ A
O A-
$\circ \mathrm{B}+$
○ $\mathrm{B}$
O B-
$\circ \mathrm{C}+$
$\circ \mathrm{C}$
○ C-
○ D
- No grade or don't know

9. What is your current relationship status? (Choose one answer)

- Single, not in a relationship

- Single, in a relationship

- Married/partnered

o Other:

For questions 10 - 13, a drink is equivalent to a12 $\mathrm{fl} \mathrm{oz}$ regular beer, $5 \mathrm{fl} \mathrm{oz}$ wine or $1.5 \mathrm{fl} \mathrm{oz} \mathrm{80}$-proof distilled liquor.

10. Think back over the last two weeks. Have you had...? (Choose all that apply)

○ 2-3 drinks in a row

- 4 drinks in a row

- 5 or more drinks in a row

11. The last time you had $\underline{4}$ or more drinks in a row during the past 2 weeks, how many drinks did you actually have? (Choose one answer)

○ 4 drinks

○ 5 drinks

- 6 drinks

○ 7 drinks

- 8 drinks 
○ 9 drinks

○ 10-14 drinks

○ 15 or more drinks

12. How often do you think the typical student at your university usually has an alcoholic drink? Please check only one.

○ 3 or more times a day

- 2 times a day

O Once a day

- Nearly every day

- 3 or 4 times a week

- Once or twice a week

- 2 or 3 times a month

- About once a month

- Less than once a month but at least once a year

- Less than once a year

- I have never had alcohol

13. In general, what do you think is the usual number of drinks the typical student at your university consumes in social situations? DRINKS.

14. In general, how often do you drink enough to get drunk? (By drunk, we mean unsteady, dizzy, or sick to your stomach.) (Choose one answer)

○ Not at all

○ Daily

○ Nearly every day

- 3 or 4 times a week

- Once or twice a week

- 2 or 3 times a month

- About once a month

- Less than once a month but at least once a year

- Less than once a year

- I have never had alcohol

15. In the past 30 days, on how many occasions did you drink enough to get drunk? (By drunk, we mean unsteady, dizzy, or sick to your stomach.) 


\begin{tabular}{|c|c|c|c|c|c|}
\hline $\begin{array}{l}\text { Since the beginning of the school } \\
\text { year, how often has your drinking } \\
\text { caused you to...? } \\
\text { (Choose one answer in each row) }\end{array}$ & $\begin{array}{c}(1) \\
\text { Not at } \\
\text { all }\end{array}$ & $\begin{array}{c}(2) \\
\text { Once }\end{array}$ & $\begin{array}{l}\text { (3) } \\
\text { Twice }\end{array}$ & $\begin{array}{c}(4) \\
3 \\
\text { Times }\end{array}$ & $\begin{array}{l}(5) \\
4 \text { or } \\
\text { More } \\
\text { Times } \\
\end{array}$ \\
\hline a. Have a hangover & (1) & (2) & (3) & (4) & (5) \\
\hline b. Miss a class & (1) & (2) & (3) & (4) & $(5)$ \\
\hline c. Get behind in school work & (1) & (2) & (3) & (4) & $(5)$ \\
\hline d. Do something you later regret & (1) & (2) & (3) & (4) & $(5)$ \\
\hline $\begin{array}{l}\text { e. Forget where you were or } \\
\text { what you did }\end{array}$ & (1) & (2) & (3) & (4) & (5) \\
\hline f. Argue with friends & (1) & (2) & (3) & (4) & (5) \\
\hline $\begin{array}{l}\text { g. Engage in unplanned sexual } \\
\text { activity }\end{array}$ & (1) & (2) & (3) & (4) & (5) \\
\hline $\begin{array}{l}\text { h. Not use protection when you } \\
\text { had sex }\end{array}$ & (1) & (2) & (3) & (4) & (5) \\
\hline i. Damage property & (1) & (2) & (3) & (4) & (5) \\
\hline $\begin{array}{l}\text { j. Get into trouble with the } \\
\text { campus or local police }\end{array}$ & (1) & (2) & (3) & (4) & (5) \\
\hline k. Get hurt or injured & (1) & (2) & (3) & (4) & (5) \\
\hline $\begin{array}{l}\text { 1. Require medical treatment for } \\
\text { an alcohol overdose }\end{array}$ & (1) & (2) & (3) & (4) & (5) \\
\hline
\end{tabular}

16. Do you consider your own drinking to be...? (Choose only one)

$\begin{array}{lllll}1 & 2 & 3 & 4 & 5\end{array}$

Not Slightly Moderately Highly Does not

problematic problematic problematic problematic apply/I don't at all drink 
17. Please describe the worst alcohol-related experience that ... (Select one)

- You have had during college

- A friend of yours has had during college.

(Your friend's gender: Female; Male; ___ Other)

(Limit 250 words)

18. How distressing did/do you find the experience you just described to be?

\begin{tabular}{|c|c|c|c|c|}
\hline 1 & 2 & 3 & 4 & 5 \\
\hline $\begin{array}{c}\text { Not } \\
\text { distressing } \\
\text { at all }\end{array}$ & $\begin{array}{c}\text { Slightly } \\
\text { distressing }\end{array}$ & $\begin{array}{c}\text { Moderately } \\
\text { distressing }\end{array}$ & $\begin{array}{c}\text { Highly } \\
\text { distressing }\end{array}$ & $\begin{array}{c}\text { Extremely } \\
\text { distressing }\end{array}$ \\
\hline
\end{tabular}


Appendix B.

\section{Individual Alcohol Consumption.}

Please answer the following questions as honestly as possible. And remember, your answers will remain anonymous. Please answer all questions.

A drink or an alcoholic beverage is equivalent to a12 $\mathrm{fl} \mathrm{oz}$ regular beer, $5 \mathrm{fl} \mathrm{oz}$ wine or $1.5 \mathrm{fl} \mathrm{oz} \mathrm{80}$-proof distilled liquor.

1. How often do you usually have alcoholic beverages (including beer, wine, or liquor)? Please check only one.

1. 3 or more times a day

2. 2 times a day

3. Once a day

4. Nearly every day

5.3 or 4 times a week

6. Once or twice a week

7. 2 or 3 times a month

8. About once a month

9. Less than once a month but at least once a year

10. Less than once a year

11. I have never had alcohol

2. In general, what is the usual number of drinks you consume in social situations? DRINKS. 
Appendix C:

Perceived Peer Norms

1. Please list the initials of three of your closest friends:

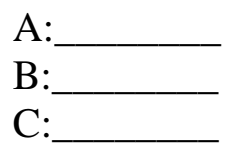

In this next section, please rate the above friends' drinking behavior to the best of your ability. Please remember to fill in all questions:

Friend A:

2. How often does usually have alcoholic beverages?

\section{PLEASE CHECK ONLY ONE.}

1. 3 or more times a day

2. 2 times a day

3. Once a day

4. Nearly every day

5.3 or 4 times a week

6. Once or twice a week

7. 2 or 3 times a month

8. About once a month

9. Less than once a month but at least once a year

10. Less than once a year

11. I have never had alcohol

In general, what is the USUAL numbers of drinks Friend A consumes in social situations?

A: DRINKS 
Friend B:

2. How often does usually have alcoholic beverages?

\section{PLEASE CHECK ONLY ONE.}

1. 3 or more times a day

2. 2 times a day

3. Once a day

4. Nearly every day

5. 3 or 4 times a week

6. Once or twice a week

7. 2 or 3 times a month

8. About once a month

9. Less than once a month but at least once a year

10. Less than once a year

11. I have never had alcohol

In general, what is the USUAL numbers of drinks Friend B consumes in social situations?

B: DRINKS

Friend C:

2. How often does usually have alcoholic beverages?

\section{PLEASE CHECK ONLY ONE.}

1. 3 or more times a day

2. 2 times a day

3. Once a day

4. Nearly every day

5. 3 or 4 times a week

6. Once or twice a week

7. 2 or 3 times a month

8. About once a month

9. Less than once a month but at least once a year

10. Less than once a year

11. I have never had alcohol

In general, what is the USUAL numbers of drinks Friend $\mathrm{C}$ consumes in social situations?

C: DRINKS 


\section{Appendix D:}

\section{Impulsive Sensation Seeking}

Answer every statement either True $(\mathrm{T})$ or False $(\mathrm{F})$ even if you are not sure of your answer.

T $\quad$ F I often do things on impulse.

T $\quad \mathrm{F} \quad$ I would like to take off on a trip with no preplanned or definite routes or timetables.

T F I enjoy getting into new situations where you can't predict how things will turn out.

T F I sometimes like to do things that are a little frightening.

T F I'll try anything once.

T $\quad \mathrm{F} \quad$ I would like the kind of life where one is on the move and traveling a lot with lots of change and excitement.

T F I sometimes do "crazy" things just for fun.

T $\quad \mathrm{F} \quad$ I prefer friends who are excitingly unpredictable.

T $\quad \mathrm{F} \quad$ I often get so carried away by new and exciting things and ideas that I never think of possible complications.

T F I like "wild" uninhibited parties. 
Appendix E.

Alcohol Expectancy Questionnaire, 68-Item Version

This scale has been removed at the request of the authors not to publish it. 


\section{Appendix F:}

\section{Recruitment script.}

Invitation to participate in a study about college drinking:

Participate in an anonymous online study titled College Student Perceptions of Alcohol Use on University Campuses and may be eligible for either course credit or the opportunity to win one of three $\$ 20$ gift certificates for Amazon.com! This study requires you to complete an online questionnaire that will take 25-30 min.

Researchers are interested in studying a variety of factors that may influence college drinking and you will be asked questions about your and others' alcohol intake, your beliefs about the effects of alcohol, your tendencies to engage in certain activities, alcohol-related consequences that you or your friends may have experienced, and other general background information.

Eligibility: You must be 18-24 years old and currently enrolled as an undergraduate student at the University of Maryland, College Park.

Link to survey: http://www.surveymonkey.com/s/JZNGW8Y

For questions contact Popovska@umd.edu. 
Appendix G: Informed Consent Form.

\begin{tabular}{|c|c|}
\hline Project Title & College Student Perceptions of Alcohol Use on University Campuses \\
\hline Purpose of the Study & $\begin{array}{l}\text { This research is being conducted by Dr. Mary Ann Hoffman and Ana } \\
\text { Popovska at the University of Maryland, College Park. We are inviting } \\
\text { you to participate in this research project because you are currently } \\
\text { enrolled as an undergraduate student at the university of Maryland and } \\
\text { you are } 18 \text { - } 24 \text { years old. The purpose of this study is to investigate the } \\
\text { influence of several factors on college student drinking among } \\
\text { traditional-aged undergraduate students from a multilevel perspective. }\end{array}$ \\
\hline Procedures & $\begin{array}{l}\text { You will be asked to complete an online survey that will take 30-45 } \\
\text { minutes. You will be asked questions about your and other students, } \\
\text { alcohol consumption and alcohol-related consequences and experiences. } \\
\text { Other questions will inquire about your sensation seeking tendencies, your } \\
\text { beliefs about the effects of alcohol, your close friends' alcohol } \\
\text { consumption, and general background information. At the end of the } \\
\text { survey, you will be redirected to a link where you can provide your name, } \\
\text { email address and course number if you are eligible for and wish to } \\
\text { receive course credit. Alternatively, you may participate in a raffle for } \\
\text { three } \$ 20 \text { gift certificates to Amazon.com. You may either receive course } \\
\text { credit at the discretion of your instructor or participate in the raffle but not } \\
\text { both. }\end{array}$ \\
\hline $\begin{array}{l}\text { Potential Risks and } \\
\text { Discomforts }\end{array}$ & $\begin{array}{l}\text { There are no known risks to participating in this study. However, you may } \\
\text { experience some psychological distress due to disclosing about and/or } \\
\text { reflecting upon your or your friends' alcohol consumption and alcohol- } \\
\text { related consequences and adverse events. If you experience any distress, } \\
\text { we urge you to consult the additional sources for help and support we have } \\
\text { provided in order to minimize any risk of participation. }\end{array}$ \\
\hline Potential Benefits & $\begin{array}{l}\text { There are no direct benefits for your participation. However, it may be } \\
\text { helpful for you to reflect on your alcohol consumption and drinking } \\
\text { experiences and that of your close friends. We hope that, in the future, } \\
\text { other people might benefit from this study through improved understanding } \\
\text { of the factors that influence college student drinking. }\end{array}$ \\
\hline Confidentiality & $\begin{array}{l}\text { Your survey responses will be anonymous. Your name, email address, and } \\
\text { course number provided for the purposes of extra credit or raffle } \\
\text { participation will be collected independently of your survey responses. } \\
\text { If we write a report or article about this research project, your identity will } \\
\text { be protected to the maximum extent possible and it will not be associated } \\
\text { with the responses you provide in the online questionnaire. } \\
\text { Open-ended responses will be coded for main themes but precautions will }\end{array}$ \\
\hline
\end{tabular}




\begin{tabular}{|c|c|}
\hline & $\begin{array}{l}\text { be taken not to disclose any identifying or potentially identifying } \\
\text { information. Pseudonyms may be used in publication or presentation of } \\
\text { this research. } \\
\text { Your information may be shared with representatives of the University of } \\
\text { Maryland, College Park or governmental authorities if you or someone } \\
\text { else is in danger or if we are required to do so by law. }\end{array}$ \\
\hline Medical Treatment & $\begin{array}{l}\text { The University of Maryland does not provide any medical, hospitalization } \\
\text { or other insurance for participants in this research study, nor will the } \\
\text { University of Maryland provide any medical treatment or compensation for } \\
\text { any injury sustained as a result of participation in this research study, } \\
\text { except as required by law. }\end{array}$ \\
\hline $\begin{array}{l}\text { Right to Withdraw and } \\
\text { Questions }\end{array}$ & $\begin{array}{l}\text { Your participation in this research is completely voluntary. You may } \\
\text { choose not to take part at all. If you decide to participate in this research, } \\
\text { you may stop participating at any time. If you decide not to participate in } \\
\text { this study or if you stop participating at any time, you will not be penalized } \\
\text { or lose any benefits to which you otherwise qualify. } \\
\text { If you decide to stop taking part in the study, if you have questions, } \\
\text { concerns, or complaints, or if you need to report an injury related to the } \\
\text { research, please contact the investigator, Dr. Mary Ann Hoffman at: } 3214 \\
\text { Benjamin Building, University of Maryland, College Park, MD 20742; } \\
\text { phone: } 301-405-2865 ; \text { hoffmanm@umd.edu or Ms. Ana Popovsa at } \\
\text { Popovska @umd.edu. }\end{array}$ \\
\hline nt Rights & $\begin{array}{l}\text { If you have questions about your rights as a research participant or wish to } \\
\text { report a research-related injury, please contact: } \\
\text { University of Maryland College Park } \\
\text { Institutional Review Board Office } \\
\text { 1204 Marie Mount } \\
\text { College Park, Maryland, } 20742 \\
\text { E-mail: } \underline{\text { irb @ umd.edu }} \\
\text { Telephone: } \mathbf{3 0 1 - 4 0 5 - 0 6 7 8} \\
\text { This research has been reviewed according to the University of Maryland, } \\
\text { College Park IRB procedures for research involving human subjects. }\end{array}$ \\
\hline Statement of Consent & $\begin{array}{l}\text { To proceed, please select ONE: } \\
\text { O By checking here, you indicate that you are at least } 18 \text { years of } \\
\text { age; you have read this consent form or have had it read to you; } \\
\text { your questions have been answered to your satisfaction and you } \\
\text { voluntarily agree to participate in this research study. You may } \\
\text { exit the study at any time. } \\
\text { - If you do NOT agree, please check here and exit the study. }\end{array}$ \\
\hline
\end{tabular}




\section{Appendix H:}

\section{Debriefing Script.}

The purpose of this study is to understand how factors such as gender, sensation seeking, peer influence, and beliefs about the effects of alcohol may affect individual student alcohol consumption. The investigators have chosen the variables of interest based on a theoretical framework known as the biopsychosocial model, which posits that factors at three different levels (the biological, psychological, and social) interact to influence health behaviors. We are also interested in learning more about specific alcohol-related experiences, such as adverse consequences or events related to alcohol use. You were asked to provide an open-ended response to a question about "worst alcohol-related experience" because little is known about the subjective experiences of alcohol-related adverse events.

In case you experienced any distress due to the questions you were asked, please consult the following websites for more information and support:

University of Maryland Counseling Center: http://www.counseling.umd.edu/ University of Maryland Health Center: http://www.health.umd.edu

Sexual Assault Response and Prevention Program:

http://www.health.umd.edu/mentalhealth/sarpp 
Appendix I.

Principal Components Analysis. Item content has been removed at the request of the scale authors.

\begin{tabular}{|c|c|c|c|c|c|c|c|c|c|c|c|}
\hline & \multicolumn{11}{|c|}{ Component } \\
\hline & 1 & 2 & 3 & 4 & 5 & 6 & 7 & 8 & 9 & 10 & 11 \\
\hline 1. & .198 & .067 & .027 & .147 & .016 & .088 & .093 & -.008 & .810 & -.040 & -.067 \\
\hline 2. & .702 & .192 & .132 & .071 & .006 & .093 & .036 & -.061 & .433 & .113 & .132 \\
\hline 3. & .848 & .181 & .086 & .079 & .098 & .162 & .179 & .071 & .080 & .004 & -.143 \\
\hline 4. & .640 & .101 & .358 & -.031 & .224 & .041 & .000 & .148 & .116 & .052 & -.104 \\
\hline 5. & .385 & -.024 & .125 & .131 & .271 & .040 & .220 & -.075 & .001 & .560 & -.058 \\
\hline 6. & .220 & .272 & .537 & .121 & .268 & .180 & .061 & .164 & -.154 & .298 & -.007 \\
\hline 7. & .717 & .218 & .124 & .095 & .165 & .059 & .180 & .244 & -.033 & .069 & -.093 \\
\hline 8. & .679 & .116 & .279 & .159 & .013 & .102 & .148 & .031 & .248 & .208 & .258 \\
\hline 9. & .290 & .115 & .637 & .086 & .151 & .162 & .059 & .116 & .108 & -.019 & -.007 \\
\hline 10. & .714 & .009 & .079 & .077 & .058 & .096 & -.094 & .013 & .392 & .296 & .148 \\
\hline 11. & .658 & .102 & .332 & .210 & .075 & .244 & .156 & -.179 & -.030 & .059 & -.050 \\
\hline 12. & .563 & .174 & .506 & .190 & .061 & .226 & .039 & -.018 & .065 & -.049 & .127 \\
\hline 13. & .604 & .103 & .284 & .216 & .298 & -.033 & .007 & .089 & -.086 & .134 & -.192 \\
\hline 14. & .530 & .113 & .395 & .313 & .112 & .046 & .158 & .175 & .045 & .216 & .202 \\
\hline 15. & .762 & .217 & .098 & .072 & .139 & -.079 & .038 & .201 & .137 & -.056 & -.192 \\
\hline 16. & .776 & .162 & .175 & .037 & .058 & .095 & .088 & .137 & .281 & .068 & .062 \\
\hline 17. & .377 & .183 & .018 & .058 & .067 & .044 & .057 & .109 & .752 & .060 & .088 \\
\hline 18. & .594 & .197 & .203 & .425 & -.039 & .089 & .123 & .093 & .160 & .085 & .038 \\
\hline 19. & .401 & .193 & .427 & .235 & .079 & -.090 & .204 & .180 & .092 & -.034 & -.171 \\
\hline 20. & .105 & .143 & .184 & .076 & .531 & .198 & .044 & .399 & .103 & .134 & -.061 \\
\hline 21. & .642 & .149 & .125 & .230 & .176 & .204 & .300 & .207 & -.033 & .058 & -.046 \\
\hline 22. & .136 & .172 & .315 & .021 & .146 & .142 & .744 & .025 & .146 & .069 & .119 \\
\hline 23. & .333 & .150 & .191 & .224 & .045 & .077 & .730 & .093 & .119 & .073 & -.007 \\
\hline 24. & .511 & .096 & .115 & .261 & .273 & .023 & .299 & .112 & -.029 & .061 & .051 \\
\hline 25. & .145 & .111 & .422 & .171 & .031 & .067 & .403 & .109 & -.081 & .264 & -.339 \\
\hline 26. & .752 & .139 & .220 & .191 & .119 & .057 & .006 & .017 & .047 & .124 & .205 \\
\hline 27. & .193 & .093 & .727 & .264 & .038 & .121 & .201 & .102 & .029 & .141 & -.004 \\
\hline 28. & .524 & .435 & .179 & .086 & .170 & .012 & .052 & .411 & -.055 & .080 & -.013 \\
\hline 29. & .082 & .256 & .316 & .581 & .171 & .041 & -.040 & .315 & .153 & .199 & -.157 \\
\hline 30. & .044 & 209 & .051 & .447 & .016 & .304 & .233 & .337 & .351 & .377 & .117 \\
\hline 31. & .183 & .273 & .312 & .167 & .246 & .198 & .113 & .656 & .004 & -.033 & .001 \\
\hline 32. & .409 & .250 & .281 & .488 & .020 & .208 & .085 & .361 & -.072 & .010 & .086 \\
\hline 33. & .240 & .221 & .234 & .373 & .087 & .171 & .135 & .561 & .163 & -.011 & .128 \\
\hline 34. & .182 & .242 & .289 & .143 & .124 & .730 & .081 & .204 & .136 & .025 & .062 \\
\hline
\end{tabular}




\begin{tabular}{|c|c|c|c|c|c|c|c|c|c|c|c|}
\hline 35. & .246 & .666 & .285 & .079 & -.027 & .267 & .146 & .193 & .001 & .131 & -.031 \\
\hline 36. & .256 & .142 & .060 & .331 & 157 & .441 & 297 & .244 & -.031 & .265 & 139 \\
\hline 37. & .501 & .108 & .158 & .350 & .120 & .365 & 287 & .131 & -.008 & -.017 & .145 \\
\hline 38. & .782 & .170 & -.016 & .212 & .193 & .135 & .191 & .175 & .079 & -.113 & -.002 \\
\hline 9. & .615 & .210 & .160 & .371 & .232 & .162 & .009 & .109 & .108 & .034 & .323 \\
\hline 40. & .179 & .391 & .601 & .215 & .115 & .103 & .003 & .063 & .042 & -.017 & .166 \\
\hline 41. & .034 & .568 & .433 & .229 & .044 & .094 & .179 & .115 & .179 & -.077 & .080 \\
\hline 42. & 192 & .258 & .496 & .584 & .179 & .134 & .037 & .232 & .101 & -.108 & .028 \\
\hline 43. & .461 & .189 & .176 & .311 & .118 & .166 & .076 & .346 & .057 & .148 & .182 \\
\hline H. & .311 & .090 & .237 & .666 & .133 & .031 & .181 & .135 & .148 & .099 & .007 \\
\hline 5. & .013 & .217 & .546 & .270 & .073 & .218 & .308 & .074 & -.015 & .077 & -.009 \\
\hline 46. & .272 & .169 & .448 & 197 & .297 & .068 & .284 & .226 & -.038 & -.117 & -.006 \\
\hline 7. & .740 & .190 & -.027 & .125 & 289 & .114 & .260 & .122 & .023 & -.128 & .051 \\
\hline 48. & .265 & .185 & .274 & .094 & .163 & .739 & .106 & .076 & .122 & .044 & .042 \\
\hline 9. & .331 & .057 & .234 & .615 & .254 & .161 & .092 & 209 & .028 & .025 & .091 \\
\hline 50. & .233 & .142 & .030 & .391 & .072 & .239 & .344 & .165 & .038 & .043 & .498 \\
\hline 51. & .274 & .804 & .142 & .062 & .087 & .070 & .070 & .115 & .119 & .008 & -.027 \\
\hline 52. & .188 & .658 & .327 & .161 & .142 & .063 & .274 & .093 & -.012 & -.024 & .088 \\
\hline 53. & .305 & .617 & .237 & .203 & .206 & .157 & .046 & .335 & -.003 & -.032 & .054 \\
\hline 54. & .141 & .519 & .376 & .166 & 249 & .374 & .181 & .183 & .035 & .086 & .026 \\
\hline 55. & .227 & .524 & .030 & .082 & .012 & .316 & .045 & .174 & .182 & .455 & .134 \\
\hline 56. & .570 & .202 & .173 & .171 & .290 & .158 & .113 & .180 & .024 & .053 & .358 \\
\hline 57. & .728 & .207 & .097 & .148 & .119 & .041 & -.041 & -.062 & .174 & .077 & .165 \\
\hline 58. & .405 & .186 & .340 & .422 & .130 & .170 & .217 & -102 & -.101 & -197 & .178 \\
\hline 59. & .381 & .731 & .029 & .239 & .146 & .027 & -.009 & -.012 & .085 & -.025 & -.041 \\
\hline 60. & .547 & .180 & .155 & .212 & -.079 & .337 & -.009 & -.067 & .051 & .213 & -.048 \\
\hline 61. & .644 & .277 & -.103 & .329 & .333 & .266 & .080 & .056 & -.069 & -.018 & -.160 \\
\hline 62. & .300 & .267 & .229 & .298 & .500 & .349 & .114 & .034 & -.007 & -.039 & -.245 \\
\hline 63. & .467 & .230 & .211 & .014 & .511 & .152 & .093 & .075 & .064 & -.092 & .203 \\
\hline 64. & .435 & .135 & .158 & .198 & .673 & .115 & .114 & .079 & -.047 & .007 & -.003 \\
\hline 65. & .232 & 149 & .114 & 199 & .736 & -.006 & .058 & .070 & .065 & .135 & .100 \\
\hline 66 & .298 & .613 & .027 & .254 & .382 & .091 & .040 & -.084 & .184 & .141 & .059 \\
\hline 67 & .196 & .347 & .344 & .651 & .221 & .011 & .117 & -.101 & .064 & .080 & .011 \\
\hline 68. & .452 & .314 & .142 & .586 & .122 & .212 & .077 & -.085 & .142 & .047 & .045 \\
\hline
\end{tabular}

Extraction Method: Principal Component Analysis.

Rotation Method: Varimax with Kaiser Normalization.

a. Rotation converged in 11 iterations. 


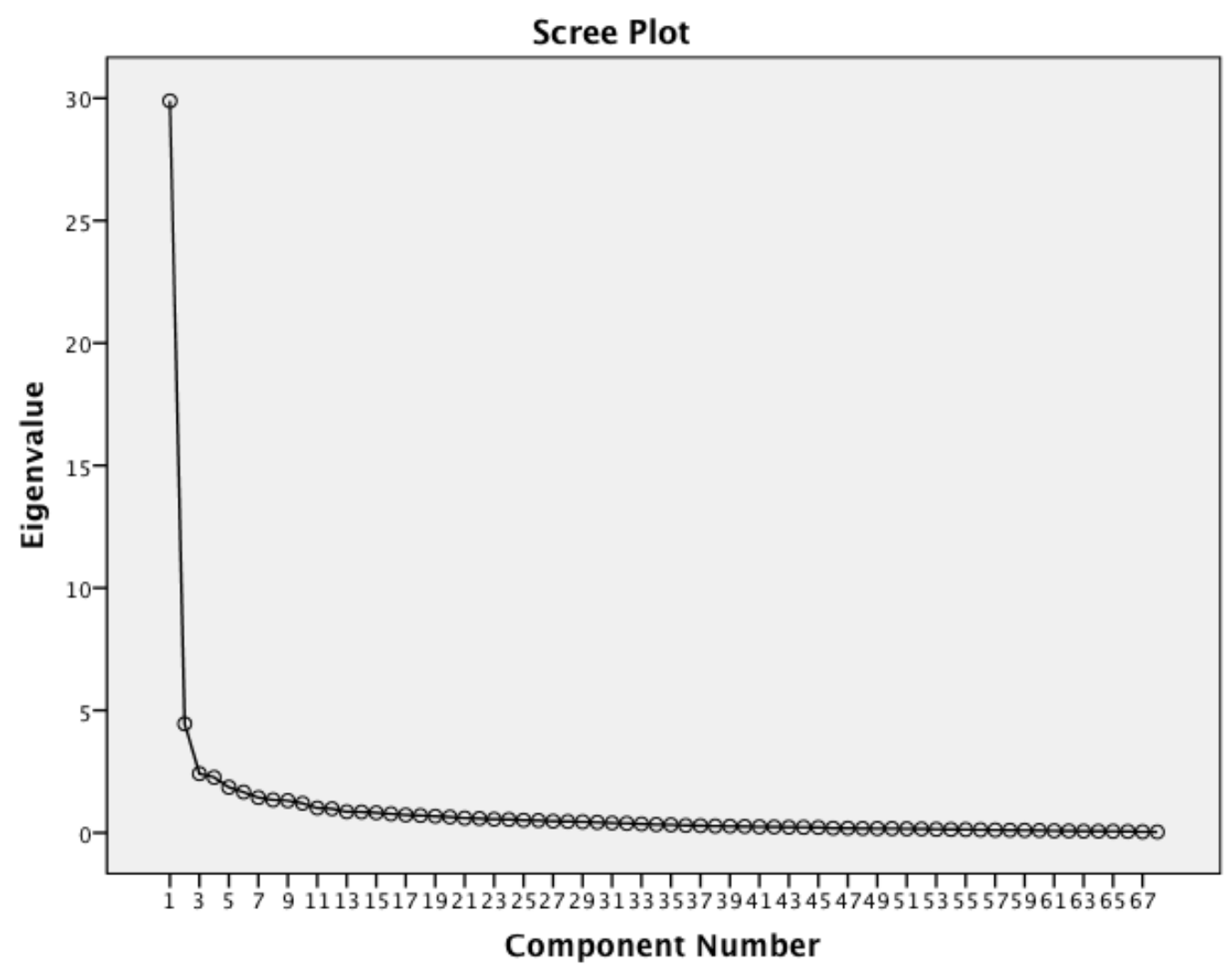


Appendix J.

Distribution of scores for key continuous variables.
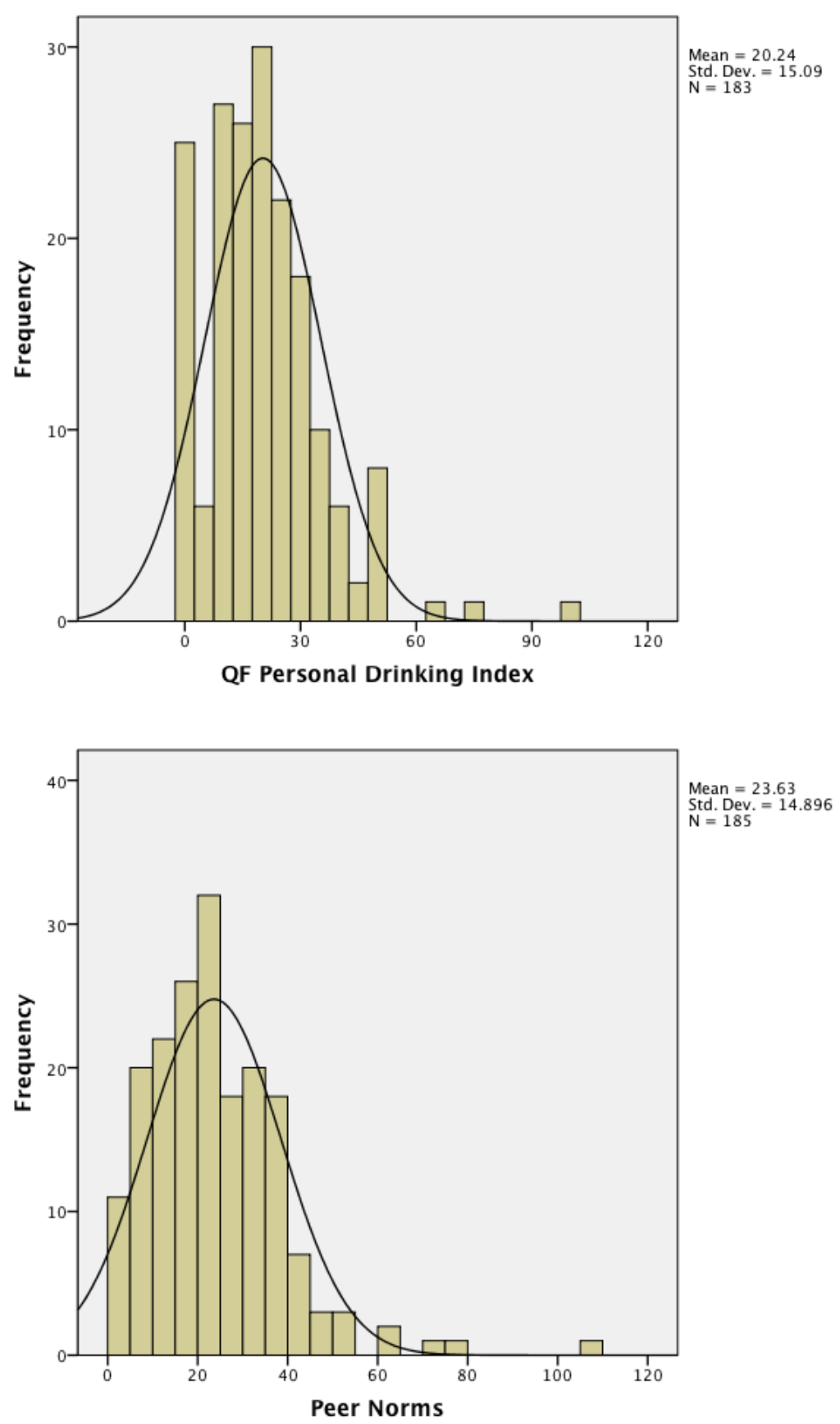

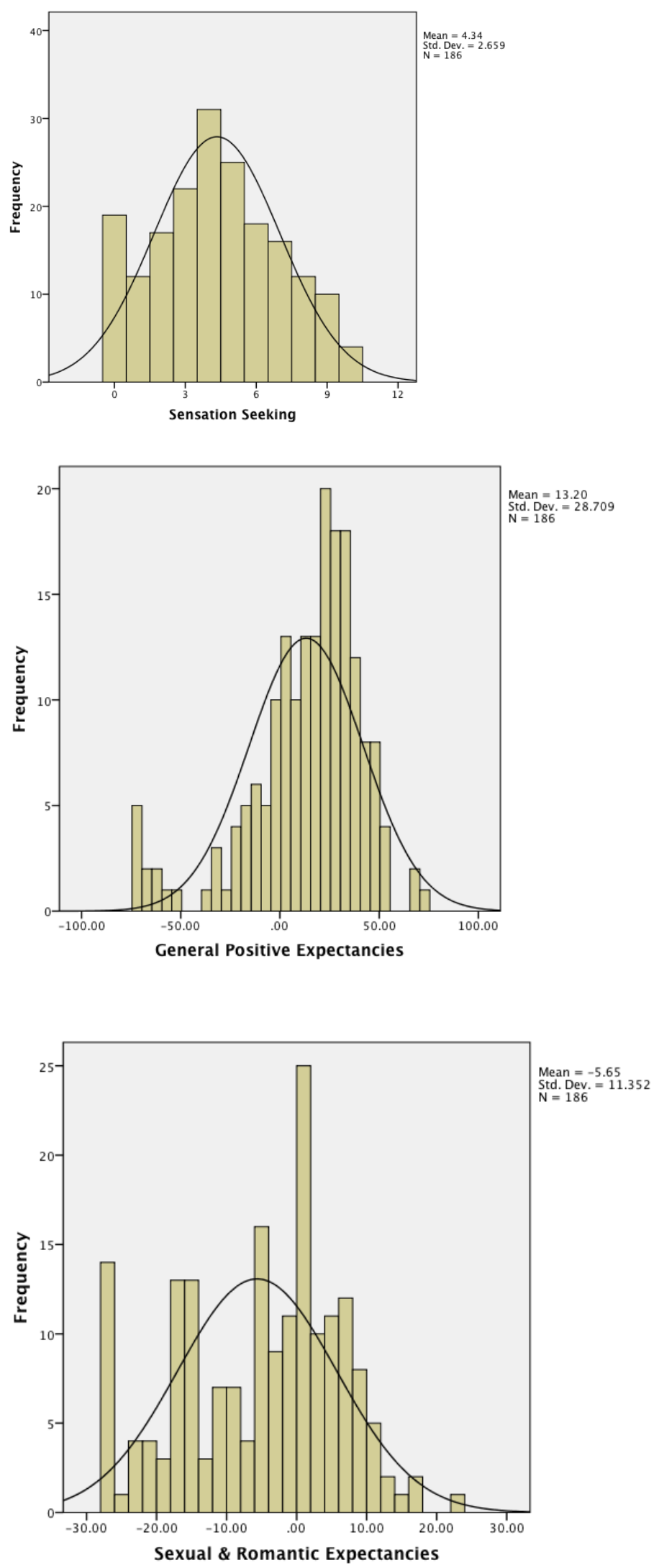


\section{Appendix K.}

\section{Regression diagnostics 1. Deviations from linearity, homoscedasticity, and indepedence.}

Plots of regression standardized residuals vs. regression predicted values for each predictor and the dependent variable.
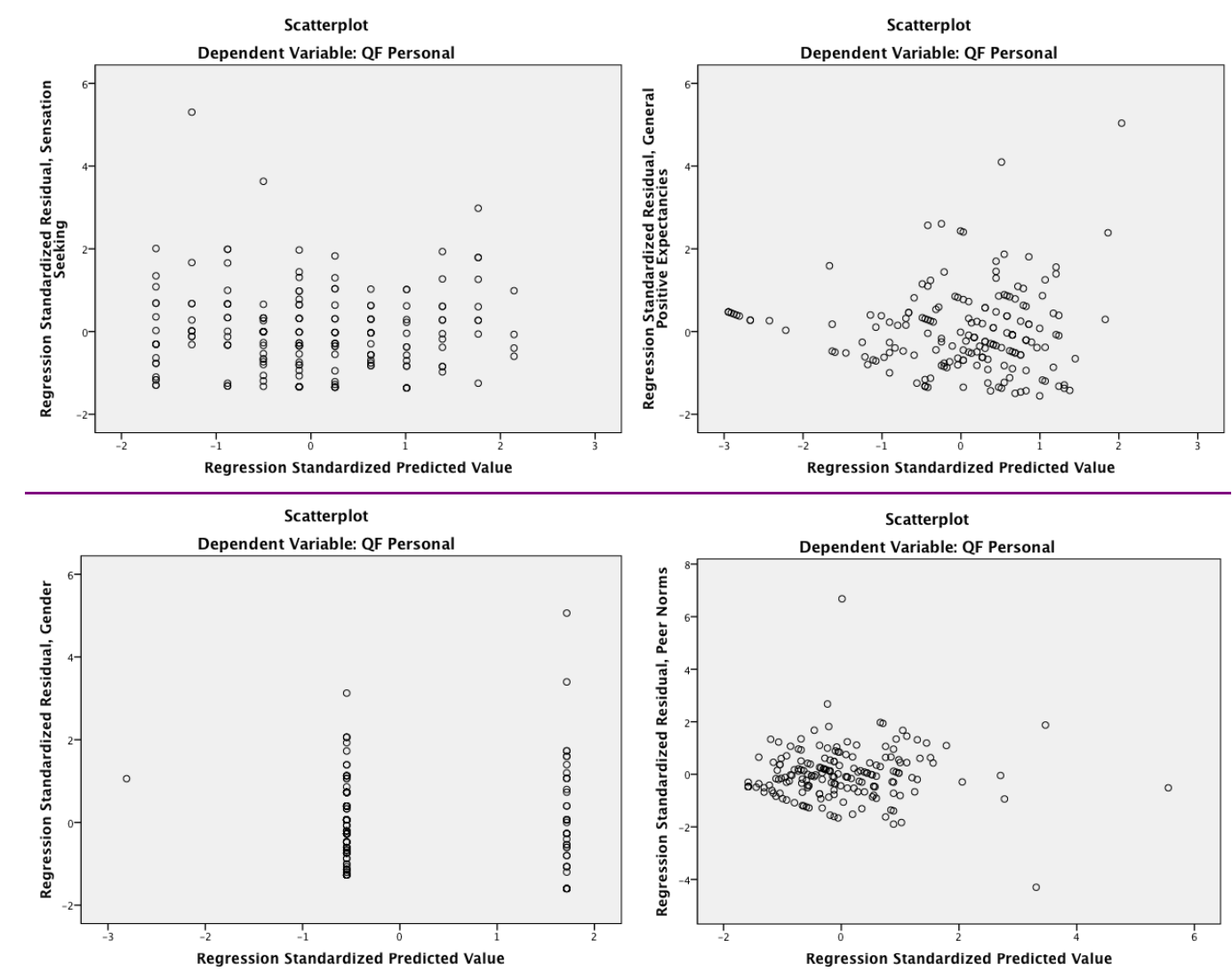

Linear combination of all four predictors: Regression standardized residuals
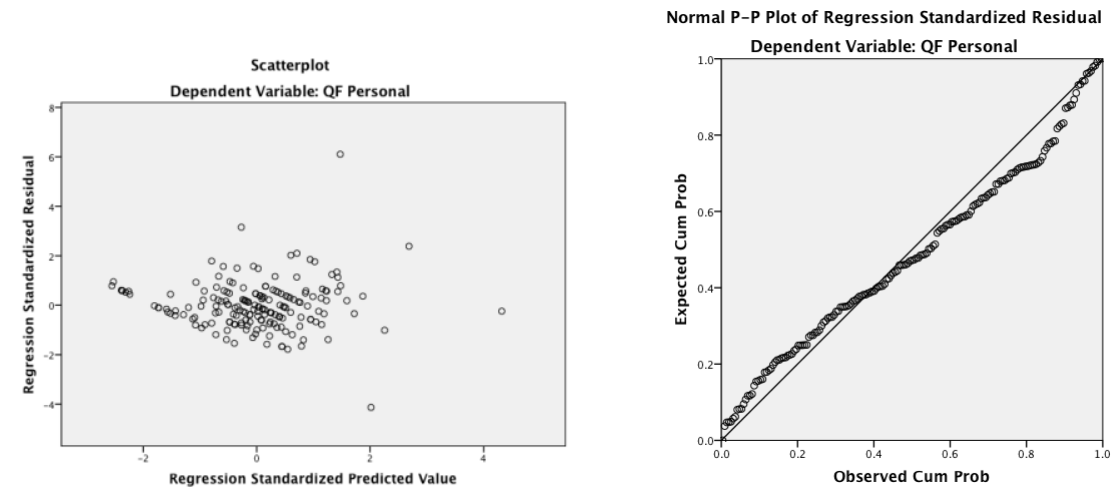


\section{Appendix L.}

\section{Regression Diagnostics 2. Deviations from normality.}

Score distributions and PP plots of regression standardized residuals for each predictor of the dependent variable.

1. General Positive Expectancies.
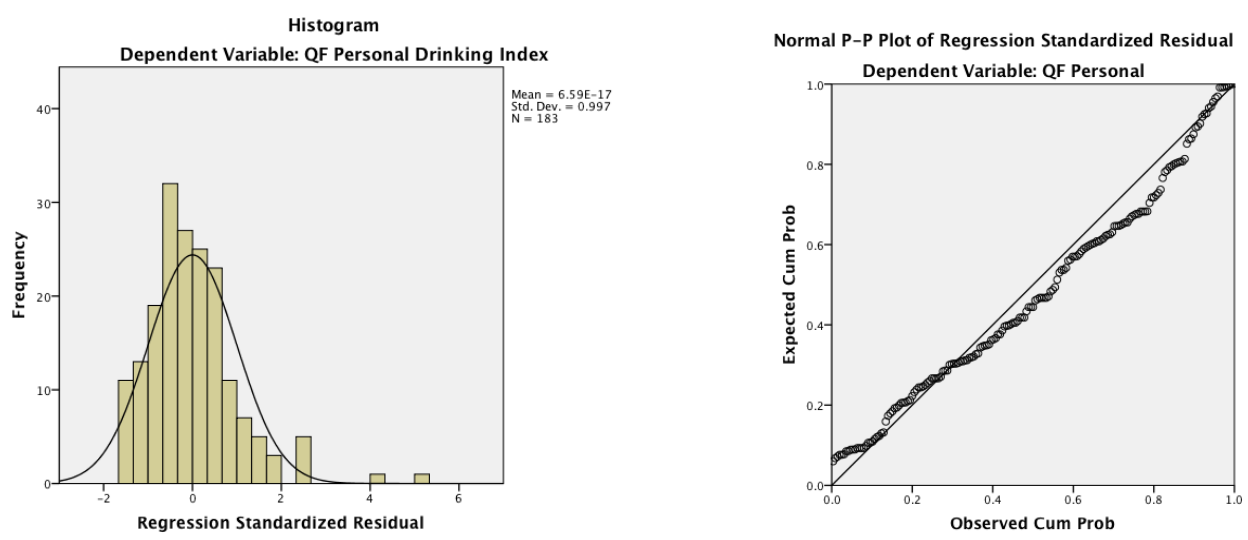

2. Sensation Seeking.
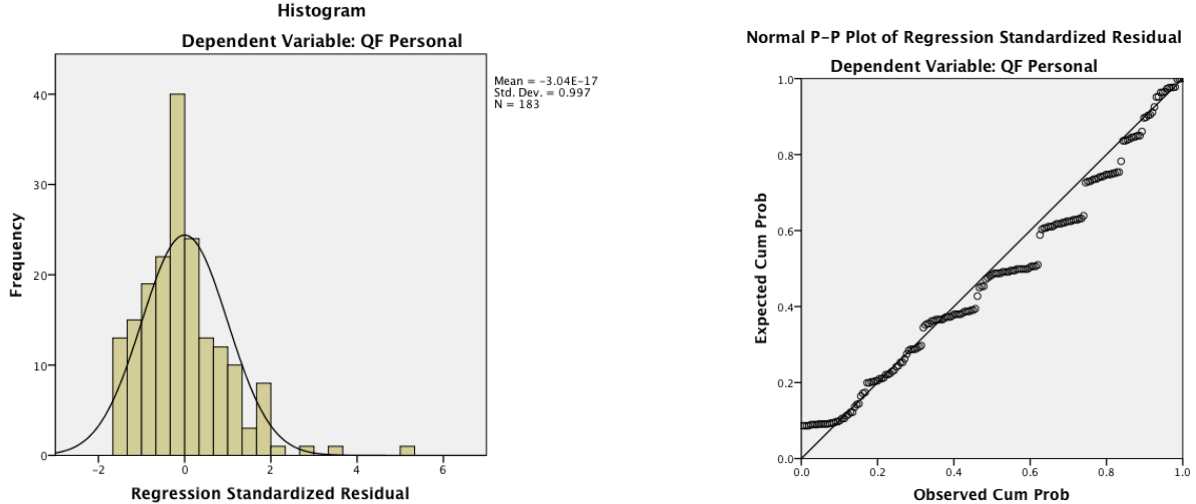


\section{Peer Norms.}

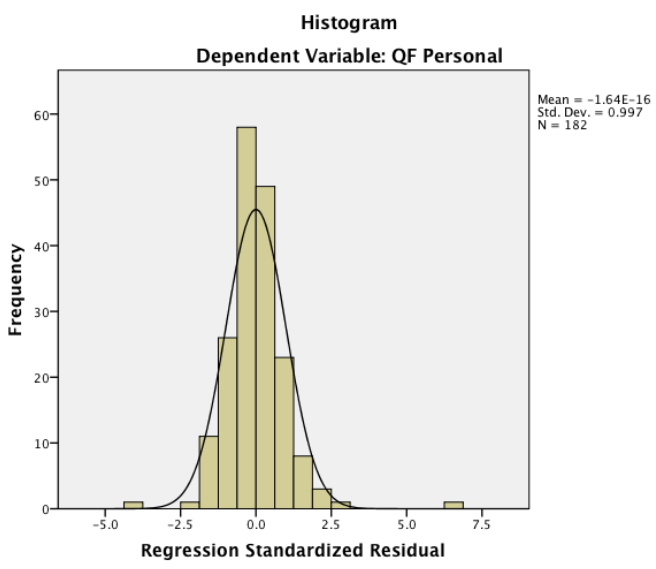

Normal P-P Plot of Regression Standardized Residual

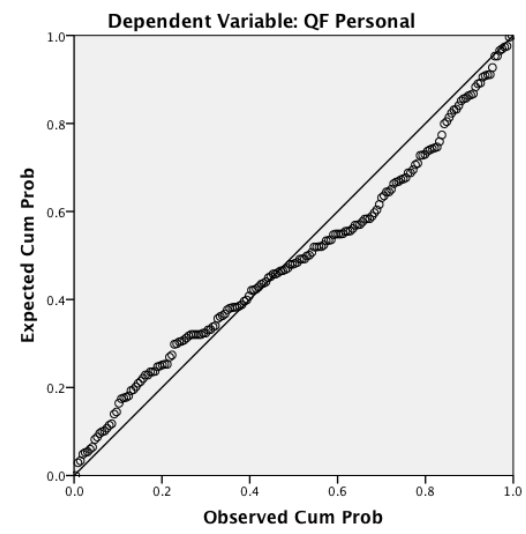

\section{Gender.}
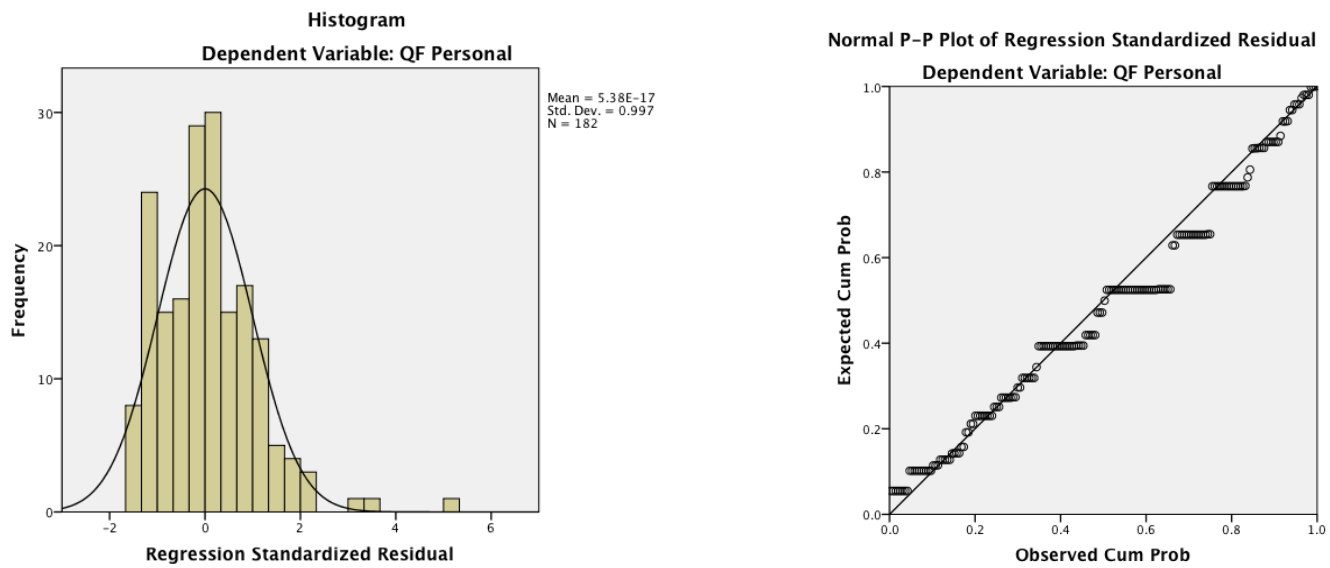


\section{Reference}

Abrams, D. B., \& Wilson, G. T. (1979). Effects of alcohol on social anxiety in women: Cognitive versus physiological processes. Journal of Abnormal Psychology, 88(2), 161-173.

Baer, J. S. (2002). Student factors: Understanding individual variation in college drinking. Journal of Studies on Alcohol, Supplement 14, Special issue: College drinking, what it is, and what do to about it: Review of the state of the science. $40-53$.

Ball, S. A., Carroll, K. M.; Rounsaville, B. J. (1994). Sensation seeking, substance abuse, and psychopathology in treatment-seeking and community cocaine abusers. Journal of Consulting and Clinical Psychology, 62(5), 1053-105.

Berry, W. D. \& Feldman, S. (1985). Multiple regression in practice. Sage University Paper Series on Quantitative Applications in the Social Sciences, 07-050. Newbury Park, CA: Sage.

Bolger, N., Davis, A., \& Rafaeli, E. (2002). Diary Methods: Capturing Life as it is lived. Annual Reviews of Psychology, 54, 579 - 616.

Bonin, M. F.; McCreary, D. R.; Sadava, Stanley W. (2000). Problem drinking behavior in two community-based samples of adults: Influence of gender, coping, loneliness, and depression. Psychology of Addictive Behaviors, 14(2), 151-161

Borsari, B. \& Carey, K.B. (2001). Peer influences on college drinking: A review of the research. Journal of Substance Abuse, 13(4), 391-424.

Brown, S.A., Christiansen, B.A., \& Goldman, M.S. (1987). The Alcohol Expectancy Questionnaire: An instrument for the assessment of adolescent and adult alcohol expectancies. Journal of Studies on Alcohol, 48(5), 483 - 491.

Brown, S. A., Goldman, M. S., Inn, A., \& Anderson, L. R. (1980). Expectations of reinforcement from alcohol: Their domain and relation to drinking patterns. Journal of Consulting and Clinical Psychology, 48, 419-426. 
Brown, S. A.; Goldman, M. S.; Christiansen, B. A.(1985). Do alcohol expectancies mediate drinking patterns of adults? Journal of Consulting and Clinical Psychology, 53(4), 512-519.

Carey, K. B. (1995). Alcohol-related expectancies predict quantity and frequency of heavy drinking among college students. Psychology of Addictive Behaviors, 9(4), 236-241.

Cohen, J., Cohen, P., West, S.G., Aiken, L.S. (2002). Multiple regression/correlation analysis for the behavioral sciences ( ${ }^{\text {rd }}$ Ed.). New Jersey: Lawrence Erlbaum Associates, Inc., Publishers.

Darkes, J., Greenbaum, P. E., \& Goldman, M. S. (1998). Sensation seekingdistribution and alcohol use: Exploring issues of criterion contamination. Psychological Assessment, 10(1), 71-76.

Darkes, J., Greenbaum, P. E., \& Goldman, M. S. (2004). Alcohol expectancy mediation of biopsychoosocial risk: Complex patterns of mediation. Experimental and Clinical Psychopharmacology, 12(1), 27-38.

Earleywine, M. \& Finn, P.R. (1991). Sensation seeking explains the relation between behavioral disinhibition and alcohol consumption. Addictive Behavior, 16, 123-128.

Engel, G. (1977). The need for a new medical model: A challenge for biomedicine. Science, $196,129-136$.

Fabrigar, L. R., Wegener, D. T., MacCallum, R. C., \& Strahan, E. J. (1999). Evaluating the use of exploratory factor analysis in psychological research. Psychological Methods, 4, 272-299.

Fillmore, K. M., Golding, J. M., Leino, E.V., Motoyoshi, M., Shoemaker, C., Terry, 
H. et al. (1997). Patterns and trends in women's and men's drinking. In R. W. Wilsnack \& S. C. Wilsnack (Eds.), Gender and alcohol: Individual and social perspectives (pp.21-48). Pscataway, NJ: Rutgers Center for Alcohol Studies.

Gonzales (1990). Effects of drinking age on reduced consumption of alcohol reported by college students: 1981-1986. Journal of Drug Issues.

Graham, K., Wilsnack, R., Dawson, D., \& Vogeltanz, N. (1998). Should alcohol consumption measures be adjusted for gender differences? Addiction, 93(8), $1137-1147$.

Hingson, R.W., Zha, W., \& Wietzman, E. R (2009). Magnitude of and trends in alcohol-related mortality and morbidity among U.S. college students ages 1824, 1998-2005. Journal of Studies on Alcohol, Supplement 16, 12-20.

Hittner, J. B. \& Swickert, R. (2006). Sensation seeking and alcohol use: A metaanalytic review. Addictive Behaviors, 31, $1383-1401$

Hull, J. G., Bond, C. F. (1986). Social and behavioral consequences of alcohol consumption and expectancy: A meta-analysis. Psychological Bulletin, 99(3), 347-360.

Katz, E.C., Fromme, K., \& D’Amico, E. J. (2000). Effects of outcome expectancies and personality on young adults' illicit drug use, heavy drinking, and risky sexual behavior. Cognitive Therapy and Research, 24(1), 1-22.

Klatsky, A. L., Armstrong, M. A., \& Friedman, G. D. (1992). Alcohol and mortality. Annals of Internal Medicine, 117, 646-654.

Kroopsman, J. R., Boomsma, D. I., Heath, A. C., van Doornen, L. J. (1995). A multivariate genetic analysis of sensation seeking. Behavior Genetics, 25(4), 349-356. 
Johnson, T. J., \& Cropsey, K. L. (2000). Sensation seeking and drinking game participation in heavy-drinking college students. Addictive Behaviors, 25(1), 109-116.

Joireman, J. \& Kuhlman, D. M. (2004). The Zuckerman-Kuhlman Personality Questionnaire: Origin, Development, and Validity of a Measure to Assess an Alternative Five-Factor Model of Personality. In Stelmack, R. M. (Ed.), On the psychobiology of personality: Essays in honor of Marvin Zuckerman (pp. 49 -64). Elsevier.

Jones, B. T., Corbin, W., \& Fromme, K. (2001). Conceptualizing addiction: A review of expectancy theory and alcohol consumption. Addiction, 96, 57-72.

Kahler, C. W., Read, J. P., Wood, M. D., \& Palfai, T. P. (2003). Social environmental selection as a mediator of gender, ethnic, and personality effects on college student drinking. Psychology of Addictive Behaviors, 17(3), 226-234.

Kahn, J. H. (2006). Factor analysis in counseling psychology research, training, and practice: Principles, advances, and applications. The Counseling Psychologist, $34,684-718$.

Krosnick, J.A., \& Presser, S. (2010). Question and Questionnaire Design. In Wright, J., \& Marsden, P. (Eds.) Handbook of Survey Research, Second Edition (pp. 263 - 313). United Kingdom: Emerald Group Publishing Limited.

Larimer, M. E., Cronce, J. M. (2002). Identification, prevention, and treatment: A review of individual-focused strategies to reduce problematic alcohol consumption by college students. Journal of Studies on Alcohol, Supplement 14, Special issue: College drinking, what it is, and what do to about it: Review 
of the state of the science. $148-163$

Leeman, R. F., Toll, B. A., Taylor, L. A., \& Volpicelli, J. R. (2009). Alcohol-induced disinhibition expectancies and impaired control as prospective predictors of problem drinking in undergraduates. Psychology of Addictive Behaviors, 23(4), 553-563.

Leigh, B. C. (1989). In search of the seven dwarves: Issues of measurement and meaning in alcohol expectancy research. Psychological Bulletin, 105(3), 361373.

Lewis, B.A. \& O’Neill, H.K. (2000). Alcohol expectancies and social deficits relating to problem drinking among college students. Addictive Behaviors, 25(2), 295299. doi:10.1016/S0306-4603(99)00063-5

Lieber, C. S. (1997). Gender differences in alcohol metabolism and susceptibility. In: R.W. Wilsnack, \& S. C. Wilsnack (Eds.), Gender and alcohol: Individual and social perspectives (pp. 77-89). Piscataway, NJ, US: Rutgers Center of Alcohol Studies.

Martin, C. M. \& Hoffman, M. A. (1993). Alcohol expectancies, living environment, peer influence, and gender: A model of college-student drinking. Journal of College Student Development, 34(3), 206-211.

Neighbors, C., Lee, C.M., Lewis, M.A., Fossos, N., \& Larimer, M.E. (2007). Are Social Norms the Best Predictor of Outcomes Among Heavy-Drinking College Students? Journal of Studies on Alcohol and Drugs, 68(4), 556-565.

Nolen-Hoeksema, S. \& Hilt, L. (2006). Possible contributors to the gender differences in alcohol use and problems. The Journal of General Psychology, 133(4), 357374.

O’Malley, P.M. \& Johnston, L.D. (2002). Epidemiology of alcohol and other drug use among American college students. Journal of Studies on Alcohol, Supplement 14, Special issue: College drinking, what it is, and what do to about it: Review of the state of the science. 23-39 
Perkins, H. W., Meilman, P., Leichliter, J.S., Cashin, J. R., \& Presley, C.A. (1999). Misperceptions of the norms for the frequency of alcohol and other drug use on college campuses. Journal of American College Health, 47(6), 253-258.

Perkins, H. W. (2002). Surveying the damage: A review of research on consequences of alcohol misuse in college populations. Journal of Studies on Alcohol, Supplement 14. Special issue: College drinking, what it is, and what do to about it: Review of the state of the science, 91-100.

Perkins, H. W. (2002). Social norms and the prevention of alcohol misuse in collegiate contexts. Journal of Studies on Alcohol, Supplement 14, Special issue: College drinking, what it is, and what do to about it: Review of the state of the science. 164-172.

Perkins, H. W., \& Wechsler, H. (1996). Variation in perceived college drinking norms and its impact on alcohol abuse: A nationwide study. Journal of Drug Issues, 26(4), 961-974.

Perkins, H. W. (2006). 'Success and failure in social norms interventions': Reply. Journal of Studies on Alcohol, 67(3), 483-484

Rabow, J. \& Duncan-Schill, M. (1995). Drinking among college students. Journal of Drug and Alcohol Education, 40 (2), 52-64.

Read, J. P., Wood, M. D.; Kahler, C. W., Maddock, J. E., \& Palfai, T. P. (2003). Examining the role of drinking motives in college student alcohol use and problems. Psychology of Addictive Behaviors, 17(1), 13-23.

Rauch, S.M. \& Bryant, J.B. (2000). Gender and context differences in alcohol expectancies. The Journal of Social Psychology, 140(2), 240-253.

Rosenblitt, J.C., Soler, H., Johnson, S.E., \& Quadagno, D.M. (2001). Sensation seeking and hormones in men and women: Exploring the link. Hormones and Behavior, 40, 396-402.

Rubio, D. M., Bucholz, K., Neuman, R.J., Rauch, S. M. (2001). Factor analysis of the alcohol expectancy questionnaire in a middle-aged community sample. 
Journal of Studies on Alcohol, 64, 428 - 431.

Sadava, S.W. (1985). Problem behavior theory and consumption and consequences of alcohol use. Journal of Studies on Alcohol, 46, 392-397.

Scheier, L.M. \& Botvin, G.J. (1997). Expectancies as mediators of the effects of social influences and alcohol knowledge on adolescent alcohol use: A prospective analysis. Psychology of Addictive Behaviors, 11(1), 48-64.

Schlomer, G. L., Bauman, S. \& Card, N. A. (2010). Best practices for missing data management in counseling psychology. Journal of Counseling Psychology, 57(1), 1-10.

Sher, K. J., Wood, M. D., Wood, P. K., \& Raskin, G. (1996). Alcohol outcome expectancies and alcohol use: A latent variable cross-lagged panel study. Journal of Abnormal Psychology, 105(4), 561-574.

Sobell, L.C., \& Sobell, M. B. (2003). Alcohol Consumption Measures. In Assessing Alcohol Problems : A Guide for clinicians and researchers, $2^{\text {nd }} \mathrm{Ed} . \mathrm{NIH}$ Publication No. 03-3745 Revised 2003

Stacy, A. W., Widaman, K.F., \& Marlatt, A. (1990). Expectancy models of alcohol use. Journal of Personality and Social Psychology, 58(5), 918-928.

Suls, J. \& Rothman, A.J. (2004). Evolution of the psychosocial model: Implications for the future of health psychology. Health Psychology, 23, 119-125.

Velazquez, C.E., Pasch, K.E., Laska, M.N., Lust, K., Story, M., Ehlinger, E.P. (2011). Differential prevalence of alcohol use among 2-year and 4-year college students. Addictive Behaviors, 36(12), 1353-1356.

Wechsler, H., \& Nelson, T.F. (2008). What have we learned from the Harvard School of Public Health College Alcohol Study: Focusing attention on college student alcohol consumption and environmental conditions that promote it? Journal of Studies on Alcohol and Drugs, 69, 481-490.

Wechsler, H., Lee, J. E., Kuo, M., Seibring, M., Nelson, T. F., \& Lee, H. (2002). Trends in college binge drinking during a period of increased prevention 
efforts. Journal of American College Health, 50(5), 203-217.

Wilson, G.T., \& Abrams, D. (1977). Effects of alcohol on social anxiety and physiological arousal: cognitive versus pharmacological processes. Cognitive Therapy and Research, 1, 195-210

Wood, M. D., Sher, K. J., \& Strathman, A. (1996). Alcohol outcome expectancies and alcohol use and problems. Journal of Studies on Alcohol, 57, 283-288.

Wood, M. D., Nagoshi, C. T., Dennis, D. A. (1992). Alcohol norms and expectations as predictors of alcohol use and problems in a college student sample. American Journal of Alcohol Abuse, 18(4), 461-476.

Yanovitzky, I. (2006). Sensation Seeking and Alcohol Use by College Students: Examining Multiple Pathways of Effects. Journal of Health Communication, 11(3), 269-280.

Zuckerman, M. (1994). Behavioral expressions and biosocial bases of sensation seeking. New York, NY, US: Cambridge University Press.

Zuckerman, M., \& Kuhlman, D. M. (1993). Zuckerman-Kuhlman Personality Questionnaire Cross-Cultural 50-items version. Measure obtained from the authors.

Zuckerman, M., Kuhlman, D. M. (2000). Personality and risk-taking: Common biosocial factors. Journal of Personality, 68(6). Special issue: Personality processes and problem behavior. 999-1029.

Zuckerman, M. (2010). The neurobiology of impulsive sensation seeking. In Canli. T. (Ed.) Biology of Personality and Individual Differences, p. 31-52. The Guilford Press: New York. 